University of Tennessee Health Science Center

UTHSC Digital Commons

\title{
$5-2013$
}

\section{Virologic Factors Contributing to the Genetic Diversification of Influenza Viruses Circulating in North American Swine}

Thomas Paul Fabrizio II

University of Tennessee Health Science Center

Follow this and additional works at: https://dc.uthsc.edu/dissertations

Part of the Genetic Processes Commons, and the Medical Immunology Commons

\section{Recommended Citation}

Fabrizio, Thomas Paul II , "Virologic Factors Contributing to the Genetic Diversification of Influenza Viruses Circulating in North American Swine" (2013). Theses and Dissertations (ETD). Paper 85. http://dx.doi.org/10.21007/etd.cghs.2013.0088. 


\title{
Virologic Factors Contributing to the Genetic Diversification of Influenza Viruses Circulating in North American Swine
}

\begin{abstract}
The purpose of this study was to determine mechanisms of reassortment of swine influenza viruses and determine if certain reassortant gene combinations can drive evolution and host adaptation in the context of the triple reassortant internal gene (TRIG) cassette. The TRIG contains a unique combination of a human polymerase basic 1 (PB1) gene with avian polymerase basic 2 (PB2) and polymerase acidic (PA) genes. The remaining internal genes, nucleoprotein (NP), matrix (M), and non-structural (NS) are of swine origin. This differs considerably from classical swine lineage viruses which are drifted variants of the 1918 pandemic with all swine origin genes. We hypothesized that the viruses containing the TRIG cassette reassort more frequently because the polymerase gene constellation is more promiscuous in its ability to replicate with novel HA and NA genes. Better understanding of these mechanisms that control reassortment can be applied to identifying high risk viruses that have an increased ability to reassort and potentially zoonotically transmit to humans. The segmented nature of influenza viruses provides an opportunity for gene segment reassortment in which a virus can exchange segments with another virus. Despite the ability to detect these reassortant viruses, there is little understanding of the mechanisms that control or drive this process. The first two aims addressed a barrier in the influenza field by determining what mechanisms restrict reassortment in particular viral genotypes. This can further be applied to predict the likelihood that other viruses may reassort or be restricted from reassorting. Based on epidemiologic data not all viruses have the same ability to reassort, thus giving some viruses particular advantages over others. However, our studies indicated that there are no virologic specific functions that restrict reassortment, but there are trends demonstrating that the TRIG cassette is more promiscuous than the classical swine viruses. Thus the propensity of the TRIG viruses to reassert, as seen in the field, was likely the result of a change in pig farming rather than one particular viral function. We next assessed the viral fitness of human HA and NA reassortants on both of the swine virus backbones. There were no observable differences with the human $\mathrm{H} 3$ and $\mathrm{N} 2$ on either of the swine backbones when compared to the parental swine backbones. However, we did see some viral fitness attenuation when the polymerase complex genes were reassorted between the TRIG and classical swine viruses, suggesting that viral growth efficiency is altered if the polymerase genes and presumable their interactions are changed. Influenza gene reassortment plays a major role in the evolution of new viruses, however, it may also drive these reassortant viruses to evolve more quickly and adapt to a new host. The final aim of the study is evaluated the role reassortment plays in driving host adaption and influenza evolution. This aim is designed to test a hypothesis derived from natural observations in which avian-like Eurasian swine virus HAs phylogenetically cluster with increased nucleotide changes in viruses containing the TRIG NS. We hypothesized that the TRIG and TRIG NS increase the number of nucleotide mutations in the HA gene resulting in increased viral diversity leading to more rapid host adaptation as observed by viral fitness in vitro. We found that this evolutionary burst was observed when the TRIG NS is rescued on the classical swine virus backbone; however it was not seen in a wholly TRIG virus. It is likely the introduction of a different gene segment that destabilizes the viral genome leading to the observed evolutionary burst rather than the inherent properties of the TRIG NS. However, this does raise the concern that reassortment can lead to more rapid host adaption through genetic diversity which could lead to novel subtypes entering pigs or humans. Of significant concern is that humans are immunologically naïve to most influenza subtypes. These revelations could help direct the influenza research community to focus on these particular rapidly evolving viruses that pose the most significant threat to public and agricultural health.
\end{abstract}

\section{Document Type}

Dissertation 


\section{Degree Name}

Doctor of Philosophy (PhD)

\section{Program}

Biomedical Sciences

\section{Research Advisor}

Richard J. Webby, Ph.D.

\section{Keywords}

Influenza A, Influenza Reassortment, Viral Evolution, North American Swine Influenza Viruses.

\section{Subject Categories}

Genetic Processes | Medical Immunology | Medical Sciences | Medicine and Health Sciences 
Virologic Factors Contributing to the Genetic Diversification of Influenza Viruses Circulating in North American Swine

\author{
A Dissertation \\ Presented for \\ The Graduate Studies Council \\ The University of Tennessee \\ Health Science Center \\ In Partial Fulfillment \\ Of the Requirements for the Degree \\ Doctor of Philosophy \\ From The University of Tennessee
}

By

Thomas Paul Fabrizio II

May 2013 
Copyright (C) 2013 by Thomas Paul Fabrizio II. All rights reserved. 


\section{DEDICATION}

I dedicate this dissertation to my fiance, Mckenzie, who has supported me through my graduate research and has always been a good listener when experiments didn't work. This dissertation is also dedicated to my parents, who have always encouraged me to dream big and work hard, and to my brother and sister who have inspired me to be a good role model and who were always willing to make time to enjoy activities together. 


\section{ACKNOWLEDGEMENTS}

I would like to thank my graduate research advisor, Dr. Richard Webby, who gave me an exceptional opportunity to complete my graduate training in his lab. He was always open to new ideas and ways to help incorporate them into my research projects. Dr. Webby was also willing to provide recommendations and guidance when experiments were not working.

I would also like the thank all of the members of my graduate committee, Dr. Kui Li, Dr. Pat Ryan, Dr. Stacey Schultz-Cherry, and Dr. Paul Thomas, who provided constructive criticism of my work and helped me to more critically analyze my results. All of the members were also more than happy to help me design experiments and discuss my future goals.

I also extend my gratitude to the St. Jude Flu Group who made all of the experiments possible. I would especially like to thank Dr. Jacco Boon for guidance through graduate school, many discussions about influenza viruses, and experimental planning. I would also like to thank Dr. Mariette Ducatez, Dr. Sun-Woo Yoon, and Dr. Sook-San Wong for training in different laboratory techniques, experimental design discussions, and providing assistance with animal experiments. Other members who deserve recognition include Ashley Webb, Jennifer DeBeauchamp, Jeri Carol Crumpton, Patrick Seiler, and Trushar Jeevan for helping with laboratory and animal experiments and John Franks for sequencing and cloning advice. 


\begin{abstract}
The purpose of this study was to determine mechanisms of reassortment of swine influenza viruses and determine if certain reassortant gene combinations can drive evolution and host adaptation in the context of the triple reassortant internal gene (TRIG) cassette. The TRIG contains a unique combination of a human polymerase basic 1 (PB1) gene with avian polymerase basic 2 (PB2) and polymerase acidic (PA) genes. The remaining internal genes, nucleoprotein (NP), matrix (M), and non-structural (NS) are of swine origin. This differs considerably from classical swine lineage viruses which are drifted variants of the 1918 pandemic with all swine origin genes. We hypothesized that the viruses containing the TRIG cassette reassort more frequently because the polymerase gene constellation is more promiscuous in its ability to replicate with novel HA and NA genes. Better understanding of these mechanisms that control reassortment can be applied to identifying high risk viruses that have an increased ability to reassort and potentially zoonotically transmit to humans.
\end{abstract}

The segmented nature of influenza viruses provides an opportunity for gene segment reassortment in which a virus can exchange segments with another virus. Despite the ability to detect these reassortant viruses, there is little understanding of the mechanisms that control or drive this process. The first two aims addressed a barrier in the influenza field by determining what mechanisms restrict reassortment in particular viral genotypes. This can further be applied to predict the likelihood that other viruses may reassort or be restricted from reassorting. Based on epidemiologic data not all viruses have the same ability to reassort, thus giving some viruses particular advantages over others. However, our studies indicated that there are no virologic specific functions that restrict reassortment, but there are trends demonstrating that the TRIG cassette is more promiscuous than the classical swine viruses. Thus the propensity of the TRIG viruses to reassert, as seen in the field, was likely the result of a change in pig farming rather than one particular viral function.

We next assessed the viral fitness of human HA and NA reassortants on both of the swine virus backbones. There were no observable differences with the human $\mathrm{H} 3$ and $\mathrm{N} 2$ on either of the swine backbones when compared to the parental swine backbones. However, we did see some viral fitness attenuation when the polymerase complex genes were reassorted between the TRIG and classical swine viruses, suggesting that viral growth efficiency is altered if the polymerase genes and presumable their interactions are changed.

Influenza gene reassortment plays a major role in the evolution of new viruses, however, it may also drive these reassortant viruses to evolve more quickly and adapt to a new host. The final aim of the study is evaluated the role reassortment plays in driving host adaption and influenza evolution. This aim is designed to test a hypothesis derived from natural observations in which avian-like Eurasian swine virus HAs phylogenetically cluster with increased nucleotide changes in viruses containing the TRIG NS. We hypothesized that the TRIG and TRIG NS increase the number of nucleotide mutations in 
the HA gene resulting in increased viral diversity leading to more rapid host adaptation as observed by viral fitness in vitro. We found that this evolutionary burst was observed when the TRIG NS is rescued on the classical swine virus backbone; however it was not seen in a wholly TRIG virus. It is likely the introduction of a different gene segment that destabilizes the viral genome leading to the observed evolutionary burst rather than the inherent properties of the TRIG NS. However, this does raise the concern that reassortment can lead to more rapid host adaption through genetic diversity which could lead to novel subtypes entering pigs or humans. Of significant concern is that humans are immunologically naïve to most influenza subtypes. These revelations could help direct the influenza research community to focus on these particular rapidly evolving viruses that pose the most significant threat to public and agricultural health. 


\section{TABLE OF CONTENTS}

CHAPTER 1. INTRODUCTION ....................................................................................1

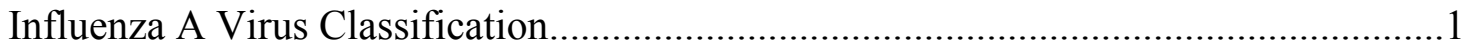

Influenza A Virus Structure and Function ...............................................................

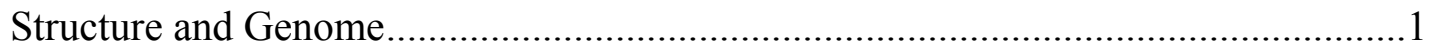

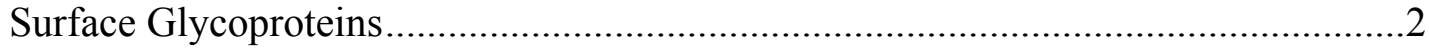

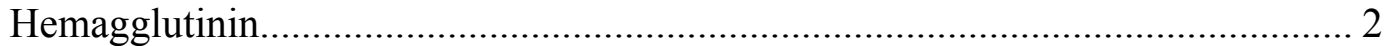

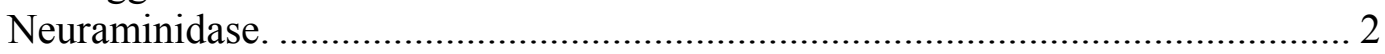

Internal Gene Segments .................................................................................

Polymerase Complex. ............................................................................... 3

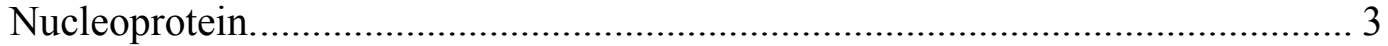

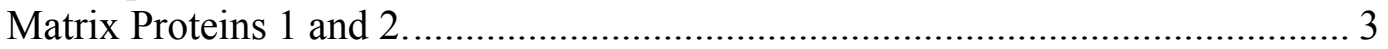

Non-Structural Proteins. .............................................................................. 4

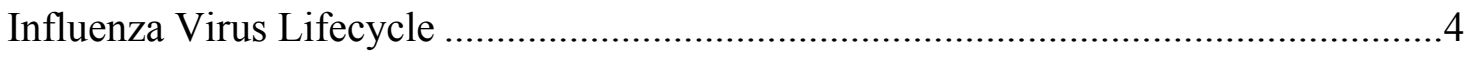

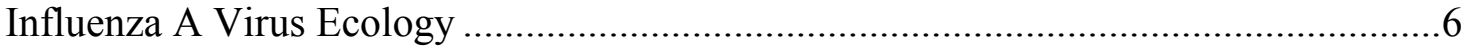

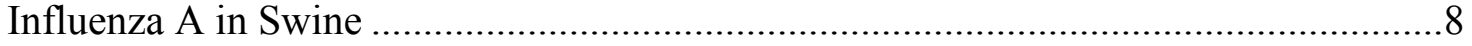

Classical Swine Viruses ........................................................................

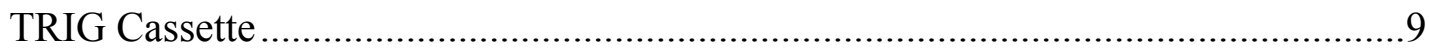

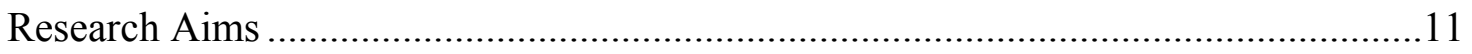

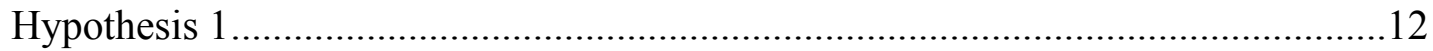

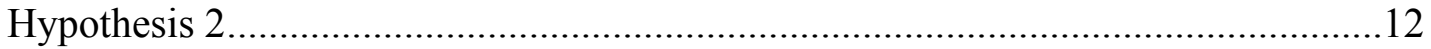

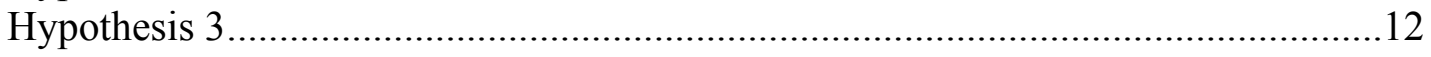

\section{CHAPTER 2. INFLUENZA VIRUS SUPERINFECTION EXCLUSION AND}

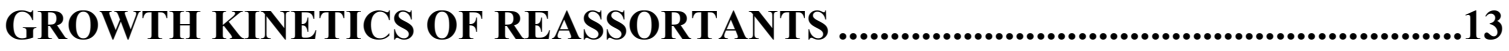

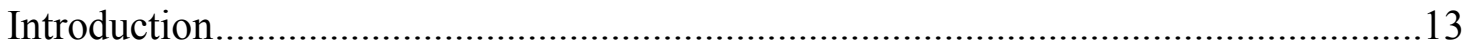

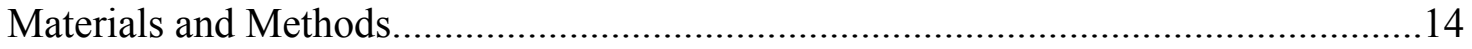

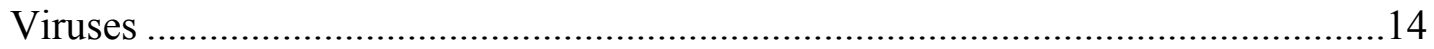

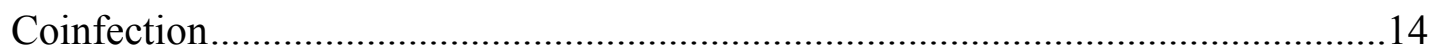

Antibody Purification and Fluorescent Labeling ............................................. 17

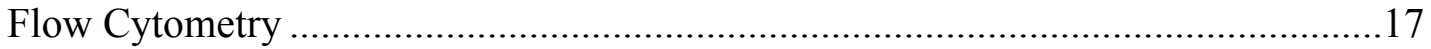

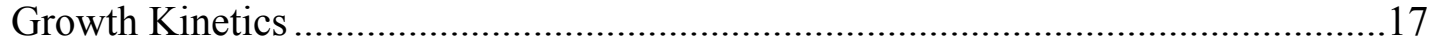

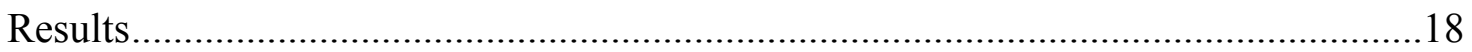

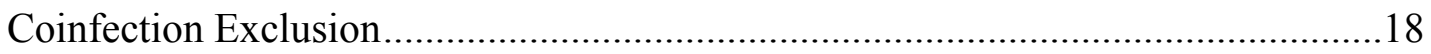

Growth Differences in MDCK Cells .....................................................................22

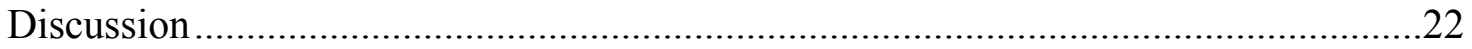

Simultaneous Coinfection Provides the Greatest Possibility for Superinfection.......22

Both MN/99 and NC/02 Are Compatible with Human H3 and N2 .......................25

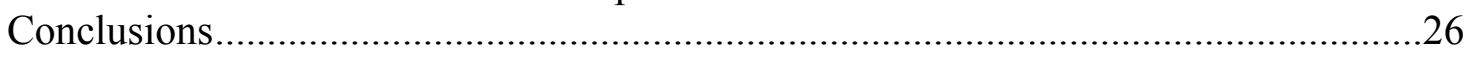

\section{CHAPTER 3. INFLUENZA VIRUS GENE COMPATIBILITY AND MECHANISMS OF REASSORTMENT ..............................................................27}

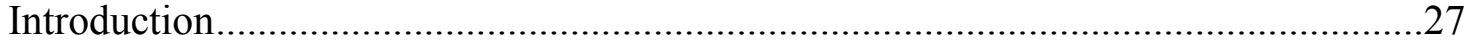

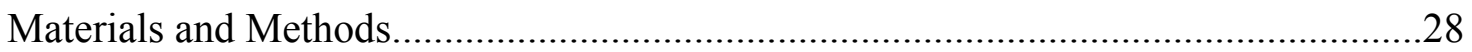


Reverse Genetics Viruses ...............................................................................28

Primary Swine Respiratory Epithelial Cells (pSRECs) ………………………........28

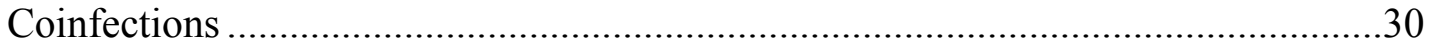

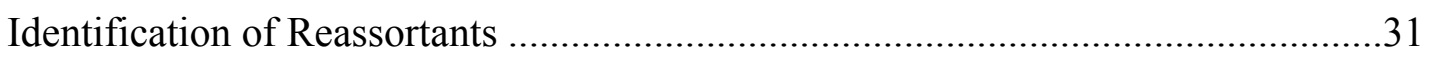

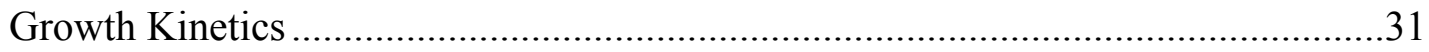

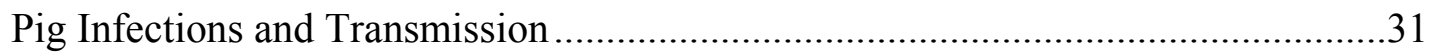

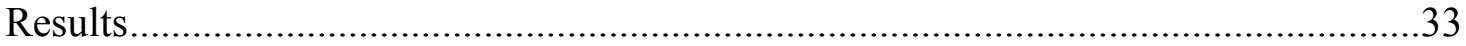

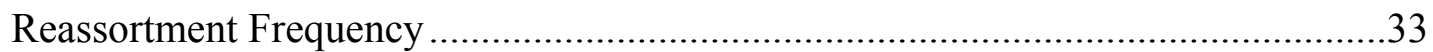

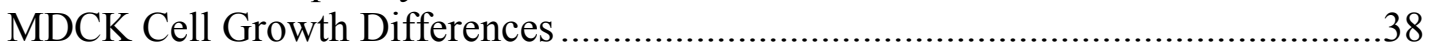

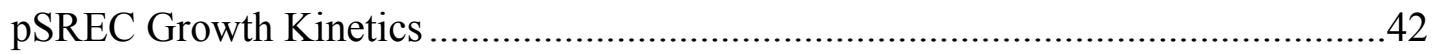

Reassortant Swine Virus Infectivity and Transmissibility in Pigs.............................47

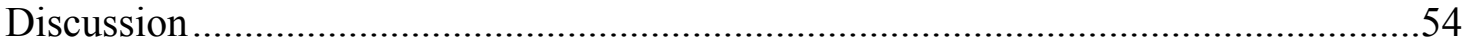

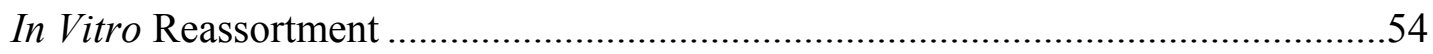

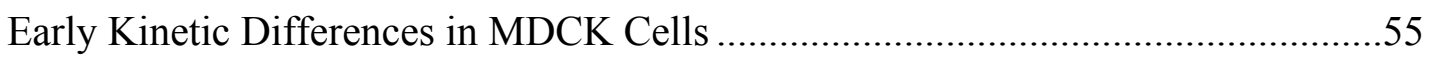

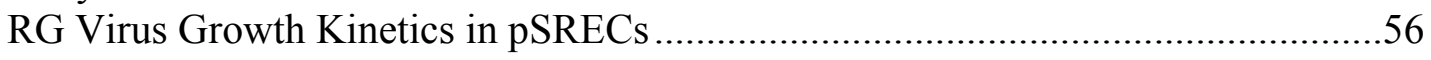

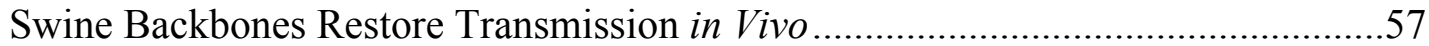

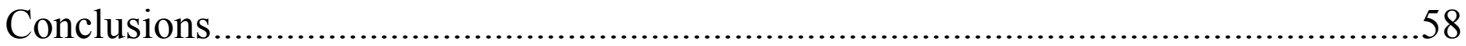

\section{CHAPTER 4. EVOLUTIONARY BURST OF REVERSE GENETIC VIRUSES}

PASSAGED IN SWINE EPITHELIAL CELLS .................................................59

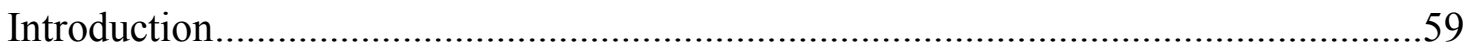

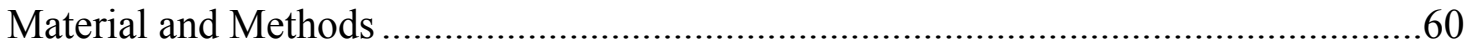

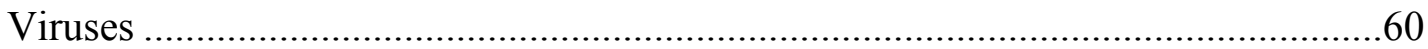

Viral Passaging in pSRECs..........................................................................60

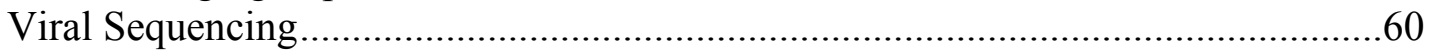

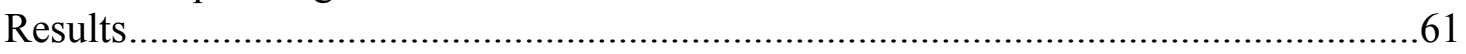

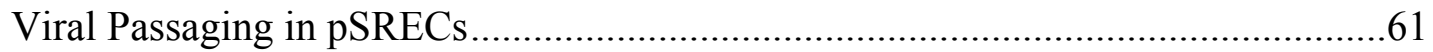

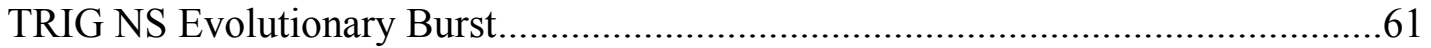

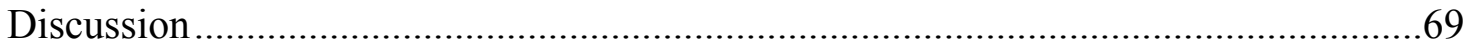

Viral Passages in pSRECs Do Not Mirror Nature ......................................................69

The TRIG NS Does Cause an Evolutionary Burst on the Classical Swine

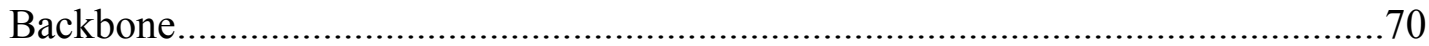

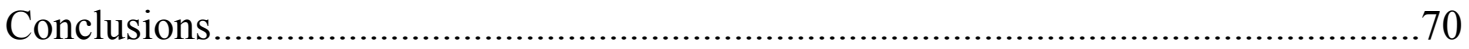

CHAPTER 5. GENERAL DISCUSSION, CONCLUSIONS, AND FUTURE

DIRECTIONS ...............................................................................................................71

LIST OF REFERENCES .................................................................................................75

APPENDIX A. ANTIBODY PURIFICATION FROM ASCITES FLUID..................82

APPENDIX B. ISOLATION AND GROWTH OF PRIMARY SWINE RESPIRATORY EPITHELIAL CELLS ........................................................................85

VITA 


\section{LIST OF TABLES}

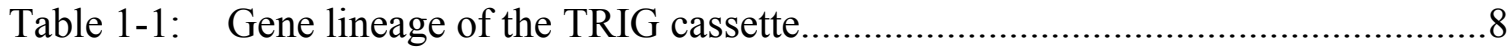

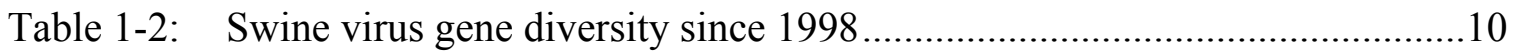

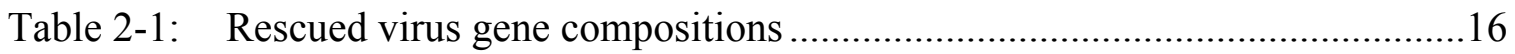

Table 3-1: Gene segment origins for rescued viruses ...........................................29

Table 3-2: $\quad$ Primer sequences used for influenza genome amplification........................32

Table 3-3: Thermocycler conditions for full influenza genome amplification ..............32

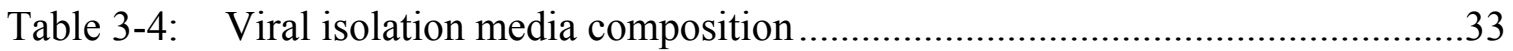

Table 3-5: Reassortment frequency between MN/99 and TX/96 when coinfected in

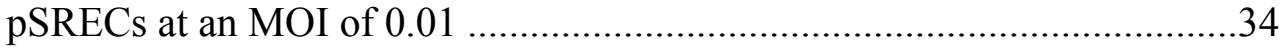

Table 3-6: Correlation analysis of $\mathrm{MN}$ and TX reassortant genotypes .........................36

Table 3-7: Reassortment frequency between NC/02 and TX/96 when coinfected in

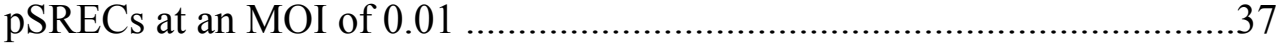

Table 3-8: Correlation analysis of NC and TX reassortant genotypes .........................38

Table 4-1: Viral genotypes and gene constellations for pSREC passage......................63

Table 4-2: $\quad$ Viral genotypes and gene constellations for pSREC passaging after 6

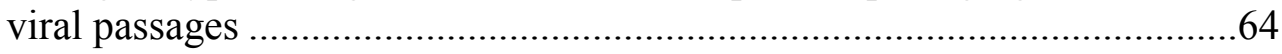

Table 4-3: $\quad$ Nucleotide position and frequency of detected variants .............................68 


\section{LIST OF FIGURES}

Figure 1-1: Illustration of influenza A lifecycle

Figure 2-1: Illustration of the dual promoter eight plasmid system to rescue cloned viruses

Figure 2-2: Flow cytometry dot plots at an MOI of 0.01

Figure 2-3: Percentage of cells infected with either H1, H3, or coinfected with a starting MOI of 0.01 .20

Figure 2-4: Flow cytometry dot plots at an MOI of 1

Figure 2-5: Percentage of cells infected with either $\mathrm{H} 1, \mathrm{H} 3$, or coinfected with a starting MOI of 1

Figure 2-6: Viral growth kinetics on MDCK cells at an MOI of 0.01

Figure 3-1: MDCK growth kinetics of parental and 6+2 viruses at an MOI $=0.01$

Figure 3-2: Growth kinetics of RG viruses in MDCK cells where the polymerase gene segments have been swapped on the MN/TX viral backbone....

Figure 3-3: Growth kinetics of RG viruses in MDCK cells where MN-PB1 was swapped on the NC/TX viral backbone

Figure 3-4: MDCK growth of RG viruses with TRIG NS

Figure 3-5: Preliminary pSREC growth kinetics at an MOI of 0.01

Figure 3-6: pSREC growth kinetics at an MOI of 0.01

Figure 3-7: Growth kinetics of RG viruses in pSRECs where the polymerase gene segments have been swapped on the MN/TX viral backbone

Figure 3-8: Growth kinetics of RG viruses in MDCK cells where MN-PB1 was swapped on the NC/TX viral backbone

Figure 3-9: Reassortant viruses with TRIG NS in pSRECs

Figure 3-10: Growth and transmission of human TX/96 in pigs

Figure 3-11: Growth and transmission of MN/TX/NC-PB1 in pigs 51

Figure 3-12: Growth and transmission of MN/TX in pigs 52

Figure 3-13: Growth and transmission of NC/TX in pigs .53 
Figure 4-1: HA titers of viruses during passaging within pSRECs ............................62

Figure 4-2: Infectivity titers of the RG viruses after serial passaging in pSRECs .........65

Figure 4-3: Comparison of quality-based variant detection results between MN/TX, NC/TX, and MN/TX/NC-NS .........................................................66 


\section{LIST OF ABBREVIATIONS}

\begin{tabular}{|c|c|}
\hline $\mathrm{BGH}$ & Bovine growth hormone \\
\hline BSA & Bovine serum albumin \\
\hline cDNA & Complimentary deoxyribonucleic acid \\
\hline CMV & Cytomegalovirus \\
\hline $\mathrm{CPE}$ & Cytopathic effect \\
\hline CRM1 & Chromosome region maintenance 1 protein \\
\hline cRNA & Complimentary ribonucleic acid \\
\hline cs & Classical swine \\
\hline DI & Defective interfering \\
\hline DNA & Deoxyribonucleic acid \\
\hline dpi & Days post infection \\
\hline $\mathrm{dr}$ & Double reassortant \\
\hline dsRNA & Double-stranded RNA \\
\hline FCS & Fetal calf serum \\
\hline $\mathrm{h}$ & Human \\
\hline HA & Hemagglutinin \\
\hline HI & Hemagglutination inhibition \\
\hline hpi & Hours post infection \\
\hline ILI & Influenza-like-illness \\
\hline M1 & Matrix 1 protein \\
\hline M2 & Matrix 2 protein \\
\hline MDCK & Madin Darby canine kidney \\
\hline MOI & Multiplicity of infection \\
\hline
\end{tabular}




\begin{tabular}{|c|c|}
\hline mRNA & Messenger ribonucleic acid \\
\hline NA & Neuraminidase \\
\hline NES & Nuclear export sequence \\
\hline NP & Nucleoprotein \\
\hline NS1 & Nonstructural protein 1 \\
\hline NS2/NEP & Nonstructural protein $2 /$ Nuclear export protein \\
\hline PA & Polymerase acidic protein \\
\hline PAX & Polymerase acidic protein frameshift \\
\hline PB1 & Polymerase basic 1 protein \\
\hline PB1-F2 & Polymerase basic 1 protein frame 2 \\
\hline PB2 & Polymerase basic 2 protein \\
\hline Pol I & RNA polymerase I \\
\hline pSREC & Primary swine respiratory epithelial cells \\
\hline RG & Reverse genetics \\
\hline RG-MN/99 & $\begin{array}{l}\text { Reverse genetics classical swine } \mathrm{H} 1 \mathrm{~N} 1 \text { virus } \\
\mathrm{A} / \text { swine/MN/37866/1999 }\end{array}$ \\
\hline RG-NC/02 & $\begin{array}{l}\text { Reverse genetics triple reassortant swine H1N1 virus } \\
\mathrm{A} / \text { swine/NC/18161/2002 }\end{array}$ \\
\hline rh & Reassortant human \\
\hline RNA & Ribonucleic acid \\
\hline RNP & Ribonucleoprotein \\
\hline RT-PCR & Reverse transcription polymerase chain reaction \\
\hline $\mathrm{TCID}_{50}$ & $50 \%$ tissue culture infectious dose \\
\hline $\operatorname{tr}$ & Triple reassortant \\
\hline TRIG & Triple reassortant internal gene \\
\hline $\mathrm{TX} / 96$ & Human $\mathrm{H} 3 \mathrm{~N} 2$ virus $\mathrm{A} / \mathrm{TX} / 6 / 1996$ \\
\hline
\end{tabular}


vPx

vRNA

wt
Viral passage

Viral RNA

Wild type 


\section{CHAPTER 1. INTRODUCTION}

\section{Influenza A Virus Classification}

Influenza viruses are members of the Orthomyxoviridae family and further divided into three genera; Influenza A, B, and C. Influenza A viruses are classified based on the two surface glycoproteins, hemagglutinin (HA) and neuraminidase (NA). ${ }^{1}$ Currently, there are 16 identified HA subtypes and 9 NA subtypes. ${ }^{2-5}$ Wild aquatic birds have been identified as the natural reservoir, however, Influenza A viruses infect numerous hosts, including; ducks, shorebirds, gulls, poultry, pigs, horses, seals, mink, and humans. Research in host range and restriction has identified species-specific viral gene lineages, but these lineages are not absolute and viruses have shown the ability to cross species boundaries. ${ }^{6}$

\section{Influenza A Virus Structure and Function}

\section{Structure and Genome}

The influenza virus is enveloped with a genome consisting of 8 segmented negative-sense RNA strands. Negative-sense RNA must be transcribed in order to produce cRNA for full length vRNA transcription and mRNA which will be translated into protein. The envelope consists of a host derived lipid bilayer surrounding the protein capsid embedded with the HA, NA, and matrix 2 proteins (M2) ${ }^{6,7}$ The viral capsid is composed of matrix 1 (M1) protein which surrounds the viral core consisting of the ribonucleoprotein (RNP) complex. ${ }^{7}$ The RNP complex is made up of the polymerase proteins, viral RNA (vRNA), and the nucleoprotein (NP). ${ }^{8}$ In addition to the polymerase complex, an alternative open reading frame in some polymerase basic 1 (PB1) proteins, encodes a truncated protein named PB1-F2. This truncated protein targets the inner mitochondrial membrane and induces apoptosis. ${ }^{9}$ The final 2 proteins are the nonstructural protein (NS1) and nuclear export protein (NEP) which are encoded by a single RNA segment and NS1 is an interferon antagonist while NEP is responsible for trafficking viral proteins and RNPs out of the nucleus.

Additionally, the segmented genome provides an evolutionary advantage for influenza viruses. Not only can the viruses evolve through genetic drift, where mutations accumulate due to the low fidelity of the viral polymerase, but they can also evolve through reassortment. Reassortment occurs when a cell is "super-infected" with two viruses and one or more gene segments from one virus are packaged with the remaining gene segments from the second virus. This is particularly important when the two viruses are genetically diverse and the surface viral glycoproteins are exchanged, leading to antigenic shift. Antigenic shifts are the primary modes of pandemic emergence and the direct result of reassortment. 


\section{Surface Glycoproteins}

The two surface glycoproteins, HA and NA, play the crucial roles of receptor binding and membrane fusion, along with sialic acid cleavage, respectively. The HA protein is the predominant surface protein with roughly four times as many present compared to NA. ${ }^{7}$

Hemagglutinin. The HA protein consists of a homotrimer and is largely regarded as the primary host determinant factor due to the preference of avian HAs to bind to $\alpha 2,3$ terminally linked sialic acids while mammalian viruses preferentially bind to $\alpha 2,6$ linked sialic acids. ${ }^{10,11}$ In addition to binding to sialic acids along the cell surface, HA also causes membrane fusion between the viral envelope and the endosomal membrane to release the viral RNP in to the cytoplasm. The inactive from of HA (HA0) consists of a non-cleaved homotrimer. The HA0 is cleaved by a species specific trypsin-like protease into HA1 and HA2 which remain connected by a disulfide bond. ${ }^{6}$ The cleavage is required for HA activation and infectivity. The globular head of the HA molecule consists entirely of the HA1 domain and contains the receptor binding site, while the stalk domain consists of primary HA2 and a small portion of HA1. The stalk domain contains the proteolytic cleavage sequence which exposes the fusion peptide. Under low $\mathrm{pH}$ conditions, the HA molecule undergoes a significant conformational shift leading to membrane fusion. ${ }^{7}$

Neuraminidase. The second major surface glycoprotein is NA which is responsible for viral spread by cleaving terminal sialic acids and consists of a homotetramer. ${ }^{6,7}$ The enzymatic activity of NA provides multiple functions to the influenza virus. During viral budding from the infected cell, the HA proteins can bind to target sialic acids, so the NA is required to cleave these targets in order to release the new virion. Additionally, as new virions bud, their envelope is host derived and contains terminal sialic acids. The NA activity can prevent aggregation of virions by cleaving the sialic acids present within the viral envelope thus preventing other virions from binding. The sialidase activity can also cleave sialic acids present in mucus along the respiratory tract, which helps to prevent viral inactivation by host defenses. ${ }^{12}$ All of these roles help to increase intra-host and inter-host infectivity. Cleaving viral receptors in mucus increases the virus' ability to infect cells along the respiratory tract as well as release virions during sneezing to increase transmission. Similarly, preventing virion aggregation thereby increasing the distance in which the virus can spread through aerosol droplets to a new host.

\section{Internal Gene Segments}

The 6 internal gene segments encode 8 to 10 proteins including all of the polymerase proteins, the nucleoprotein, both matrix proteins (one of which is a transmembrane protein), and the non-structural proteins. 
Polymerase Complex. The influenza A polymerase complex is a heterotrimer consisting of the polymerase basic protein 2 (PB2), polymerase basic protein 1 (PB1), and polymerase acidic protein (PA). The polymerase complex is a RNA-dependent RNA polymerase held together by the PB1 N-terminal interaction with PA and C-terminal interaction with PB2. ${ }^{13}$ This complex is responsible for both viral transcription and replication. To achieve this end, the PB1 protein binds the terminal ends of vRNA, which causes an allosteric shift in PB2 allowing recognition and binding of host capped premRNAs. ${ }^{14}$ Binding of vRNA by PB1 also activates endonuclease activity of the PA protein, which cleaves the 5' mRNA cap from host pre-mRNAs to use for initiation of viral transcription. ${ }^{15,16}$ Some studies also suggest that the PA subunit contains proteolytic activity of coexpressed proteins to decrease excessive accumulation. ${ }^{17}$ Additionally, the PA subunit has been shown to interact with hCLE which is a host gene transcriptional activator. $^{18}$

Two other proteins are encoded by the frame shifts in the PB1 and PA reading frames. These proteins have not been shown to interact with the polymerase complex. The first identified was the polymerase basic 1 frame 2 (PB1-F2) protein. The PB1-F2 has been shown to localize to the inner mitochondrial membrane and when synthetically expressed, induces apoptosis. ${ }^{9}$ It has also been shown to only cause cell death in monocytes and not epithelial cells when expressed during an influenza infection. The most recently identified protein is termed the PAX. It has been shown to maintain endonuclease activity and inhibits host protein expression through host mRNA degradation. ${ }^{16}$

Nucleoprotein. The primary role of nucleoprotein is to encapsulate the vRNA. $\mathrm{NP}$ is an arginine-rich monomer, which gives it a net positive charge and allows nonspecific interactions with the negatively charged phosphate backbone of the vRNA. ${ }^{19}$ By surrounding the RNA, NP is a key component of vRNA packaging. NP has also been shown to interact with both PB1 and PB2..$^{20,21}$ This interaction is likely one method of regulating the switching of the polymerase activity from mRNA synthesis to vRNA synthesis. ${ }^{6}$

Matrix Proteins 1 and 2. The matrix RNA segment encodes two different proteins in two open reading frames, each with very distinct functions. The M1 protein is a structural protein that forms the viral capsid, found just beneath the viral lipid envelope. The M1 protein has two distinct regions, one of which is hydrophobic and inserts itself into the lipid membrane/envelope and the other region which interacts with NEP and RNPs. $^{22,23}$ These interactions are the primary methods in which new virions are assembled/packaged and the envelope is pinched off as the virion buds. ${ }^{24}$

The M2 protein is a tetramer that forms a transmembrane ion-channel in the virion. ${ }^{25}$ This ion-channel allows for acidification of the virion core as the endosome becomes a late endosome. This acidification causes the M1 protein to disassemble and release the RNP into the cytoplasm in addition to inducing an HA conformational shift to 
fuse the membranes. ${ }^{26}$ Due to the expression and export pathway of the M2 protein, it also creates a proton channel in the Golgi apparatus, thereby increasing the $\mathrm{pH}$ of the Golgi and preventing premature HA conformational shifts. ${ }^{27}$

Non-Structural Proteins. NS1 is a highly expressed non-structural protein which is not incorporated into the virion. Instead of having a role in the virion, NS1 is an interferon antagonist. ${ }^{7}$ It accomplishes this through several different pathways. NS1 has been shown to bind to double-stranded RNA (dsRNA). ${ }^{28}$ This interaction can sequester dsRNA from detection by IRF-3 which has been shown to induce activation of IFN- $\alpha / \beta$, which are the primary components of the host innate response to viral infection. ${ }^{29}$ Additionally, through its dsRNA binding domain, NS1 has been shown to prevent activation of NF- $\kappa \mathrm{B}$ which is also a strong inducer of IFN- $\alpha / \beta .^{30}$ These studies have also demonstrated that without functional NS1, IFN- $\alpha / \beta$ is not inhibited by influenza virus infection. Some additional functions attributed to NS1 include; regulation of vRNA synthesis through interactions with the polymerase complex, enhanced translation of viral mRNA over host mRNA, blocking the host antiviral response by inhibiting activity of oligoadenylate synthetase and protein kinase $\mathrm{R}$, and disruption of cellular signaling pathways by interacting with numerous host proteins through the PDZ domain. ${ }^{31}$

The NS2 protein is also known as the nuclear export protein (NEP). As mentioned previously, several studies have shown that NEP interacts with the M1 protein which also interacts with the RNP complexes. ${ }^{22,32}$ These interactions occur in the nucleus as new vRNA is synthesized and needs to be exported to the cell surface in order to be packaged with newly budding virions. To export the newly synthesized RNPs, NEP binds to the M1 protein associated with the RNPs and further interacts with human chromosome region maintenance 1 protein (CRM1). ${ }^{33}$ Human CRM1 is a highly conserved nuclear export receptor that mediates export of substrates containing a nuclear export signal from the nucleus. ${ }^{34}$ Without the expression of NEP, RNPs localized in the nucleus and did not produce any viable virus. ${ }^{33}$

\section{Influenza Virus Lifecycle}

As the virus enters a naïve host, the cleaved HA binds to terminal sialic acids on the cell surface. After binding, the virion is endocystosed and as the endosome acidifies, the HA complex undergoes a conformational shift in which the hydrophobic fusion peptide of HA2 inserts itself into the endosomal membrane. After the fusion peptide is inserted, the HA contracts pulling the viral envelope and endosomal membrane together resulting in membrane fusion. Additionally, as the late endosome becomes more acidic, some of the ions enter the virion through the M2 protein ion channel. When the virion reaches a certain $\mathrm{pH}$, the $\mathrm{M} 1$ protein begins to disassemble. This process is coordinated with the membrane fusion in order to release the viral RNP complexes into the host cell cytoplasm as illustrated in Figure 1-1. ${ }^{35}$ 


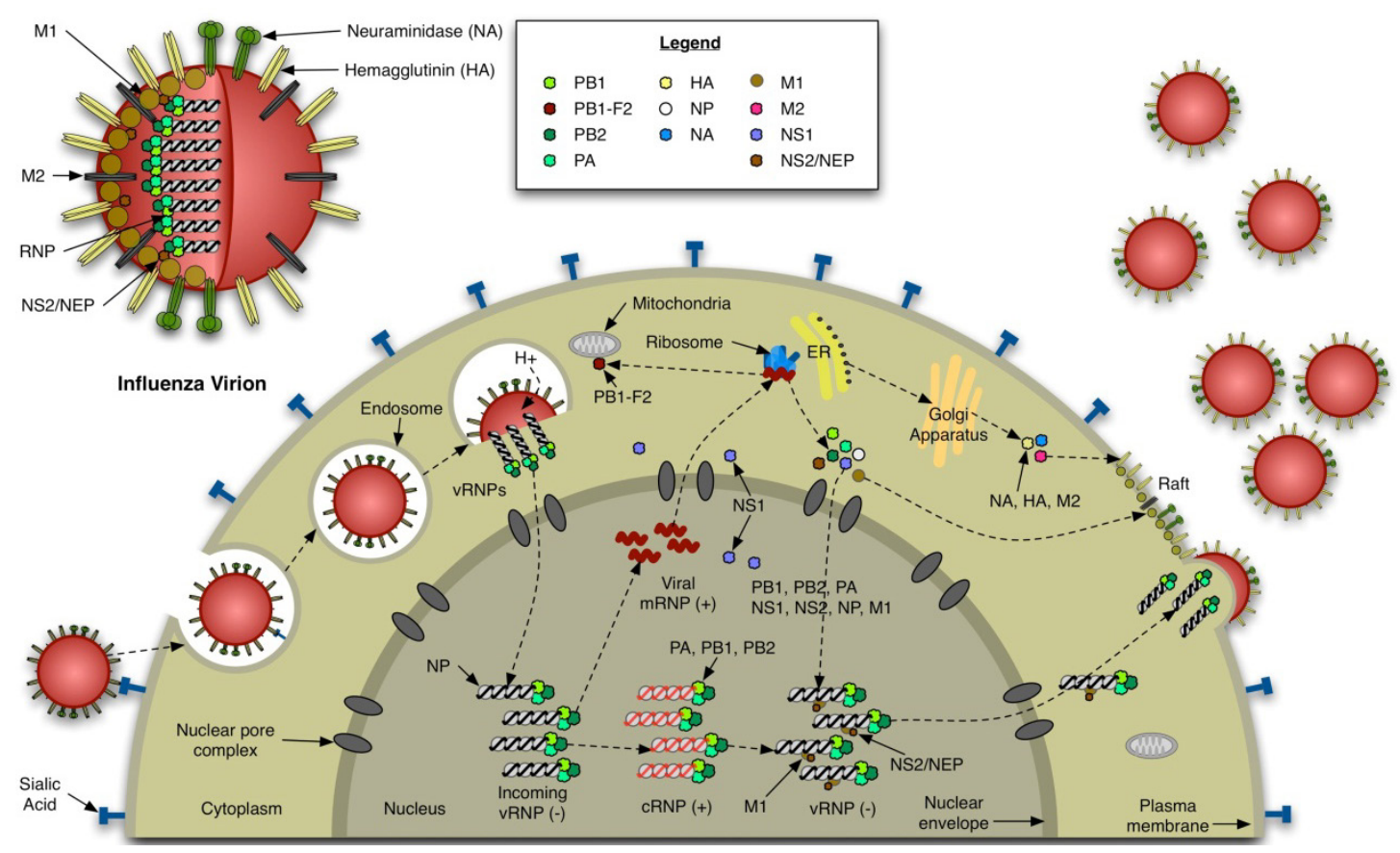

Figure 1-1: Illustration of influenza A lifecycle

Reprinted with permission and under the terms of the Creative Commons Attribution Non-Commercial License. Squires, B. et al. BioHealthBase: informatics support in the elucidation of influenza virus host pathogen interactions and virulence. Nucleic Acids Res 36, D497-503, doi:10.1093/nar/gkm905 (2008). 
The viral RNP complexes are trafficked into the nucleus where the vRNA segments are transcribed into mRNA by the polymerase complex. These newly synthesized viral mRNAs are encapsidated by available NP and exported out of the nucleus where it is then translated into protein by the host ribosome. It is believed that increased concentrations of NP within the nucleus drives a shift from viral mRNA transcription to cRNA and vRNA synthesis. ${ }^{6}$ As vRNA is transcribed, the viral proteins are also being synthesized with HA, NA, and M2 being processed and exported through the Golgi apparatus to lipid rafts within the host cell membrane.

As the viral surface glycoproteins and M2 accumulate in lipid rafts, NEP exports M1 which is bound to RNPs. These complexes are then trafficked to the cell membrane where the M1 then interacts with the cytoplasmic tails of HA and NA. Studies suggest that the M1 protein assembles into a capsid structure at the host cell membrane causing the new virion to bud from the cell as NA cleaves surface sialic acids. ${ }^{6}$

\section{Influenza A Virus Ecology}

The natural reservoirs for all influenza A virus subtypes are migratory waterfowl, however, a relatively large number of hosts, including; ducks, shorebirds, poultry, pigs, horses, seals, mink, and humans are susceptible to influenza A virus infection. ${ }^{6}$ Despite its ability to infect such a large host range, influenza A viruses are mainly restricted to either avian or mammalian species, primarily mediated through receptor specificity of HA. ${ }^{10,11}$ But, this restriction is far from absolute. Not only can some viruses cross species barriers, but when avian viruses jump into mammalian species, primarily pigs, they undergo increased nucleotide substitution rates when compared to viruses which have not crossed the species barrier. ${ }^{36}$ In addition to more rapid evolution, the entry of novel viruses in a new host increases the possibility for reassortment with native viral populations creating the opportunity to develop novel viral strains with pandemic potential. $^{37}$

Over the past century, humans have been infected with relatively few influenza subtypes, primarily H1N1, H2N2, H3N2, and influenza B. The first human subtype identified was the H1N1 subtype which emerged as a pandemic strain in 1918. This strain was initially believed to be a wholly avian virus that evolved the ability to transmit within mammalian species. However, recent phylogenetic analysis has revealed that the 1918 H1N1 pandemic virus was likely the result of reassortment between different mammalian

viruses. $^{38,39}$ It was also determined that the HA segment showed mammalian adapted mutations which had diverged from avian strains, suggesting the virus had circulated in humans or swine for several years prior to the emergence of the pandemic. ${ }^{40}$ During the pandemic, influenza-like-illness (ILI) was observed in U.S. swine herds indicating that the virus had either transmitted to swine from humans or vice versa. ${ }^{41}$

Following the 1918 pandemic, the H1N1 subtype remained relatively stable in pig populations but showed some genetic drift in the human population. Then, in 1957 the $\mathrm{H} 2 \mathrm{~N} 2$ pandemic virus emerged. This virus displaced the human H1N1 subtype and is 
believed to be generated by reassortment between the human $\mathrm{H} 1 \mathrm{~N} 1$ virus which acquired Eurasian avian lineage H2, N2, and PB1 gene segments. ${ }^{39,42-44}$ Phylogenetic analysis also suggests that the avian PB1 and N2 segments had entered the mammalian virus population several years prior to acquiring the H2 segment. Presumably, the H1N1, $\mathrm{H} 1 \mathrm{~N} 2$, and $\mathrm{H} 2 \mathrm{~N} 2$ viruses co-circulated until the $\mathrm{H} 2$ had adequate time to adapt to mammalian host receptors. Unlike the $1918 \mathrm{H} 1 \mathrm{~N} 1$ virus, the $1957 \mathrm{H} 2 \mathrm{~N} 2$ virus did not appear to transmit to swine herds.

Eleven years after the H2N2 pandemic, a novel H3N2 virus emerged as the 1968 "Hong Kong Flu" pandemic strain. Phylogenetic data indicated that the circulating H2N2 virus acquired a novel $\mathrm{H} 3$ gene segment and that the two viruses may have co-circulated for about 2 years prior to the widespread transmission of the pandemic strain and disappearance of the $\mathrm{H} 2 \mathrm{~N} 2$ virus. ${ }^{39,45}$ Due to poor swine surveillance at the time, it is difficult to determine if the reassortment of these two viruses occurred in swine or humans, however, the potential for avian and mammalian virus transmission within the swine host cannot be ignored. As with the H1N1 subtype, the H3N2 virus established a stable viral lineage within the swine population and the virus was antigenically similar to the human pandemic strain. However, the prevalence of the H3N2 subtype was significantly lower than that of the classical swine H1N1 lineage. ${ }^{46}$ Despite the low level circulation of H3N2 viruses in swine, the surveillance and phylogenetic information described above indicates cross species transmission of both mammalian and avian influenza viruses in swine populations providing an ideal host for reassortment to continue to occur.

In 1977 the H1N1 genotype virus was isolated from human in China and shortly after in Russia. This H1N1 virus was widespread throughout the Northern Hemisphere by 1978; however, most of the human population over 20 years of age had been exposed to H1N1 genotype virus, so the virus was limited in its ability to infect preventing a new pandemic. Due to the high genetic homology to H1N1 viruses from 1950, the H1N1 virus isolated in 1977 was likely the result of a laboratory release. ${ }^{47}$

In 2009, more than 40 years following the H3N2 pandemic, a novel H1N1 pandemic virus emerged. Based on surveillance and sequencing data, this virus has been determined to potentially be the result of multiple reassortment events. The first reassortment likely occurred around 1998 in a swine herd located in North Carolina and the resulting virus circulated to swine herds in Minnesota, Iowa, and Texas. This triple reassortant virus caused severe ILI in these pig herds. The isolated viruses from these herds were identified as reassorted $\mathrm{H} 3 \mathrm{~N} 2$ viruses with $\mathrm{HA}, \mathrm{NA}$, and PB1 of human lineage, NS, NP, and M segments of swine lineage, and PB2 and PA of avian lineage. ${ }^{48,49}$ This gene clustering of three distinct viral lineages, with avian lineage PB2 and PA segments, a human lineage PB1 segment, and swine lineage NP, M, and NS gene segments, is known as the triple reassortant internal gene (TRIG) cassette Table 1-1. These TRIG containing H3N2 swine viruses further reassorted with H1N1 viruses by accepting the HA and NA forming two additional distinct subtypes, H1N1 and H1N2. ${ }^{50}$ Finally, one of the swine viruses reassorted with a Eurasian swine virus and acquired the Eurasian swine $\mathrm{M}$ and NA genes which had not been previously identified outside of 
Table 1-1: Gene lineage of the TRIG cassette

\begin{tabular}{cc}
\hline \multicolumn{2}{c}{ TRIG cassette } \\
\hline Gene segment & Lineage \\
\hline PB2 & Avian origin \\
PB1 & Human origin \\
PA & Avian origin \\
NP & Swine origin \\
M & Swine origin \\
NS & Swine origin \\
\hline
\end{tabular}

Eurasian swine herds. ${ }^{51}$ This novel H1N1 virus quickly transmitted among the human population and completely displaced the previously circulating seasonal H1N1 virus. Subsequently, this TRIG containing virus has been isolated from swine and appears to continue to reassort.

\section{Influenza A in Swine}

Swine are an important host for the maintenance and evolution of influenza viruses. The emergence and generation of the $2009 \mathrm{H} 1 \mathrm{~N} 1$ pandemic virus has been linked to swine, which have been called a "mixing vessel" for influenza viruses. This is primarily because the swine respiratory tract contains both the avian influenza virus receptor $\alpha 2,3$-linked sialic acids and the mammalian influenza virus receptor $\alpha 2,6$-linked sialic acids. It has also been shown experimentally, that swine can be infected with avian influenza viruses. ${ }^{52,53}$

\section{Classical Swine Viruses}

Around the time of the 1918 pandemic, the H1N1 virus entered the U.S. swine population and circulated for roughly 80 years with little antigenic or genetic variation. ${ }^{54}$ In 1978 a study was completed to determine the prevalence of influenza A viruses within U.S. swine herds. The study identified a relatively high prevalence of influenza in swine, about $25 \%$ of all swine and up to $47 \%$ of particular herds, had been exposed or infected with the classical swine H1N1 virus which was genetically distinct from the circulating human H1N1 genotype. ${ }^{46}$ However, only about $1.4 \%$ of the pigs tested had been exposed to influenza of the H3N2 genotype. H3N2 isolated from swine from 1976-1977 were also genetically similar to 1975 human isolates, which suggests that they were recent reverse zoonotic events of the $\mathrm{H} 3 \mathrm{~N} 2$ viruses rather than sustained in the swine population like the H1N1 viruses. ${ }^{46}$ Interestingly, H3N2 viruses were frequently isolated from swine in Europe and Asia, indicating that the subtype was capable of sustained pig-to-pig transmission. ${ }^{55}$ Surprisingly, over 10 years later in $1988 / 1989$, up to $51 \%$ of swine herds in the U.S. were identified as seropositive to $\mathrm{H} 1 \mathrm{~N} 1$ viruses while only $1.1 \%$ had been exposed or infected by $\mathrm{H} 3 \mathrm{~N} 2$ viruses. ${ }^{56,57}$ These surveillance studies illustrate that prior 
to the 1990 s the classical swine H1N1 viruses predominated over any other subtype and the only other influenza viruses that could be identified in swine were human origin H3N2 subtypes. Despite the low prevalence and few H3N2 swine isolates, the cross species transmission provided opportunities for reassortment to occur between human adapted viral strains with the circulating swine influenza viruses.

Swine influenza viruses in the U.S. dramatically changed in the mid to late 1990s. From 1997-1998, 7.6\% of U.S. pigs tested seropositive against avian H1N1 viruses and $8 \%$ were seropositive against human H3N2 viruses. ${ }^{58}$ In August of 1998, there was a severe outbreak of ILI in swine from North Carolina and subsequent outbreaks on farms in Minnesota, Iowa, and Texas. ${ }^{48}$ Swine H3N2 viruses were later isolated in Nebraska, Colorado, Oklahoma, Wisconsin, and Illinois. ${ }^{49}$ This outbreak was unique not only that it was caused by an $\mathrm{H} 3 \mathrm{~N} 2$ virus, but also it showed increased virulence not previously seen with classical H1N1 infections. Not only was this a significant increase in swine H3N2 infections, but sequencing analysis of the viruses revealed 3 unique genotypes indicating that several reassortment events may have occurred. The initial genotype was recovered from a pig in Ontario and consisted of a wholly human H3N2 virus that appeared to cross the species barrier but unable to transmit to other pigs. ${ }^{57}$ The second genotype identified was a double reassortant virus and contained classical swine PB2, PA, NP, M, and NS genes with human PB1, HA, and NA genes. ${ }^{48}$ The third genotype was a triple reassortant virus with classical swine NP, M, and NS genes, human origin PB1, HA, and NA genes and avian origin PB2 and PA genes. ${ }^{49}$ This triple reassortant virus contained and propagated the TRIG cassette among swine herds in the U.S. and established several new genotypes within the swine population as seen in Table1-2. A large surveillance study found that from 1998-2001, out of 3,561 swine samples, 31.7\% were influenza positive among which $77.3 \%$ were $\mathrm{H} 1$ positive and $22.7 \%$ were $\mathrm{H} 3$ positive. ${ }^{59}$ Further characterization revealed that $67.1 \%, 4.6 \%$, and $26.9 \%$ were positive for H1N1, H1N2, and $\mathrm{H} 3 \mathrm{~N} 2$ subtypes, respectively and $1.5 \%$ contained $\mathrm{H} 1 \mathrm{~N} 1$ and $\mathrm{H} 3 \mathrm{~N} 2$ co-infections. ${ }^{59}$ Subsequent swine influenza virus surveillance has shown that H1N1 TRIG viruses have completely displaced the classical swine H1N1 viruses across the U.S. Therefore, these TRIG containing viruses have a growth advantage over the other genotypes and also can be maintained within swine herds rather than continued reverse zoonotic events. ${ }^{57}$ It is evident that the presence of the TRIG cassette helped the virus sustain transmission among the swine herds by potentially limiting host restriction through new combinations of internal genes, or by increasing the reassortment and evolutionary rate, thereby having a superior gene constellation that allowed it to outcompete the other predominant strains.

\section{TRIG Cassette}

Following the introduction of the TRIG cassette in the circulating swine viruses, additional reassorted viruses discovered were derived from the triple reassortant H3N2 viruses previously mentioned. They contained novel HA and NA genes on the TRIG backbone. In 1999, an H1N2 virus was isolated from an Indiana farm with a classical swine $\mathrm{H} 1$ and the remaining 7 genes showed sequence homology with the triple reassortant $\mathrm{H} 3 \mathrm{~N} 2$ virus, suggesting this was an additional reassortment after the 
Table 1-2: $\quad$ Swine virus gene diversity since 1998

\begin{tabular}{cccccccc}
\hline $\begin{array}{c}\text { Gene } \\
\text { segment }\end{array}$ & $\begin{array}{c}\text { csH1N1 } \\
(\mathbf{6 7 . 1 \% )}\end{array}$ & drH1N1 & $\begin{array}{c}\text { H3N2 } \\
\mathbf{( 2 6 . 9 \% )}\end{array}$ & $\begin{array}{c}\text { H1N2 } \\
\mathbf{( 4 . 6 \% )}\end{array}$ & hH1N1 & trH1N2 & rhH1N1 \\
\hline PB2 & swine & avian & avian & avian & human & avian & avian \\
PB1 & swine & human & human & human & human & human & human \\
PA & swine & avian & avian & avian & human & avian & avian \\
HA & swine & swine & human & swine & human & human & human \\
NP & swine & swine & swine & swine & human & swine & swine \\
NA & swine & swine & human & human & human & human & human \\
M & swine & swine & swine & swine & human & swine & swine \\
NS & swine & swine & swine & swine & human & swine & swine \\
\hline
\end{tabular}

The orange boxes represent gene segments of swine origin. The green boxes show gene segments of avian origin. The blue boxes indicate human lineage gene segments. The pink boxes highlight the $\mathrm{H} 3$ or N2 gene segments of human origin while the gray boxes indicate the human $\mathrm{H} 1$ or $\mathrm{N} 1$ gene segments.

This table was compiled from U.S. swine surveillance studies conducted from 1998 to 2001.

generation of the TRIG cassette (Table 1-2). ${ }^{60}$ Additionally, in 2004, an H3N1 virus was isolated from swine in Minnesota with the same TRIG cassette. ${ }^{61}$

Influenza viruses circulating in swine herds experience little selective pressure due to the lack of immunity resulting from the short life span of commercial swine, which is usually only 5 to 6 months. ${ }^{62}$ Therefore, it is expected that the influenza virus HA nucleotide substitution rate would be relatively low compared to viruses in the human population. This was observed up to about 1998; however, with the development of the TRIG cassette in swine viruses, the rate of antigenic drift as well as shift, or reassortment, has dramatically increased in the past 10-15 years. ${ }^{63}$ Specifically, the HA of classical swine H1N1 from 1930 genetically clusters with more modern classical swine viruses of 1973 despite some genetic drift and also show considerable serologic cross-reactivity. However, the modern $\mathrm{H} 1$ reassortant viruses show distinctly clustered HA sequences and decreased serologic cross-reactivity with each other and with classical swine HAs when tested in hemagglutination inhibition assays. ${ }^{50,64}$ These studies suggest that there has been considerable drift in swine influenza viruses during the last decade when compared to classical swine viruses that circulated for roughly 80 years and underwent very little antigenic drift. Similar data has been reported about the H3N2 triple reassortant viruses circulating in U.S. swine, yet further surveillance needs to be conducted. ${ }^{64}$

The reasons for the increased antigenic shift and drift remain largely unclear. However, there have been several hypotheses, none of which have been thoroughly explored. First, the TRIG cassette, particularly the combination of human and avian polymerase genes, is more promiscuous in accepting multiple HAs and NAs. This idea has clearly been observed in nature and in the laboratory; however, the actual mechanism 
is not defined. ${ }^{65}$ Secondly, viruses containing the TRIG cassette have a significant growth advantage over other viruses within swine. This growth advantage not only allowed the TRIG virus to outcompete the other circulating strains, but also leads to greater genetic diversity providing greater opportunities to either evade host immune responses or for generating host adapted mutations. ${ }^{50}$ It has been proposed that in addition to having a greater growth advantage, the TRIG NS gene is more effective at suppressing the initial host interferon response, therefore allowing a more rapid viral replication after infection (P. Thomas, personal communication, October 13, 2010). This early rapid viral replication increases the possibility of mutant viruses emerging and establishing a new viral subpopulation. This would be observed as an increase in the number of mutants or the evolutionary rate for TRIG viruses.

The stable circulation of the classical swine H1N1 viruses indicated that it lacked the ability to successfully reassort despite some low level human H3N2 introduction into swine. However, after the formation of the TRIG cassette in the mid-1990s, the viral diversity in swine had significantly increased by 2002. This swine surveillance data clearly demonstrates a clear advantage of reassortment for viruses that contain the TRIG cassette when compared to classical swine viruses in the field. This phenomenon was further demonstrated in the laboratory by coinfecting Madin Darby canine kidney (MDCK) cells with A/TX/6/1996 (TX/96), a human H3N2 virus similar to H3N2 viruses isolated from swine in the late 1990s and either A/swine/MN/37866/1999 (MN/99), a classical swine $\mathrm{H} 1 \mathrm{~N} 1$ virus, or $\mathrm{A} / \mathrm{swine} / \mathrm{NC} / 18161 / 2002$ (NC/02), a triple reassortant swine H1N1 virus that contains the TRIG cassette. Analysis of these samples by reverse transcription polymerase chain reaction (RT-PCR) revealed that in samples coinfected with MN/99 and TX/96, 48 samples were positive for the human $\mathrm{H} 3$ gene and of the 48, none were positive for MN/99 PA or PB2 genes. ${ }^{66}$ Contrastingly, the RT-PCR results of samples coinfected with $\mathrm{NC} / 02$ and $\mathrm{TX} / 96$ that of the 38 samples positive for the human $\mathrm{H} 3$ gene, $28.9 \%$ contained the $\mathrm{NC} / 02 \mathrm{PA}$ gene and $52.6 \%$ contained both of the $\mathrm{NC} / 02$ PB2 and PA genes. ${ }^{66}$

This experiment demonstrated that MN/99 lacks the ability to successfully acquire the human $\mathrm{H} 3$ gene and produce viable virus. It also supports the surveillance data of swine influenza viruses prior to 1998 . However, the NC/02 triple reassortant virus showed an increased propensity to acquire the human $\mathrm{H} 3$ gene under multiple conditions, similar to what was observed with swine viruses once the TRIG cassette was introduced in the viral population around 1998.

\section{Research Aims}

In the last 10-15 years, swine influenza viruses in the U.S. have proven to be rapidly evolving through genetic drift and shift compared to what was seen in the previous 80 years. This increased genetic drift and shift corresponds with the formation of the TRIG cassette in U.S. swine. However, there is little laboratory evidence for why the TRIG is not only more promiscuous in its ability to replicate and transmit with novel HA and NA gene segments, but also what virologic factors contribute to observed 
increased nucleotide substitutions. These observations helped to formulate the following 3 hypotheses.

\section{Hypothesis 1}

Viruses including influenza virus have shown the ability to prevent additional viruses from infecting the same cell. The classical swine influenza viruses have the ability to more effectively exclude a second virus from infecting the same cell when compared to the swine viruses which contain the TRIG cassette.

\section{Hypothesis 2}

TRIG containing viruses have shown an increased propensity to grow with a variety of HA and NA combinations compared to what was seen with classical swine viruses. Therefore, the TRIG viruses must reassort more readily and following reassortment produce progeny virions with sufficient growth advantages to compete with the parental genotypes and transmit to naïve hosts.

\section{Hypothesis 3}

Phylogenetic analysis of influenza viruses in nature with the TRIG and with the TRIG NS have shown increased nucleotide substitutions in the HA, suggesting they evolve more rapidly. If this is a purely virologic aspect, then viruses rescued on the TRIG

backbone or with the TRIG NS should show increased nucleotide substitutions in rescued viruses. 


\section{CHAPTER 2. INFLUENZA VIRUS SUPERINFECTION EXCLUSION AND GROWTH KINETICS OF REASSORTANTS}

\section{Introduction}

Reassortment plays a crucial role for influenza virus adaptation and evolution. However, the mechanisms that govern reassortment are poorly understood. This includes the ability to accept new genes as well as the frequency in which new gene combinations arise. The classical swine $\mathrm{H} 1 \mathrm{~N} 1$ viruses remained genotypically stable for about 80 years. However, once the TRIG cassette was formed and propagated within the swine viral population, the rate of reassortment greatly increased. Suggesting there is some inherent property of the TRIG gene arrangement that allows it to more readily acquire new HA and NA genes when compared to the classical swine gene constellations.

In order for reassortment to occur, a single cell must be infected with at least two viruses, also known as superinfection. The NA of influenza viruses may play a role in preventing superinfection by cleaving sialic acid receptors off the cell surface as it is expressed. ${ }^{67}$ Plasmid expression of NA in cells resulted in the release of sialic acids from the cell surface, prevented HA mediated viral entry, and in the presence of NA inhibitors more cells were superinfected with $\mathrm{H} 1$ and $\mathrm{H} 3$ viral subtypes. This viral exclusion also prevents reinfection of the cell by new budding virions. Other viruses have also been shown to possess unique mechanisms to prevent superinfection by reducing expression of the viral receptors or inducing internalization of viral receptors. ${ }^{68,69}$

Previous experiments have shown that $\mathrm{NC} / 02$ is able to reassort with the human H3N2 virus, TX/96, while the classical swine MN/99 lacks the ability to reassort. Therefore, it is hypothesized that the MN/99 virus is able to more efficiently exclude another virus from superinfection compared to $\mathrm{NC} / 02$. This would greatly reduce the possibility of the MN/99 virus producing reassortant progeny. This will be tested using fluorescently labeled monoclonal antibodies specific for $\mathrm{H} 1$ or $\mathrm{H} 3$ to quantify the number of superinfected cells during simultaneous or delayed infections.

Not only do cells have to be superinfected in order for reassortment to be a possibility, but the progeny virions must be of sufficient fitness to compete with or outcompete the parental strains. This led the hypothesis that if superinfection exclusion is not responsible for the differences between $\mathrm{MN} / 99$ and $\mathrm{NC} / 02$ in their ability to reassort, then the 80 years of MN/99 evolution created an optimized and stable gene constellation in which reassorting with human virus gene segments does not produce progeny with the growth properties required to outcompete the parental strains. Growth kinetics will be completed for these viruses including reverse genetic reassortants to determine if the addition of the human HA and NA on the swine backbones causes any attenuation. 


\section{Materials and Methods}

\section{Viruses}

For flow cytometry two reverse genetics (RG) viruses RG-MN/99, a classical swine $\mathrm{H} 1 \mathrm{~N} 1$ virus with all 8 gene segments of swine origin lineage, and RG-NC/02, a triple reassortant $\mathrm{H} 1 \mathrm{~N} 1$ virus with the TRIG cassette and swine origin HA and NA genes,

and one wild type virus TX/96, a human seasonal H3N2 virus with all 8 gene segments of human lineage origins, were used for the following experiments. The RG viruses were generated using the dual promoter eight plasmid system as outlined in Figure 2-1. ${ }^{70}$ Briefly, the RNA is extracted from the virus of interest and is amplified by RT-PCR. The amplified gene segments are purified, digested with BsmBI, BsaI, or AarI and then ligated into the pHW2000 plasmid. All 8 plasmids are then simultaneously transfected into a 90-95\% confluent MDCK-293T cell co-culture using TransIT-LT1 (Mirus catalog number MIR 2304). The rescued virus supernatants are then injected into 10 day old embryonated chicken eggs and incubated at $35^{\circ} \mathrm{C}$ for 48 hours. The allantoic fluid is harvested and re-injected into embryonated chicken eggs for a second passage. The virus is harvested, aliquoted, and stored at $-80^{\circ} \mathrm{C}$. Each vial is only thawed once before use in each experiment.

For the growth kinetics experiments reverse genetics viruses were rescued by adding the human H3N2 viral glycoproteins on both of the swine backbones (Table 2-1). The MN/TX genotype consists of the human H3 and N2 from TX/96 with the remaining 6 gene segments from the MN/99 virus. The NC/TX virus contains the TRIG cassette with the human $\mathrm{H} 3$ and $\mathrm{N} 2$ derived from TX/96.

\section{Coinfection}

MDCK cells were grown to about $80-90 \%$ confluency in a $24-w e l l$ tissue culture plate. Prior to infection, one well was trypsinized and cells were counted using the Invitrogen Countess (catalog number C10227). Cells were infected at multiplicities of infection (MOI) of 0.01 and 1, based on the live cell counts as outlined. For simultaneous infection times, the desired amounts of NC/02+TX/96 and MN/99+TX/96 were mixed prior to addition to the cells. For delayed infections, each virus, NC/02, TX/96, or MN/99 were added at time point 0 . These infections were incubated at $37^{\circ} \mathrm{C}$ with $5 \% \mathrm{CO}_{2}$ for 1 hour and then the viral dilutions were washed from the cells using sterile PBS ( $\mathrm{pH} 7.4$ ). Following the wash, infection media (1X minimum essential media (MEM) supplemented with antibiotics (Gibco catalog number 15240-062), vitamins (Gibco catalog number 11120-052), $400 \mu \mathrm{M}$ glutamine (Gibco catalog number 25030-081), $0.1 \%$ BSA (Sigma catalog number A8412), and $0.5 \mu \mathrm{g} / \mathrm{ml}$ TPCK-Trypsin) was added and incubated at $37^{\circ} \mathrm{C}$ with $5 \% \mathrm{CO}_{2}$ for 24 hours. At 24 hours post infection (hpi), supernatants were aspirated from the cells and for single and simultaneously infected cells, new infection media was added. For the 24 hour delayed infections, the infection media contained the second virus to be added at the proper MOI dilution and plates were 


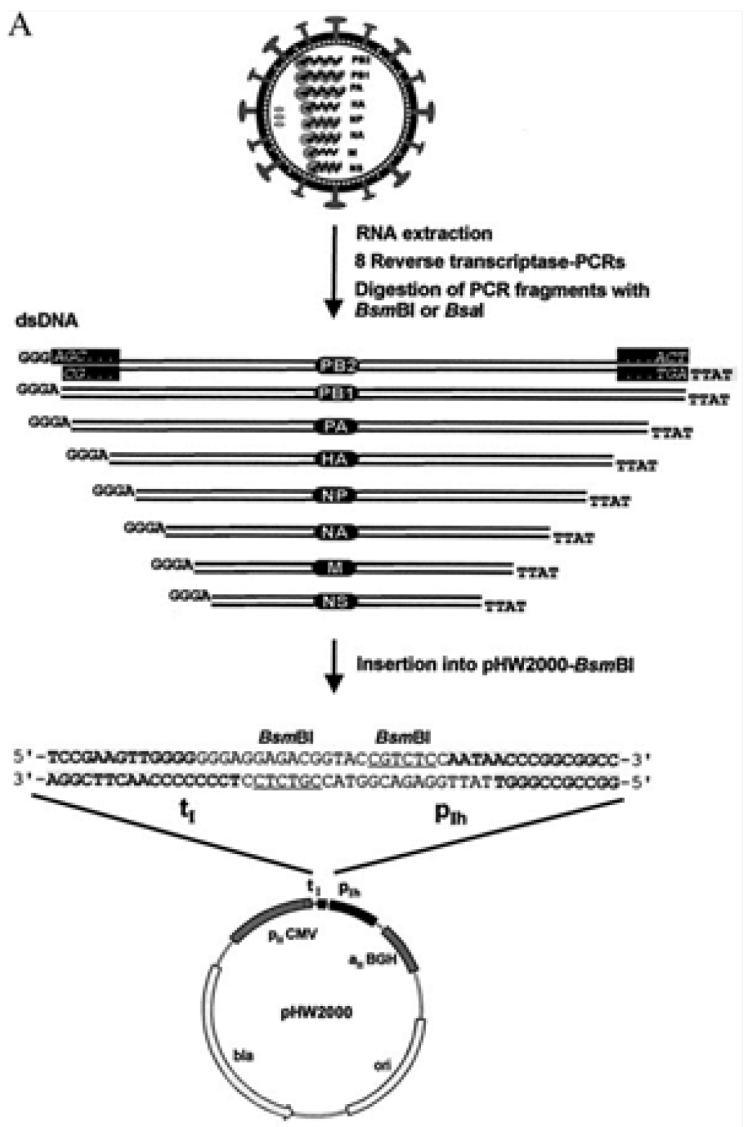

B

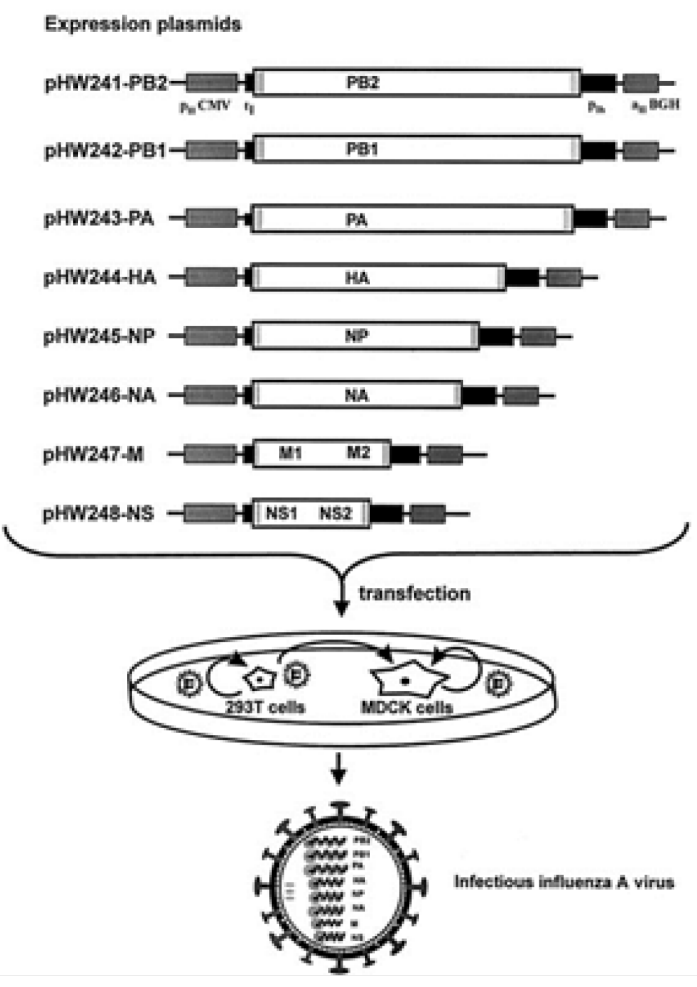

Figure 2-1: Illustration of the dual promoter eight plasmid system to rescue cloned viruses

A) Viral RNA is extracted, reverse transcribed, and then amplified using RT-PCR. All 8 of the amplified dsDNA influenza segments are digested using BsmBI, BsaI, or AarI, and ligated into the plasmid pHW2000 directly between the human Pol I promoter and pol I terminator, both of which are flanked by the CMV promoter and the $\mathrm{BGH}$ polyadenylation signal. B) The cloned influenza gene segments in the pHW2000 expression vector are transfected into confluent MDCK and 293T cell monolayers and incubated at $37^{\circ} \mathrm{C}$ with $5 \% \mathrm{CO}_{2}$ for 72 hours. The $293 \mathrm{~T}$ cells produce the initial virions which can infect and replicate in the MDCK cells.

Reprinted with permission by the National Academy of Sciences, U.S.A. and Dr. Robert Webster. Hoffmann, E., Neumann, G., Kawaoka, Y., Hobom, G. \& Webster, R. G. A DNA transfection system for generation of influenza A virus from eight plasmids. Proc Natl Acad Sci U S A 97, 6108-6113, doi:10.1073/pnas.100133697 (2000). Copyright 2000 National Academy of Sciences, U.S.A. 
Table 2-1: $\quad$ Rescued virus gene compositions

\begin{tabular}{ccccccccc}
\hline \multirow{2}{*}{$\begin{array}{c}\text { RG-virus } \\
\text { abbreviation }\end{array}$} & PB2 & PB1 & PA & HA & NP & NA & M & NS \\
\hline NC/02 & NC/02 & NC/02 & NC/02 & NC/02 & NC/02 & NC/02 & NC/02 & NC/02 \\
MN/99 & MN/99 & MN/99 & MN/99 & MN/99 & MN/99 & MN/99 & MN/99 & MN/99 \\
TX/96* & & & & Wild Type & & & \\
NC/TX 6+2 & NC/02 & NC/02 & NC/02 & TX/96 & NC/02 & TX/96 & NC/02 & NC/02 \\
MN/TX 6+2 & MN/99 & MN/99 & MN/99 & TX/96 & MN/99 & TX/96 & MN/99 & MN/99 \\
\hline
\end{tabular}

The orange boxes indicate gene segments from the TRIG swine virus $\mathrm{NC} / 02$. The blue boxes indicate gene segments of classical swine lineage from $\mathrm{MN} / 99$ and the green boxes are genes derived from the human $\mathrm{H} 3 \mathrm{~N} 2$ virus, $\mathrm{TX} / 96$.

* TX/96 is a wild type virus and only HA and NA were cloned for rescue on the swine viral backbones. 
incubated at $37^{\circ} \mathrm{C}$ with $5 \% \mathrm{CO}_{2}$ for 1 hour followed by aspiration of the virus supernatant and addition of fresh infection media.

\section{Antibody Purification and Fluorescent Labeling}

Anti-H1 and anti-H3 antibodies were identified using hemagglutination inhibition assays that specifically targeted the $\mathrm{NC} / 02, \mathrm{MN} / 99$, and $\mathrm{TX} / 96$ viruses and to confirm these antibodies did not non-specifically bind to the alternate subtype. The antibodies were purified from the ascites fluid as outlined in Appendix A. Briefly, the lipid content is removed from the ascites fluid using PHM-L Liposorb (EMD Millipore catalog number 524371) and the monoclonal antibody is bound by a $1 \mathrm{ml}$ HiTrap Protein $\mathrm{G}$ column (GE Healthcare catalog number 17-0404-01). The column is washed with PBS until the flow through contains no detectable protein contamination as determined by absorbance reading at $280 \mathrm{~nm}$ (A280) less than 0.002 as determined by a NanoDrop 1000 spectrophotometer instrument. Then the antibody is eluted using an acid buffer into $1 \mathrm{ml}$ fractions and only fractions containing protein as determined by A280 readings are pooled and desalted using a Zeba spin 7K MWCO, $2 \mathrm{ml}$ spin desalting column (catalog number 89889). The final concentration of the IgG was determined by a NanoDrop 1000 instrument and directly labeled.

The purified anti-H1 and anti-H3 antibodies were fluorescently labeled with Alexa Fluor 488 (Invitrogen catalog number A20181) and Alexa Fluor 555 (Invitrogen catalog number A20187), respectively. The antibodies were diluted to $1 \mathrm{mg} / \mathrm{ml}$ in $1 \mathrm{ml}$ and added $100 \mu \mathrm{l}$ of $1 \mathrm{M}$ sodium bicarbonate. To the provided reactive dye vial, $100 \mu \mathrm{l}$ of the antibody dilution was added. This was gently inverted on a rocking plate for 1 hour at room temperature. This solution was then added to a prepared $\sim 1.5 \mathrm{ml}$ purification resin column and centrifuged at $1100 \mathrm{x}$ g for $5 \mathrm{~min}$. The eluent is labeled antibody in $1 \mathrm{X}$ PBS at a $\mathrm{pH}$ of 7.2 with $2 \mathrm{mM}$ sodium azide.

\section{Flow Cytometry}

The infected MDCK monolayer was washed with PBS and trypsinized and moved to a 96 well plate. The cells were stained with either Alexa Fluor 488 conjugated anti-H1 antibody or Alexa Fluor 555 conjugated anti-H3 antibody or both. The stained samples were analyzed on a BD FACS Canto II.

\section{Growth Kinetics}

To an $80 \%$ confluent monolayer of MDCK cells, the RG viruses and wt TX/96, as outlined in Table 2-1, were used to infect at MOIs of 0.01. MOIs were calculated by counting trypsinized cells using the Countess cell counter (Invitrogen catalog number $\mathrm{C} 10227)$. The viruses were diluted in infection media to the appropriate MOI and added to the cell monolayers and incubated at $37^{\circ} \mathrm{C}$ with $5 \% \mathrm{CO}_{2}$ for 1 hour. Cell monolayers 
were then washed with 1X PBS and infection media was added to the washed cells. For the MDCK growth kinetic experiments, $2 \times 100 \mu 1$ samples were collected at the following time points, $6,8,10,12,20,24,36$, and $48 \mathrm{hpi}$. All of the samples collected were stored at $-80^{\circ} \mathrm{C}$ until viral $\mathrm{TCID}_{50}$ titers could be determined. All TCID 50 titers were determined using MDCK cells by making 10 fold dilutions of each time point and infecting a single well of a 96 well plate with one dilution. Each time point was measured in quadruplicate using $0.5 \%(\mathrm{v} / \mathrm{v})$ turkey red blood cells in PBS. To maintain continuity, the samples did not undergo any freeze-thaw cycles prior to titration. Significance was calculated using a 2way ANOVA analysis.

\section{Results}

\section{Coinfection Exclusion}

As influenza viruses replicate, HA is expressed on the surface of the infected cell, which is incorporated into budding virions. Using fluorescent antibodies targeted to these HA molecules allowed us to identify $\mathrm{H} 1$ and $\mathrm{H} 3$ infected cell and quantify the amount of cells that were infected by either NC/02, MN/99, or TX/96 as well as those infected by both an $\mathrm{H} 1$ and an $\mathrm{H} 3$ virus. These experiments were designed to determine if MN/99 is more capable of excluding superinfection when compared to $\mathrm{NC} / 02$, explaining the lack of reassortment observed between MN/99 and TX/96.

Simultaneous infections at an MOI of 0.01 revealed that nearly 3 times fewer cells were coinfected between MN/99 and TX/96 (8.8\%) when compared to NC/02 and TX/96 (26.1\%) (Figure 2-2A and B). Nearly half of these cells were infected with the MN/99 or $\mathrm{NC} / 02$ viruses and very few were infected with the TX/96 virus (Figure 2-3). When the $\mathrm{TX} / 96$ infection is delayed by 24 hours after the initial infection with MN/99 or NC/02, $0 \%$ to $0.3 \%$ of the cells, respectively, stained positive for TX/96 infection while over half of the cells were infected with MN/99 (69.7\%) and nearly all of the cells were infected with NC/02 (92.7\%) (Figure 2-2C and D). Similar results were observed when the $\mathrm{MN} / 99$ or NC/02 swine viruses are delayed 24 hours after the TX/96 infection. The percentage of coinfected cells ranged from $0.2 \%$ when $\mathrm{NC} / 02$ is delayed to $0.3 \%$ when MN/99 was delayed (Figure 2-2E and F). While few cells were coinfected or infected with either MN/99 or NC/02 viruses, more than half of the cells analyzed were infected with TX/96 with $67.1 \%$ infected with TX/96 when MN/99 was delayed and $59.6 \%$ infected with TX/96 when NC/02 was delayed (Figure 2-2E and F). Despite a 48 hour incubation, no conditions resulted in 100\% infection rate (Figure 2-3).

When the MOI was increased to 1, very similar results were observed for the delayed infections but a smaller difference was observed during the simultaneous infection. Simultaneous infections with TX/96 and either MN/99 or NC/02 lead to very few cells only infected with TX/96, 0.8\% vs. 0.2\%, respectively (Figure 2-4A and B). At the higher MOI, there were about 1.6 times more coinfected cells when NC/02 and TX/96 were used (37.2\%) compared to when MN/99 and TX/96 were used (22.9\%) 
A Simultaneous

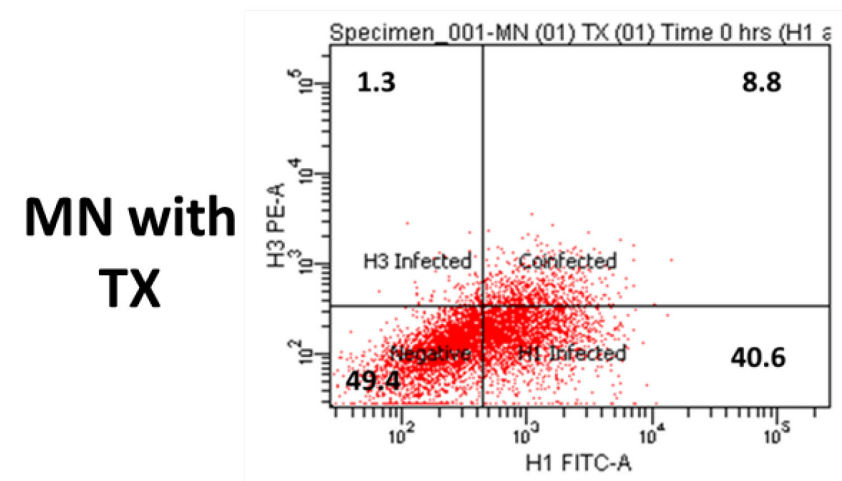

B

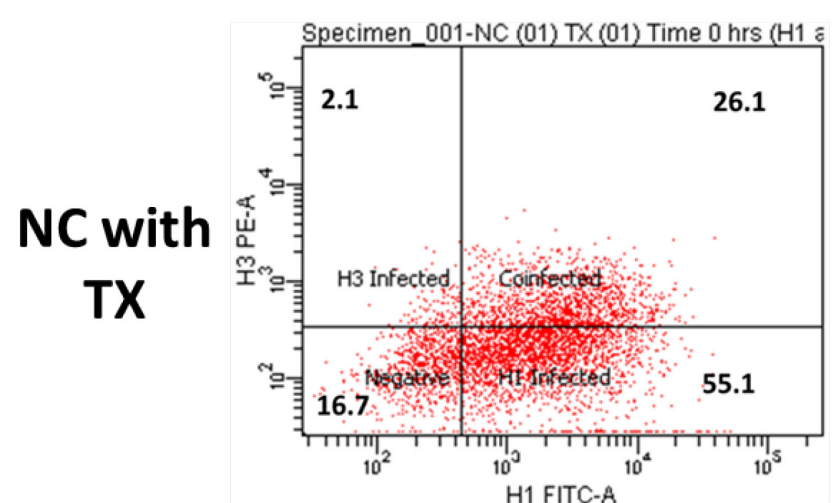

C H3 Delayed

Specimen_001-MN (01) Delayed TX (01) ( $\mathrm{H} 1$ anc

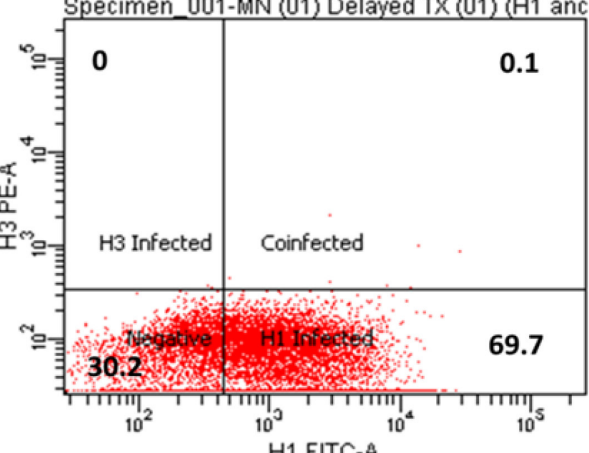

D

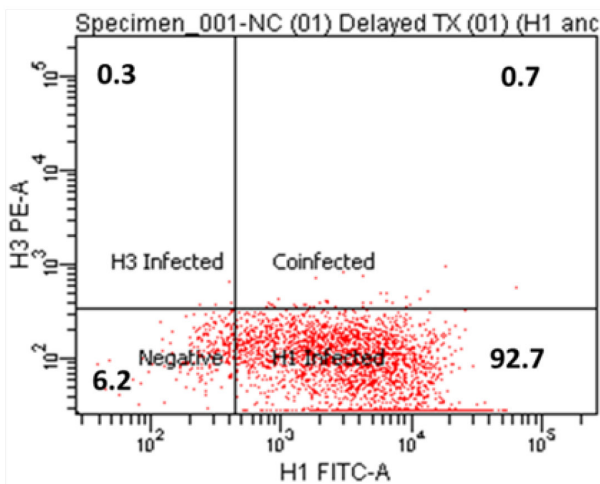

\section{E H1 Delayed}

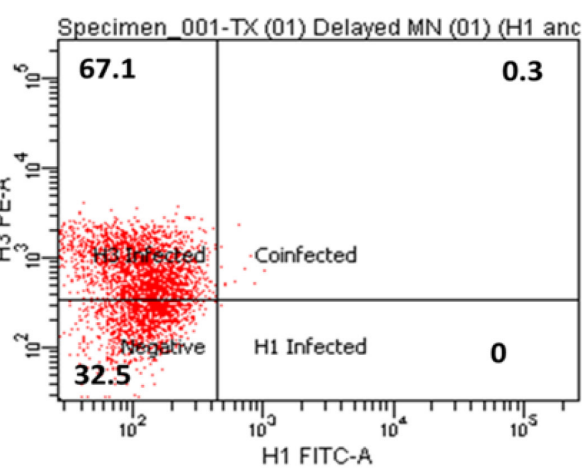

$\mathbf{F}$

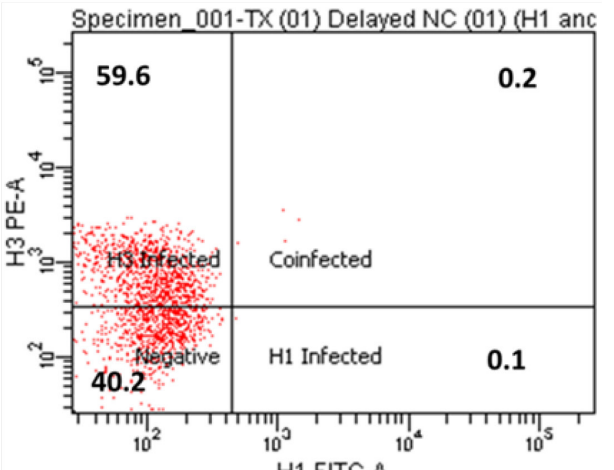

Figure 2-2: $\quad$ Flow cytometry dot plots at an MOI of 0.01

A) MDCK cells simultaneously infected with MN and TX. B) MDCK cells simultaneously infected with NC and TX. C-D) Cells infected with TX and either MN or NC added 24 hpi. E-F) MDCK cells infected with TX and either MN or NC added 24 hpi. 


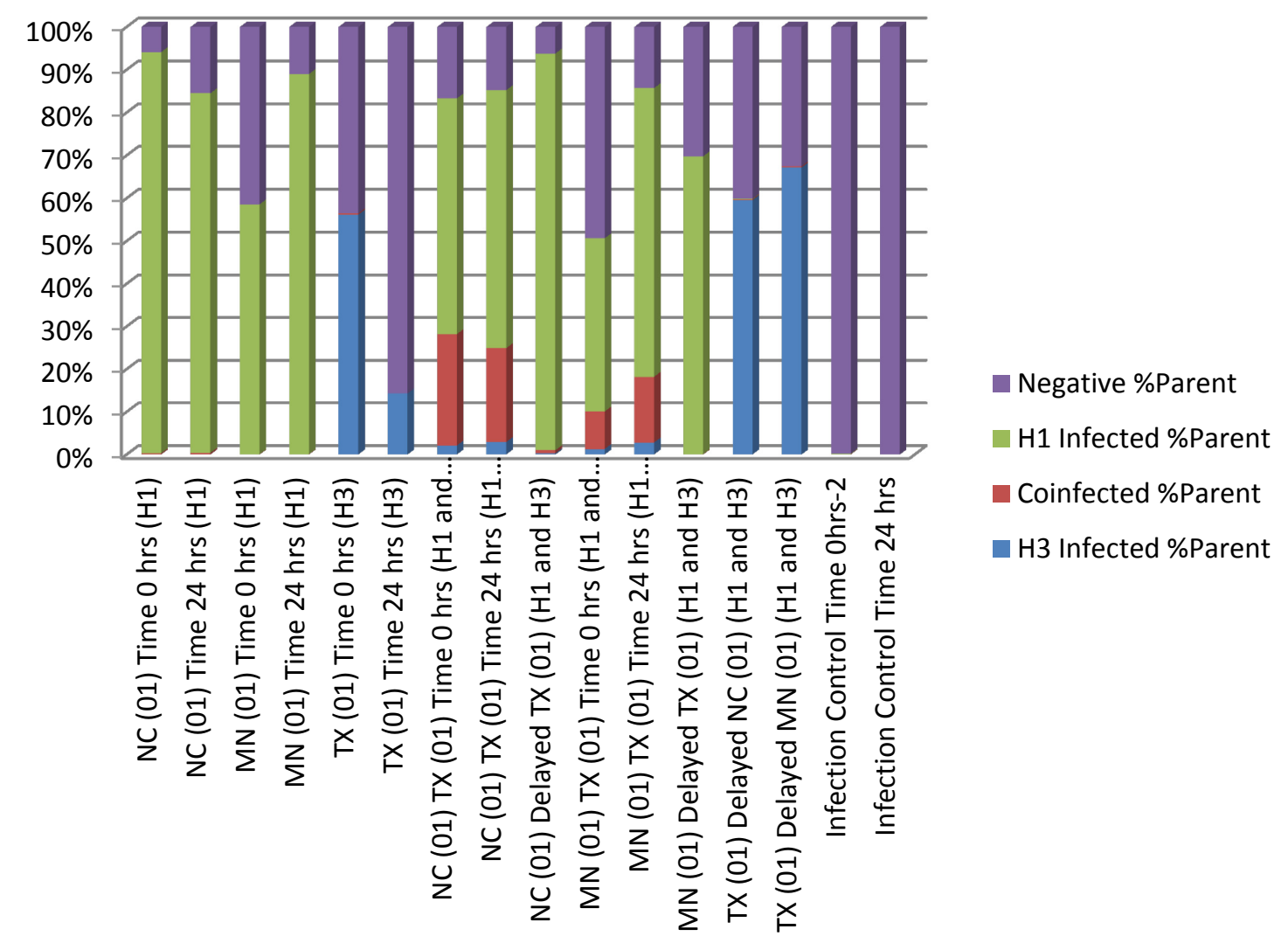

Figure 2-3: Percentage of cells infected with either $\mathrm{H1}, \mathrm{H3}$, or coinfected with a starting MOI of 0.01

Purple represents the percentage of negative cells. Green bars represent $\mathrm{H} 1$ infected while blue represent $\mathrm{H} 3$ infected cells. Red corresponds with coinfected cells. The largest percent of coinfected cells occur only during simultaneous H1N1 and H3N2 infection. When either H1N1 or H3N2 virus addition was delayed by 24 hours, there is very few to no coinfected cells detected. 


\section{A Simultaneous}

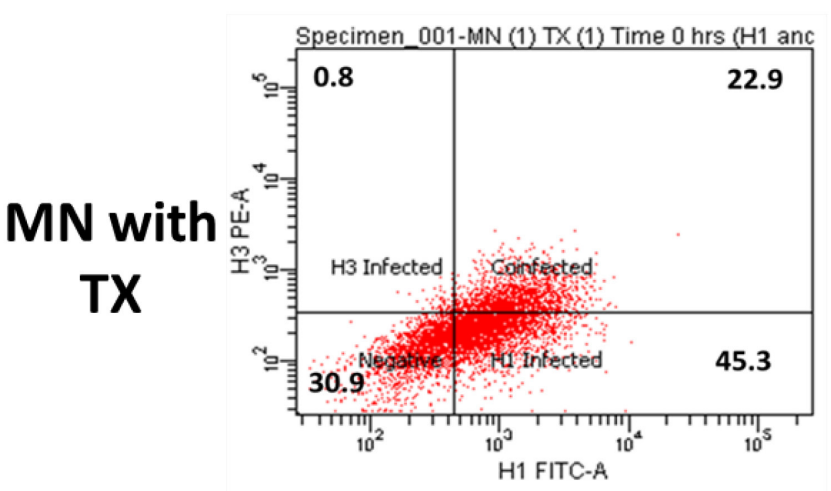

B

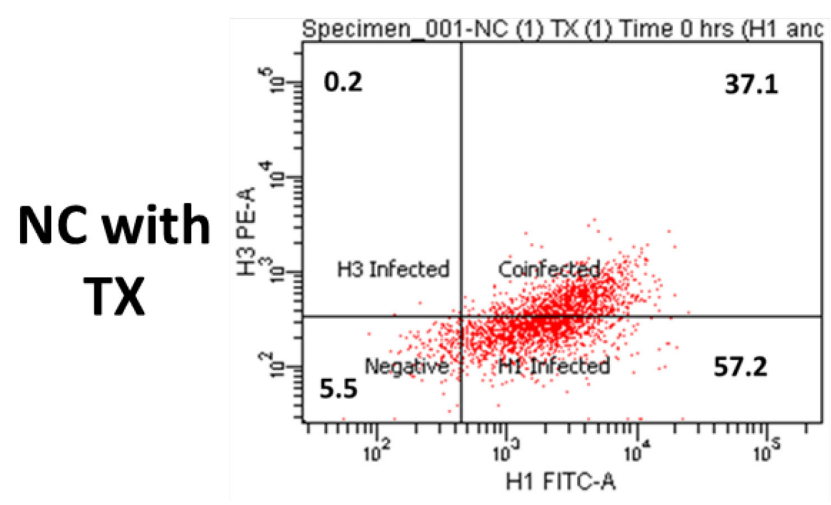

\section{H3 Delayed}

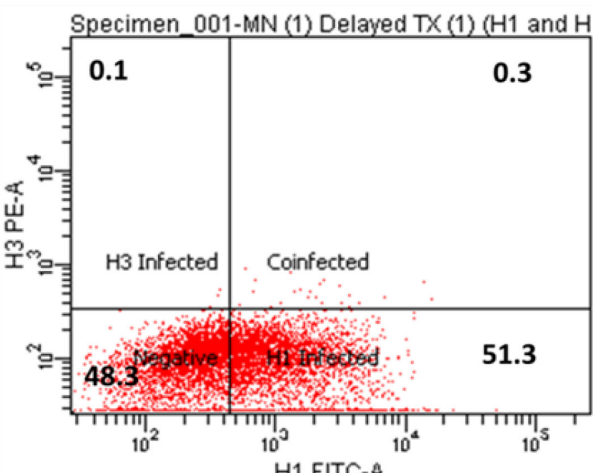

D

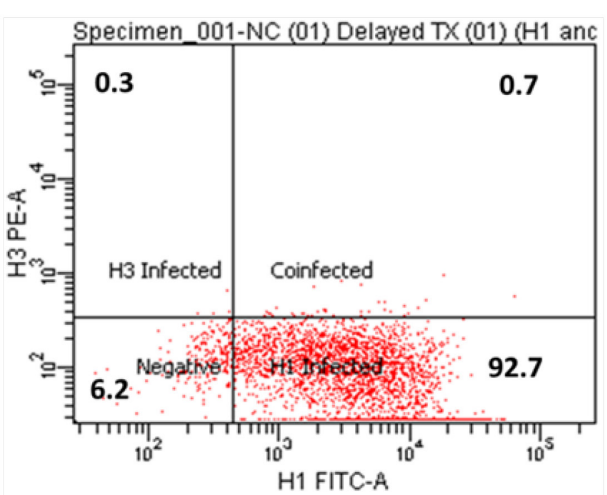

\section{E H1 Delayed}

Specimen_001-TX (1) Delayed MN (1) ( $\mathrm{H} 1$ and $H$

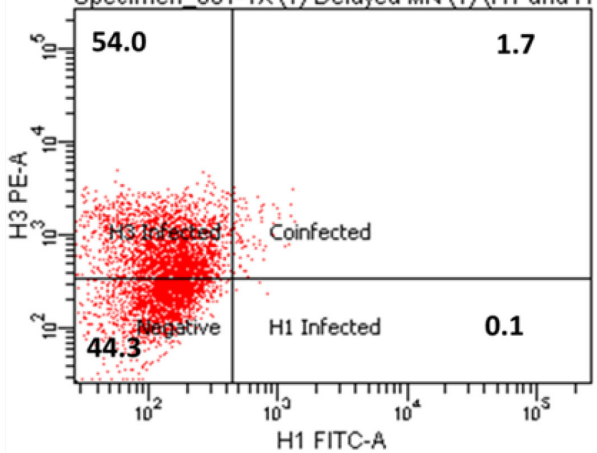

$\mathbf{F}$

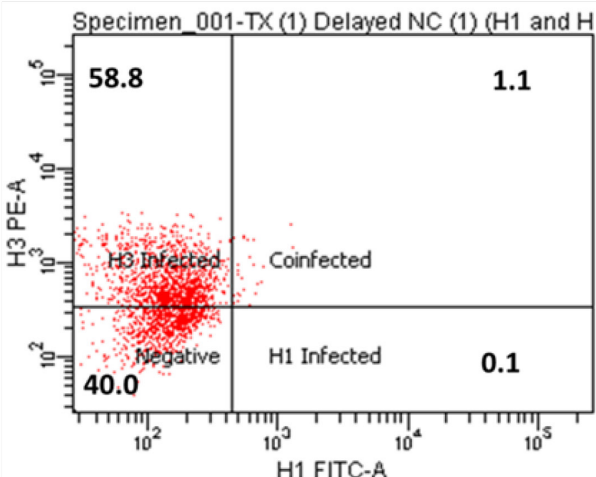

Figure 2-4: $\quad$ Flow cytometry dot plots at an MOI of 1

A) MDCK cells simultaneously infected with MN and TX. B) MDCK cells simultaneously infected with NC and TX. C-D) Cells infected with TX and either MN or NC added 24 hpi. E-F) MDCK cells infected with TX and either MN or NC added 24 hpi. 
(Figure 2-4A and B and Figure 2-5). Additionally, when TX/96 infection was delayed 24 hours, very few cells became infected with the H3 virus with only a slight increase of coinfected cells at $0.3 \%$ for MN/99 and TX/96 and $0.7 \%$ for NC/02 and TX/96 (Figure 2-4C and D). Again, when the H1 viruses were delayed by 24 hours, very few cells were coinfected with only $1.7 \%$ for MN/99 and TX/96 while only $1.1 \%$ for NC/02 and TX/96 (Figure 2-4E and F). Even at the MOI of 1 and 48 hour incubation, not all of the cells were infected (Figure 2-5).

\section{Growth Differences in MDCK Cells}

At, a simultaneous infection with an MOI of 0.01 there seemed to be more $\mathrm{H} 3$ virus exclusion observed between MN/99 and TX/96 when compared to NC/02 and TX/96 which was not seen at an MOI of 1 . However, there were still numerous superinfected cells between MN/99 and the TX/96 virus providing opportunities for reassortment. Any reassortant viruses need to have sufficient growth properties to become successful, so, growth kinetic experiments were completed to determine if $\mathrm{MN} / \mathrm{TX}$ viruses lack the fitness required to outcompete $\mathrm{MN} / 99$ compared to $\mathrm{NC} / 02$ and $\mathrm{NC} / \mathrm{TX}$ viruses. Initial growth kinetic experiments indicate that MN/99 is significantly slower at establishing an infection when compared to NC/02, NC/TX, and TX/96 at 10 and 12 hpi (Figure 2-6). NC/02 did have increased titers over $\mathrm{NC} / \mathrm{TX}$ at $10 \mathrm{hpi}(\mathrm{P}<0.01)$. Interestingly, MN/TX grew to higher titers than MN/99 at 12 hpi $(\mathrm{P}<0.05)$. Despite the early differences observed, all viruses were at similar titers by 24 hpi and remained similar through 72 hpi.

\section{Discussion}

\section{Simultaneous Coinfection Provides the Greatest Possibility for Superinfection}

In order for reassortment to occur, two distinct viruses must be able to superinfect the same cell. When the second virus is delayed by at least 24 hours, it is evident that the initial infecting virus is able to exclude the second virus from superinfection. This could be the result of various mechanisms. However, the data here suggests that either the second virus is not able to enter the cell or translation of the second viral proteins is inhibited. This is evidenced by the fact that no $\mathrm{H} 1$ is present on the cell surface when the $\mathrm{H} 1$ virus is delayed 24 hours and similarly no $\mathrm{H} 3$ is present when the $\mathrm{H} 3$ virus is delayed by 24 hours. Therefore, the infections must occur relatively close together, at least in vitro. There would likely be an increased time frame for 2 different viruses to infect a single host and still produce reassortants because the respiratory tract of either a human or pig will contain significantly more cells than can be modeled in a cell culture dish. For example, it can be expected that although full exclusion is seen after 24 hours, in a respiratory tract it is unlikely that a second virus would be fully excluded due to the large number of uninfected cells. Despite these restrictions, the only difference observed 


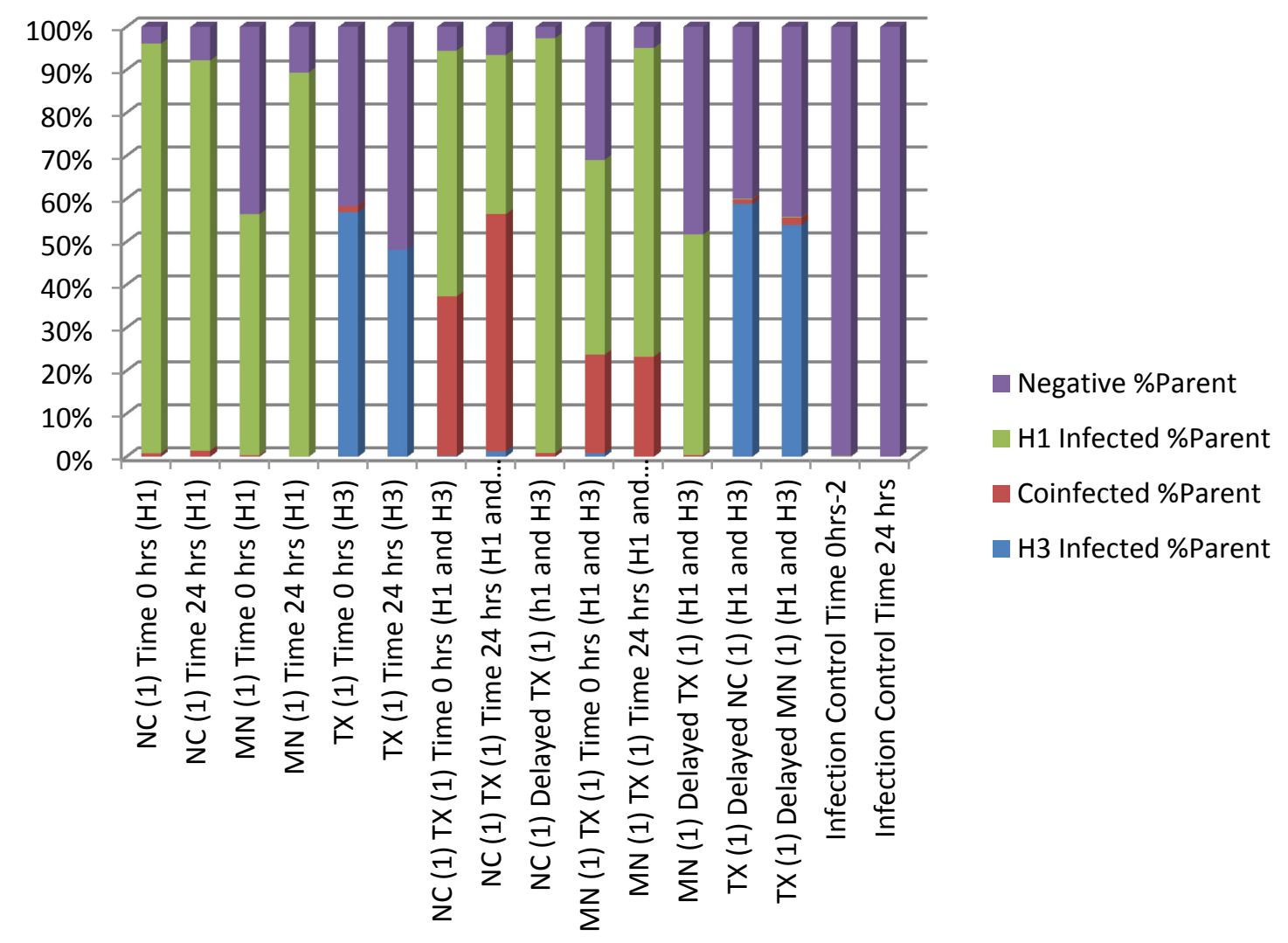

Figure 2-5: Percentage of cells infected with either $\mathrm{H1}, \mathrm{H3}$, or coinfected with a starting MOI of 1

Purple represents the percentage of negative cells. Green bars represent $\mathrm{H} 1$ infected while blue represent $\mathrm{H} 3$ infected cells. Red corresponds with coinfected cells. The largest percent of coinfected cells occur only during simultaneous H1N1 and H3N2 infection. When either H1N1 or H3N2 virus addition was delayed by 24 hours, there was very few to no coinfected cells detected. 


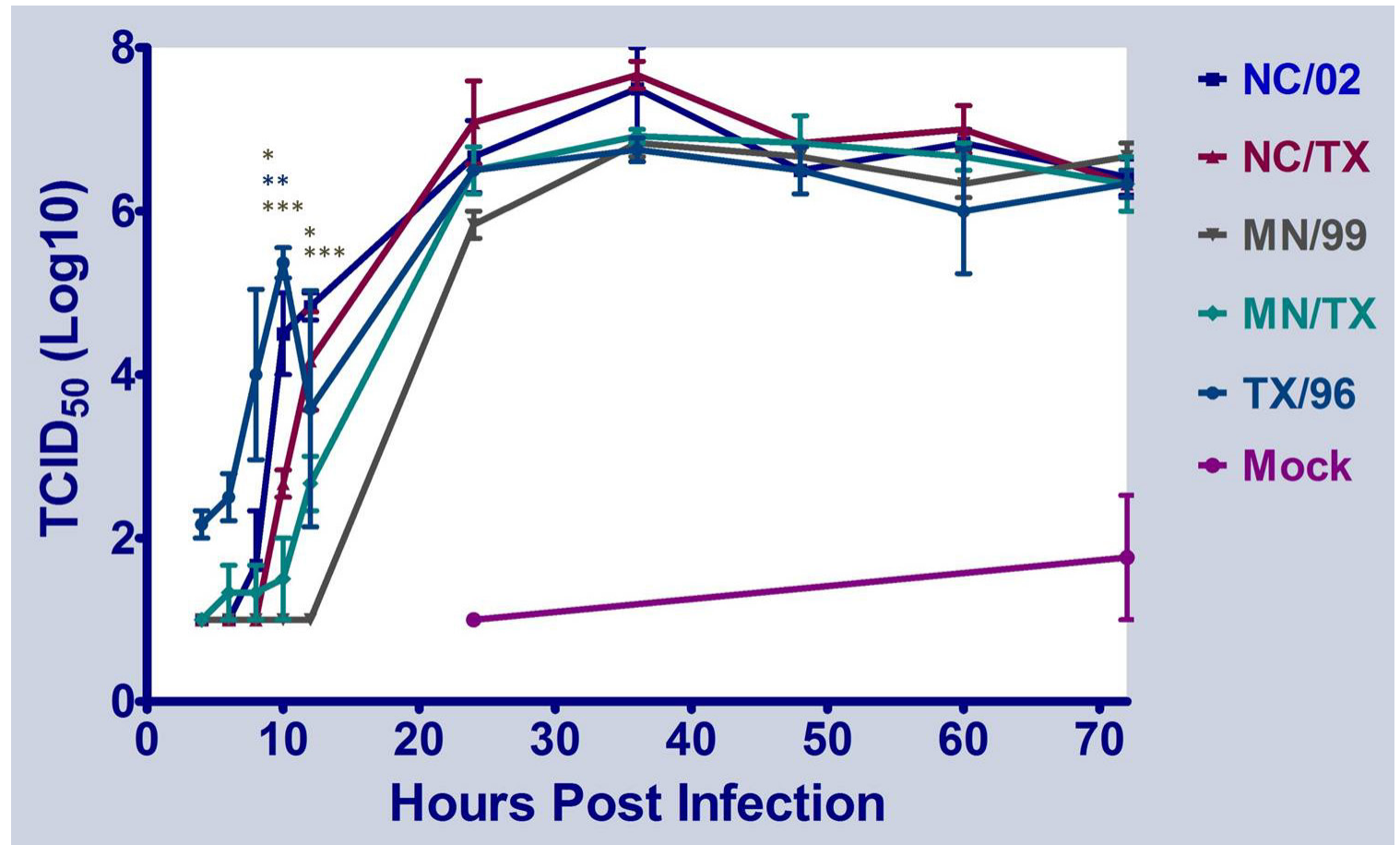

Figure 2-6: Viral growth kinetics on MDCK cells at an MOI of 0.01

$\mathrm{MN} / 99$ grows at a significantly slower rate compared to NC/02 and TX/96 at 10 and 12 hpi $(\mathrm{P}<0.001)$ and at $10 \mathrm{hpi} \mathrm{MN} / 99$ titer is significantly lower than NC/TX $(\mathrm{P}<0.05)$. $\mathrm{MN} / \mathrm{TX}$ grew to a significantly higher titer at 12 hpi compared to MN/99 $(\mathrm{P}<0.05)$. $\mathrm{NC} / 02$ grew to significantly higher titers compared to NC/TX only at 10 hpi $(\mathrm{P}<0.01)$. The asterisks denote time points with significant differences observed with the color matching the parental strain of the comparison.

$* * * \quad \mathrm{P}<0.001$

$* \quad \mathrm{P}<0.05$ 
between the number of coinfected cells of MN/99 with TX/96 and NC/02 with TX/96 occurred at the lower MOI of 0.01 during the simultaneous infection. In both MOI conditions there were more coinfected cells when NC/02 and TX/96 than MN/99 and TX/96, but this difference could be explained by the difference in growth kinetics of $\mathrm{NC} / 02$ and MN/99 rather than exclusion, because MN/99 has shown a kinetic delay in its ability to establish an infection. Thus, there would be an overall lower percentage of cells infected with MN/99 which reduces the possibility for superinfected cells. Additionally, the lower percentage observed between MN/99 and TX/96 still provides a large number of superinfected cells capable of producing reassortant viruses. So, the biological significance of the reduced superinfection percentage is difficult to determine.

Interestingly, in both MOI conditions, there are a relatively large number of cells not infected in some instances with most percentages above $30 \%$. It is expected that after 48 hour incubations, all of the cells would be infected especially with an MOI of 1 . There are several possible explanations for this phenomenon. After infection, the cells enter an antiviral state in which IFN- $\alpha / \beta$ are produced as well as increased expression of RNase L and other antiviral proteins. This antiviral state has been known to reduce viral protein expression and the ability of viruses to infect cells. However, some cell types, including MDCK have relatively weak IFN expression profiles. Another possible explanation for the uninfected cells would be the production of defective interfering particles (DI). DI particles spontaneously arise during viral replication and are usually the result of a genetic deletion in one of the segments which results in a noninfectious virus. The segment containing the deletion can be preferentially replicated at a higher frequency due to its shorter length and can also be encapsidated in budding virions reducing the production of viable virions. These DI particles can also bind to naïve cells and induce an antiviral state which may be responsible for preventing viral replication in the uninfected cells.

\section{Both MN/99 and NC/02 Are Compatible with Human H3 and N2}

Although there is reduced opportunity for MN/99 to reassort compared to $\mathrm{NC} / 02$, the fact that $8-22 \%$ percent of cells are coinfected indicates that there is another mechanism that has prevented MN/99 reassortment. Not only do the cells need to be superinfected, but any progeny reassortant viruses need to have adequate fitness to compete with the parental strains. To test if the swine virus backbones are compatible with the human H3 and N2 genes and if the reassortant viruses have sufficient fitness to compete with the parental strains, growth kinetics were performed on MDCK cells. The MN/99 showed a significant disadvantage compared to the other viruses at the early time points but was able to recover by $24 \mathrm{hpi}$. This pattern was mirrored by the MN/TX virus, but the reassortant virus grew slightly faster than the wholly classical swine virus. This clearly demonstrates that the classical swine gene segments are compatible with the human surface viral glycoproteins. It should be noted that even though the human HA and NA are compatible on both swine virus backbones, the TRIG virus has a clear growth advantage over the classical swine virus in the context of a cell model system. This 
doesn't help to establish why MN/99 didn't reassort, but it does help to explain why the TRIG viruses have displaced the classical swine viruses today.

Interestingly, the wt TX/96 outgrew all of the tested viruses. Previous studies have shown a fitness disadvantage for TX/96 in the swine model suggesting that MDCK cells may not be the most accurate model for testing fitness and reassortment studies of swine viruses. These results should therefore be confirmed in additional models.

\section{Conclusions}

Based on the MDCK model, the classical swine viruses are capable of reassorting with the human viruses and obtaining the human HA and NA similar to what had been seen with the swine viruses containing the TRIG. The cells infected with the classical swine virus do show a decreased percentage of superinfection, however, the biological relevance is difficult to determine. Due to fewer superinfected cells, there is a reduced possibility for reassortment to occur with the classical swine viruses, regardless, there are still numerous opportunities for reassortment.

Additionally, the MN/TX virus showed increased growth kinetics compared to $\mathrm{MN}$ at early time points suggesting that the reassortant phenotype would be able to outcompete the parental strain. The triple reassortant swine virus also showed increased growth fitness compared to the classical swine viruses which helps to explain ultimately why they have become the predominant swine virus. 


\section{CHAPTER 3. INFLUENZA VIRUS GENE COMPATIBILITY AND MECHANISMS OF REASSORTMENT}

\section{Introduction}

Swine viruses with the TRIG cassette were able to displace the previously circulating classical swine viruses because they are more fit than the classical swine virus $\mathrm{MN} / 99$ and the reassortant classical swine virus MN/TX, as determined by growth kinetics studies in vitro described in Chapter 2. Interestingly, the human H3N2 virus, TX/96, grew extremely well in the MDCK cells, which is contrary to what has been seen in in vivo pig experiments previously. ${ }^{66}$ This indicates that the results need to be confirmed in an alternate model that mirrors epidemiological data. To confirm the Chapter 2 results, primary swine respiratory epithelial cells (pSRECs) were cultured to better model in vivo growth kinetics. ${ }^{71}$

The segmented nature of the influenza genome provides opportunities for reassortment to occur because individual segments can be packaged within virions of a different influenza virus. Recent studies have shown that reassortant viruses are generated quite readily in vitro. ${ }^{72-74}$ Although the segmented genome increases the possibility for the emergence of numerous reassortant viruses, there are multiple mechanisms which restrict this ability, many of which have not been thoroughly investigated. This was clearly demonstrated in vivo where swine were coinfected with a classical swine H1N1 and a TRIG H3N2 swine virus. Multiple reassortants were detected in the infected animals but only certain viruses were capable of transmission. ${ }^{65}$ One mechanism of restriction is that the HA and NA proteins need to be balanced. If the HA binds too tightly compared to NA activity, then the budding virions will not efficiently release. These virions will also have an increased tendency to aggregate. Conversely, if the NA is relatively more active, then the HA may not have enough binding affinity to bind to the cell long enough to be endocytosed, precluding infection. ${ }^{75,76}$ As mentioned previously, HA fusion is a $\mathrm{pH}$ dependent process; similarly, M1 oligomerization and disassembly are

dependent on the $\mathrm{pH} .^{77,78}$ There is no direct evidence, but presumably the HA and M need to be $\mathrm{pH}$ balanced so that the HA does not fuse the membranes prior to the proper acidification of the virion core and disassembly of the matrix capsid and vice versa. Additionally, the interactions of the polymerase proteins require that they are compatible with each other, capable of recognizing the RNP's of the particular viral genotype, as well as the ability to function within particular cell types.

Clearly, reassortment is limited by multiple polygenic mechanisms. To compare the reassortment abilities of the classical swine viruses versus triple reassortant swine viruses with a human $\mathrm{H} 3 \mathrm{~N} 2$ virus, primary swine respiratory epithelial cells (pSRECs) were coinfected with A/TX/6/1996 (TX/96) a human H3N2 and either $\mathrm{A} /$ swine/MN/37866/1999 (MN/99) a classical swine H1N1 virus, or $\mathrm{A} /$ swine/NC/18161/2002 (NC/02) a triple reassortant swine virus that contains the TRIG cassette. To test the natural ability of these viruses to reassort, swine respiratory cells were coinfected with TX/96 and MN/99 or NC/02. 
To expand upon previous reassortment experiments in which only the presence of classical swine or triple reassortant swine PB2 or PA genes with human $\mathrm{H} 3 \mathrm{~N} 2$ glycoproteins, ${ }^{66}$ the following experiments look at reassortment potential of all 8 gene segments through the use of deep sequencing. These experiments also explore the growth effects of polymerase complex reassortment by using reverse genetics to rescue viruses with differing polymerase gene compositions.

\section{Materials and Methods}

\section{Reverse Genetics Viruses}

For the following experiments multiple reverse genetics viruses were rescued based around the RG-MN/99 classical swine $\mathrm{H} 1 \mathrm{~N} 1$ virus, the RG-NC/02 triple reassortant $\mathrm{H} 1 \mathrm{~N} 1$ virus, and TX/96 human $\mathrm{H} 3 \mathrm{~N} 2$ virus. The RG viruses were generated using the dual promoter eight plasmid system as outlined in Figure 2-1 and Chapter 2. ${ }^{70}$ The rescued virus supernatants are then injected into 10 day old embryonated chicken eggs and incubated at $35^{\circ} \mathrm{C}$ for 48 hours. The allantoic fluid was harvested and reinjected into embryonated chicken eggs for a second passage. The virus was harvested, aliquoted, and stored at $-80^{\circ} \mathrm{C}$. Each vial was only thawed once before use in each experiment. All of the genotypes used for the growth kinetics experiments are identified in Table 3-1.

\section{Primary Swine Respiratory Epithelial Cells (pSRECs)}

Due to previous experiments showing MDCK growth kinetics studies differing from in vivo observations, it was determined a new model needed to be utilized to more accurately model swine. Isolation and growth of the primary swine respiratory epithelial cells was adapted from methods developed in the lab of Chris Olsen and outlined in Appendix B. ${ }^{71,81}$ Briefly, pig tracheas were collected courtesy of David Keith at the Fayette Packing Company in Eads, TN. The epithelial cells were enzymatically digested from the trachea with a Pronase/DNase mixture $(56 \mathrm{mg}$ Pronase (Roche catalog number 165921), $4 \mathrm{mg}$ DNase (sigma catalog number DN-25)). Adherent fibroblasts were removed by incubating the cell suspension on uncoated tissue culture treated petri dishes (BD Biosciences, Falcon, catalog number 353003). The epithelial cells were collected and centrifuged at $1200 \mathrm{RPM}$ for $10 \mathrm{~min}$ at $4^{\circ} \mathrm{C}$ and then resuspended in $100 \mathrm{ml}$ of DMEM/F12 media (Invitrogen catalog number 11320-033) prior to counting on a Countess cell counter (Invitrogen catalog number C10227). After counting the cells were centrifuged again at $1200 \mathrm{RPM}$ for $10 \mathrm{~min}$ at $4^{\circ} \mathrm{C}$ and resuspended in BEGM (Lonza catalog number CC-3170) supplemented with $20 \%$ FCS to $4 \times 10^{6}$ cells $/ \mathrm{ml}$. On ice, a solution of BEGM, $20 \%$ FCS and $20 \%$ DMSO was added dropwise to the cell suspension until the final cell concentration was $2 \times 10^{6}$ cells $/ \mathrm{ml}$. The cell suspension was aliquoted in $1 \mathrm{ml}$ volumes and stored in the gas phase of a liquid nitrogen storage tank. 
Table 3-1: Gene segment origins for rescued viruses

\begin{tabular}{|c|c|c|c|c|c|c|c|c|}
\hline \multirow[b]{2}{*}{$\begin{array}{c}\text { RG-virus } \\
\text { abbreviation }\end{array}$} & \multicolumn{8}{|c|}{ Gene segment source } \\
\hline & PB2 & PB1 & PA & HA & NP & NA & $\mathbf{M}$ & NS \\
\hline $\mathrm{NC} / 02$ & $\mathrm{NC} / 02$ & $\mathrm{NC} / 02$ & $\mathrm{NC} / 02$ & $\mathrm{NC} / 02$ & $\mathrm{NC} / 02$ & $\mathrm{NC} / 02$ & $\mathrm{NC} / 02$ & $\mathrm{NC} / 02$ \\
\hline MN/99 & $\mathrm{MN} / 99$ & $\mathrm{MN} / 99$ & MN/99 & $\mathrm{MN} / 99$ & MN/99 & MN/99 & $\mathrm{MN} / 99$ & MN/99 \\
\hline TX/96* & \multicolumn{8}{|c|}{ Wild Type } \\
\hline $\mathrm{NC} / \mathrm{TX}$ & $\mathrm{NC} / 02$ & $\mathrm{NC} / 02$ & $\mathrm{NC} / 02$ & TX/96 & $\mathrm{NC} / 02$ & TX/96 & $\mathrm{NC} / 02$ & $\mathrm{NC} / 02$ \\
\hline MN/TX & MN/99 & $\mathrm{MN} / 99$ & $\mathrm{MN} / 99$ & TX/96 & MN/99 & TX/96 & $\mathrm{MN} / 99$ & MN/99 \\
\hline $\begin{array}{c}\text { MN/TX/NC- } \\
\text { PB1 }\end{array}$ & MN/99 & $\mathrm{NC} / 02$ & MN/99 & $\mathrm{TX} / 96$ & MN/99 & $\mathrm{TX} / 96$ & MN/99 & $\mathrm{MN} / 99$ \\
\hline $\begin{array}{c}\text { MN/TX/NC- } \\
\text { PB2 }\end{array}$ & $\mathrm{NC} / 02$ & MN/99 & MN/99 & TX/96 & MN/99 & TX/96 & MN/99 & MN/99 \\
\hline $\begin{array}{c}\mathrm{MN} / \mathrm{TX} / \mathrm{NC}- \\
\mathrm{PA}\end{array}$ & $\mathrm{MN} / 99$ & $\mathrm{MN} / 99$ & $\mathrm{NC} / 02$ & $\mathrm{TX} / 96$ & $\mathrm{MN} / 99$ & TX/96 & $\mathrm{MN} / 99$ & MN/99 \\
\hline $\begin{array}{c}\text { MN/TX/NC- } \\
\text { PB2 PA }\end{array}$ & $\mathrm{NC} / 02$ & MN/99 & $\mathrm{NC} / 02$ & TX/96 & MN/99 & TX/96 & MN/99 & MN/99 \\
\hline $\begin{array}{c}\text { MN/TX/NC- } \\
\text { Pol }\end{array}$ & $\mathrm{NC} / 02$ & $\mathrm{NC} / 02$ & $\mathrm{NC} / 02$ & TX/96 & MN/99 & TX/96 & MN/99 & MN/99 \\
\hline $\begin{array}{c}\mathrm{MN} / \mathrm{TX} / \mathrm{NC}- \\
\mathrm{NS}\end{array}$ & MN/99 & MN/99 & MN/99 & TX/96 & $\mathrm{MN} / 99$ & TX/96 & $\mathrm{MN} / 99$ & $\mathrm{NC} / 02$ \\
\hline $\begin{array}{c}\text { NC/TX/MN- } \\
\text { PB1 }\end{array}$ & $\mathrm{NC} / 02$ & MN/99 & $\mathrm{NC} / 02$ & TX/96 & $\mathrm{NC} / 02$ & TX/96 & $\mathrm{NC} / 02$ & $\mathrm{NC} / 02$ \\
\hline
\end{tabular}

The orange boxes indicate gene segments from the TRIG swine virus $\mathrm{NC} / 02$. The blue boxes indicate gene segments of classical swine lineage from MN/99 and the green boxes are genes derived from the human H3N2 virus, TX/96.

* TX/96 is a wild type virus and only HA and NA were cloned for rescue on the swine viral backbones. 
Prior to pSREC propagation, tissue culture flasks or plates were coated with 5\% (w/v) type VI human placental collagen (Sigma catalog number C7521) dissolved in $\mathrm{ddH}_{2} \mathrm{O}$ with $0.2 \%(\mathrm{v} / \mathrm{v})$ glacial acetic acid and incubated at room temperature overnight. Prior to use, the collagen coating solution was aspirated and the flasks or plates were allowed to fully dry in a biosafety cabinet.

Cell vials were removed from liquid nitrogen storage and thawed in a $37^{\circ} \mathrm{C}$ water bath and the cell suspension was transferred to a $15 \mathrm{ml}$ tube to be slowly resuspended. Once fully resuspended in $10 \mathrm{ml}$ of DMEM/F 12 or BEGM, the cells were added to a 75 $\mathrm{cm}^{2}$ tissue culture flask with $15 \mathrm{ml}$ of BEGM and incubated at $37^{\circ} \mathrm{C}$ with $5 \% \mathrm{CO}_{2}$ overnight. Half of the media was replaced 1 or 2 days after seeding and the cells were typically $80-90 \%$ confluent $2-4$ days later.

\section{Coinfections}

To show whether MN/99 and NC/02 are able to reassort with TX/96 at different frequencies, pSRECs were coinfected and progeny viruses were genotyped. Six-well tissue culture plates were prepared with pSRECs and incubated until they were $80-90 \%$ confluent. Once nearly confluent, cells were counted to calculate MOIs. The pSRECs were simultaneously infected with TX/96 and either NC/02 or MN/99 each at an MOI of 0.01 . The viral dilution was incubated on the cells at $37^{\circ} \mathrm{C}$ at $5 \% \mathrm{CO}_{2}$ for 1 hour and then the cells were washed with PBS. Fresh BEGM, supplemented with $0.5 \mu \mathrm{g} / \mathrm{ml}$ TPCKTrypsin, was added and the infected pSRECs were incubated for 48 hours. After 48 hours the supernatants were collected and stored at $-80^{\circ} \mathrm{C}$ until plaque purification.

For plaque purification, three 6-well tissue culture plates per coinfection were prepared with MDCK cells in order to pick 96 plaques. For each coinfection, the virus was diluted 1 to $1 \times 10^{-4}$ in $8 \mathrm{ml}$ of infection media and serially diluted to $1 \times 10^{-6}$. To ensure only $\mathrm{H} 3$ viruses were selected for sequencing, $80 \mu \mathrm{l}$ of an anti-H1 antibody (selected from the St. Jude repository and created against NC/02) was added to each dilution for a 1:100 dilution. Each dilution was incubated on ice for 1 hour prior to viral absorption. The cells were then washed with $1 \mathrm{X}$ PBS and $1 \mathrm{ml}$ of the viral dilution was added to each well. The plates were incubated at $37^{\circ} \mathrm{C}$ with $5 \% \mathrm{CO}_{2}$ for 1 hour. The virus dilution was then aspirated and the MDCK monolayers were washed with 1X PBS and the cells were overlaid with $1 \mathrm{X}$ infection media mixed with $0.9 \%$ bacto agar (BD Biosciences catalog number 214010) and supplemented with $0.5 \mu \mathrm{g} / \mathrm{ml}$ TPCK-Trypsin and incubated at $37^{\circ} \mathrm{C}$ with $5 \% \mathrm{CO}_{2}$ for 48 hours. Identifiable isolated plaques were aspirated using a wide bore pipet tip (Fisherbrand catalog number 02-707-74). The viral plug was then ejected into one well of an 96-well tissue culture plate about $80 \%$ confluent with MDCK cells and each plate was incubated for an additional 72 hours. To confirm viral growth, a hemagglutination assay was performed by adding $25 \mu 1$ of $1 \mathrm{X}$ PBS to a 96-well round-bottom plate followed by $25 \mu \mathrm{l}$ of the viral supernatant and finally $50 \mu 1$ of $0.5 \%(\mathrm{v} / \mathrm{v})$ turkey red blood cells. The plate was then gently tapped to mix and incubated at room temperature for about $30 \mathrm{~min}$. After the incubation, the plates were read for red blood cell agglutination. 


\section{Identification of Reassortants}

To identify and quantify the reassortant viruses, the Illumina MiSeq platform was utilized for multiplex full genome sequencing of 96 samples in a single run. The viral RNA was extracted using the Ambion MagMAX-96 AI ND Viral RNA Isolation Kit (catalog number AM1835). The MagMAX kit is a magnetic bead based system in which the virus was lysed and the RNA was bound on magnetic beads. The beads were washed to purify the sample of contaminating protein and DNA. Finally, the RNA was eluted off of the magnetic beads. The purified viral RNA was reverse transcribed using SuperScript III reverse transcriptase (Invitrogen catalog number 18080044) and the cDNA was amplified using Phusion High-Fidelity PCR Master Mix (New England BioLabs catalog number M0531L) combined with the primers in Table 3-2 and using the thermocycler conditions outlined in Table 3-3. The amplified samples were then fragmented to 400500 base pairs using the Covaris E220 Focused-ultrasonicator with samples in AFA microtubes (Covaris catalog number 520078) at a 10\% duty cycle, intensity of 5, 200 cycles per burst, for a total of 70 seconds at $4^{\circ} \mathrm{C}$. After shearing, the samples were processed following the Bioo Scientific NEXTflex DNA sequencing kit (Bioo Scientific catalog number 5140-02). This procedure added unique adapters to each sample. The samples then underwent size selection, PCR enrichment, and a final magnetic bead clean up. The samples were then submitted to the St. Jude Hartwell Center and sequenced on the Illumina MiSeq system. The subsequent sequencing data was analyzed using the CLC Genomics Workbench version 6 program.

\section{Growth Kinetics}

The RG viruses and wt TX/96, as outlined in Table 3-1, were used to infect MDCK cell monolayers at an $80-90 \%$ confluency or pSRECs at an MOI of 0.01 . MOIs were calculated by counting trypsinized cells using the Countess (Invitrogen catalog number $\mathrm{C} 10227)$. The viruses were diluted in infection media to an MOI of 0.01 and added to the cells. After about an hour the cells were gently washed with $1 \mathrm{X}$ PBS and infection media with $0.5 \%$ TPCK-Trypsin was added. For the MDCK growth kinetic experiments, $2 \times 100 \mu \mathrm{l}$ samples were collected at the following time points, $6,8,10,12$, $20,24,36$, and $48 \mathrm{hpi}$. All of the samples collected were stored at $-80^{\circ} \mathrm{C}$ until viral TCID $_{50}$ titers could be determined. For the pSREC infections, 2 x $100 \mu 1$ samples were collected at 10, 12, 14, 16, 18, 20, 24, 36, and 48 hpi. These viral samples were also stored at $-80^{\circ} \mathrm{C}$ until $\mathrm{TCID}_{50}$ titers could be determined. No samples were thawed prior to titration. All TCID 50 titers were determined using MDCK cells in a 96 well flat bottom tissue culture plate at $80-90 \%$ confluency. Significance was calculated using a 2 way ANOVA analysis.

\section{Pig Infections and Transmission}

Twenty-two two-week-old influenza negative pigs were received from Northwoods Pork (Parker Prairie, MN). The pigs were divided into four groups of 5 pigs 
Table 3-2: Primer sequences used for influenza genome amplification

\begin{tabular}{cc}
\hline Primer name & Primer sequence \\
\hline Uni 12 & AGCAAAAGCAGG \\
Uni 13 & AGTAGAAACAAGG \\
Ba-PB2-1 & TATTGGTCTCAGGGAGCGAAAGCAGGTC \\
Ba-PB2-2341R & ATATGGTCTCGTATTAGTAGAAACAAGGTCGTTT \\
Bm-PB1-1 & TATTCGTCTCAGGGAGCGAAAGCAGGCA \\
Bm-PB1-2341R & ATATCGTCTCGTATTAGTAGAAACAAGGCATTT \\
Bm-PA-1 & TATTCGTCTCAGGGAGCGAAAGCAGGTAC \\
Bm-PA-2233R & ATATCGTCTCGTATTAGTAGAAACAAGGTACTT \\
\hline
\end{tabular}

Table 3-3: Thermocycler conditions for full influenza genome amplification

\begin{tabular}{ccc}
\hline Temperature & Time & Cycling repeats \\
\hline $98^{\circ} \mathrm{C}$ & $30 \mathrm{sec}$ & \\
$98^{\circ} \mathrm{C}$ & $10 \mathrm{sec}$ & \\
$45^{\circ} \mathrm{C}$ & $30 \mathrm{sec}$ & 10 \\
$72^{\circ} \mathrm{C}$ & $90 \mathrm{sec}$ & \\
& & \\
$98^{\circ} \mathrm{C}$ & $10 \mathrm{sec}$ & \\
$58^{\circ} \mathrm{C}$ & $30 \mathrm{sec}$ & 20 \\
$72^{\circ} \mathrm{C}$ & $90 \mathrm{sec}$ & \\
$72^{\circ} \mathrm{C}$ & $10 \mathrm{~min}$ & \\
$4^{\circ} \mathrm{C}$ & Hold & \\
\hline
\end{tabular}


and one group of 2 pigs under BSL-2 conditions and each group was housed in straw lined pens in individual cubicles with no contact with any other group. All pigs had access to food and water ad libitum and social enrichment items were included in each pen.

The viruses, RG-MN/TX, RG-NC/TX, TX/96, RG-MN/TX/NC-PB1, were diluted to $1 \times 10^{6}$ plaque forming units (PFU)/ml in $15 \mathrm{ml}$ of $1 \mathrm{X}$ PBS and $1 \mathrm{X}$ egg antibiotic (2000 units/ml penicillin, 400 units/ml streptomycin, 200 units/ml Polymyxin $\mathrm{B}, 50 \mu \mathrm{g} / \mathrm{ml}$ gentamicin). Two pigs from each group were infected intranasally with 1$2 \times 10^{6} \mathrm{PFU}$ of one of the listed viruses using a metered pump nasal spray bottle (Health Care Logistics catalog number 10271). PBS with egg antibiotic was used for the control pigs. The pigs were restrained and 2 pumps of the viral dilution were administered to each nostril for a total administration of about $2 \mathrm{ml}$. Each pig was monitored daily for any clinical signs of disease.

Starting 1 day post infection (dpi) and every-other day until 15 dpi, all pigs were swabbed in each nostril and the swabs were placed in $500 \mu \mathrm{l}$ isolation media aliquots (Table 3-4) and held on ice until they could be stored at $-80^{\circ} \mathrm{C}$. The swabs were then titrated on MDCK cells to calculate $\mathrm{TCID}_{50}$ values as described for growth kinetics.

\section{Results}

\section{Reassortment Frequency}

To test the inherent ability of MN/99 and $\mathrm{NC} / 02$ to reassort with $\mathrm{TX} / 96$, the pSRECs were coinfected at an MOI of 0.01 and the progeny were fully genotyped to identify and quantify the number of reassortant viruses created. A surprisingly large variety of reassortant viruses were recovered from the pSREC coinfections between MN/99 and TX/96 (Table 3-5). The most prevalent virus recovered was the wt TX/96 virus at $14 \%$ of the 93 genotyped viruses. Nearly $80 \%$ of the viruses had acquired the human $\mathrm{H} 3$ segment. The MN/99 NP gene segment appeared to reassort the most frequently and was identified in about $74 \%$ of the viruses followed by NS at $63 \%$ and M

Table 3-4: Viral isolation media composition

\begin{tabular}{ccc}
\hline Reagent & Volume for $\mathbf{1 0 0} \mathbf{~ m l}$ & Final concentration \\
\hline PBS & $45 \mathrm{ml}$ & \\
Glycerol & $50 \mathrm{ml}$ & $50 \%$ \\
100X Pen-Strep & $1 \mathrm{ml}$ & Penicillin $(1000 \mathrm{u} / \mathrm{ml}) ;$ \\
streptomycin $(200 \mu \mathrm{g} / \mathrm{ml}$ \\
Nystatin & $1 \mathrm{ml}$ & $50 \mathrm{u} / \mathrm{ml}$ \\
Polymyxin B & $2 \mathrm{ml}$ & $100 \mathrm{u} / \mathrm{ml}$ \\
Gentamicin & $0.5 \mathrm{ml}$ & $200 \mu \mathrm{g} / \mathrm{ml}$ \\
\hline
\end{tabular}


Table 3-5: Reassortment frequency between MN/99 and TX/96 when coinfected in pSRECs at an MOI of 0.01

\begin{tabular}{|c|c|c|c|c|c|c|c|c|c|}
\hline PB2 & PB1 & PA & HA & $\mathbf{N P}$ & NA & $\mathbf{M}$ & NS & $\begin{array}{c}\text { Number } \\
\text { identified }\end{array}$ & $\begin{array}{c}\text { \% of } \\
\text { sample } \\
\end{array}$ \\
\hline TX & TX & TX & TX & TX & TX & TX & TX & 13 & $14.0 \%$ \\
\hline TX & $\mathrm{TX}$ & $\mathrm{MN}$ & $\mathrm{TX}$ & $\mathrm{MN}$ & TX & $\mathrm{MN}$ & $\mathrm{MN}$ & 10 & $10.8 \%$ \\
\hline TX & TX & $\mathrm{TX}$ & TX & $\mathrm{MN}$ & TX & $\mathrm{TX}$ & $\mathrm{TX}$ & 7 & $7.5 \%$ \\
\hline TX & $\mathrm{TX}$ & TX & TX & $\mathrm{MN}$ & TX & $\mathrm{MN}$ & $\mathrm{MN}$ & 6 & $6.5 \%$ \\
\hline TX & TX & TX & $\mathrm{TX}$ & $\mathrm{MN}$ & TX & $\mathrm{TX}$ & $\mathrm{MN}$ & 6 & $6.5 \%$ \\
\hline $\mathrm{MN}$ & $\mathrm{TX}$ & $\mathrm{MN}$ & $\mathrm{TX}$ & $\mathrm{MN}$ & $\mathrm{TX}$ & $\mathrm{MN}$ & $\mathrm{MN}$ & 4 & $4.3 \%$ \\
\hline $\mathrm{MN}$ & TX & $\mathrm{MN}$ & $\mathrm{MN}$ & $\mathrm{MN}$ & TX & $\mathrm{MN}$ & $\mathrm{MN}$ & 3 & $3.2 \%$ \\
\hline $\mathrm{MN}$ & TX & $\mathrm{TX}$ & $\mathrm{TX}$ & $\mathrm{MN}$ & TX & $\mathrm{MN}$ & $\mathrm{MN}$ & 3 & $3.2 \%$ \\
\hline $\mathrm{TX}$ & $\mathrm{MN}$ & $\mathrm{MN}$ & TX & $\mathrm{MN}$ & TX & $\mathrm{MN}$ & $\mathrm{MN}$ & 3 & $3.2 \%$ \\
\hline TX & TX & $\mathrm{MN}$ & $\mathrm{MN}$ & $\mathrm{MN}$ & $\mathrm{TX}$ & $\mathrm{MN}$ & $\mathrm{MN}$ & 3 & $3.2 \%$ \\
\hline TX & $\mathrm{TX}$ & $\mathrm{MN}$ & TX & $\mathrm{MN}$ & $\mathrm{MN}$ & $\mathrm{MN}$ & $\mathrm{MN}$ & 3 & $3.2 \%$ \\
\hline TX & TX & $\mathrm{MN}$ & TX & $\mathrm{MN}$ & $\mathrm{TX}$ & $\mathrm{TX}$ & $\mathrm{TX}$ & 3 & $3.2 \%$ \\
\hline $\mathrm{TX}$ & TX & $\mathrm{MN}$ & TX & $\mathrm{TX}$ & TX & TX & TX & 3 & $3.2 \%$ \\
\hline TX & TX & TX & $\mathrm{MN}$ & $\mathrm{MN}$ & $\mathrm{TX}$ & $\mathrm{TX}$ & $\mathrm{MN}$ & 2 & $2.2 \%$ \\
\hline $\mathrm{TX}$ & TX & TX & $\mathrm{TX}$ & $\mathrm{MN}$ & $\mathrm{MN}$ & $\mathrm{MN}$ & $\mathrm{MN}$ & 2 & $2.2 \%$ \\
\hline $\mathrm{TX}$ & TX & TX & TX & $\mathrm{TX}$ & $\mathrm{MN}$ & $\mathrm{TX}$ & $\mathrm{TX}$ & 2 & $2.2 \%$ \\
\hline $\mathrm{MN}$ & $\mathrm{MN}$ & $\mathrm{MN}$ & $\mathrm{MN}$ & $\mathrm{MN}$ & $\mathrm{MN}$ & $\mathrm{MN}$ & $\mathrm{MN}$ & 1 & $1.1 \%$ \\
\hline $\mathrm{MN}$ & $\mathrm{MN}$ & $\mathrm{MN}$ & $\mathrm{MN}$ & $\mathrm{MN}$ & $\mathrm{TX}$ & $\mathrm{MN}$ & $\mathrm{MN}$ & 1 & $1.1 \%$ \\
\hline $\mathrm{MN}$ & $\mathrm{TX}$ & $\mathrm{MN}$ & $\mathrm{MN}$ & $\mathrm{TX}$ & TX & $\mathrm{MN}$ & $\mathrm{MN}$ & 1 & $1.1 \%$ \\
\hline $\mathrm{TX}$ & $\mathrm{MN}$ & $\mathrm{MN}$ & $\mathrm{MN}$ & $\mathrm{MN}$ & $\mathrm{MN}$ & $\mathrm{TX}$ & $\mathrm{MN}$ & 1 & $1.1 \%$ \\
\hline TX & $\mathrm{MN}$ & $\mathrm{MN}$ & $\mathrm{MN}$ & $\mathrm{MN}$ & $\mathrm{TX}$ & $\mathrm{MN}$ & $\mathrm{MN}$ & 1 & $1.1 \%$ \\
\hline TX & $\mathrm{MN}$ & $\mathrm{TX}$ & $\mathrm{TX}$ & $\mathrm{MN}$ & TX & $\mathrm{MN}$ & $\mathrm{MN}$ & 1 & $1.1 \%$ \\
\hline TX & $\mathrm{TX}$ & $\mathrm{MN}$ & $\mathrm{MN}$ & $\mathrm{MN}$ & $\mathrm{MN}$ & $\mathrm{MN}$ & $\mathrm{MN}$ & 1 & $1.1 \%$ \\
\hline TX & TX & $\mathrm{MN}$ & $\mathrm{MN}$ & $\mathrm{MN}$ & $\mathrm{MN}$ & $\mathrm{TX}$ & $\mathrm{MN}$ & 1 & $1.1 \%$ \\
\hline TX & TX & $\mathrm{MN}$ & $\mathrm{MN}$ & $\mathrm{MN}$ & $\mathrm{TX}$ & TX & $\mathrm{TX}$ & 1 & $1.1 \%$ \\
\hline TX & TX & $\mathrm{MN}$ & $\mathrm{TX}$ & $\mathrm{MN}$ & TX & $\mathrm{MN}$ & $\mathrm{TX}$ & 1 & $1.1 \%$ \\
\hline TX & TX & $\mathrm{MN}$ & TX & $\mathrm{TX}$ & $\mathrm{MN}$ & $\mathrm{MN}$ & $\mathrm{MN}$ & 1 & $1.1 \%$ \\
\hline TX & TX & $\mathrm{MN}$ & TX & TX & $\mathrm{TX}$ & $\mathrm{MN}$ & $\mathrm{TX}$ & 1 & $1.1 \%$ \\
\hline TX & TX & $\mathrm{MN}$ & TX & TX & TX & $\mathrm{TX}$ & $\mathrm{MN}$ & 1 & $1.1 \%$ \\
\hline TX & TX & $\mathrm{TX}$ & $\mathrm{MN}$ & $\mathrm{MN}$ & $\mathrm{MN}$ & $\mathrm{MN}$ & $\mathrm{MN}$ & 1 & $1.1 \%$ \\
\hline TX & TX & TX & $\mathrm{MN}$ & $\mathrm{MN}$ & $\mathrm{MN}$ & $\mathrm{TX}$ & $\mathrm{TX}$ & 1 & $1.1 \%$ \\
\hline TX & TX & TX & $\mathrm{MN}$ & $\mathrm{TX}$ & $\mathrm{MN}$ & $\mathrm{MN}$ & $\mathrm{MN}$ & 1 & $1.1 \%$ \\
\hline TX & TX & TX & $\mathrm{TX}$ & $\mathrm{MN}$ & $\mathrm{MN}$ & $\mathrm{MN}$ & $\mathrm{TX}$ & 1 & $1.1 \%$ \\
\hline TX & TX & TX & TX & $\mathrm{MN}$ & $\mathrm{MN}$ & $\mathrm{TX}$ & $\mathrm{MN}$ & 1 & $1.1 \%$ \\
\hline TX & TX & TX & TX & $\mathrm{MN}$ & $\mathrm{TX}$ & $\mathrm{MN}$ & TX & 1 & $1.1 \%$ \\
\hline TX & TX & TX & TX & TX & TX & TX & $\mathrm{MN}$ & 1 & $1.1 \%$ \\
\hline
\end{tabular}




\section{Table 3-5: $\quad$ (Continued)}

The blue boxes indicate gene segments of classical swine lineage and the green boxes are genes derived from the human $\mathrm{H} 3 \mathrm{~N} 2$ virus, TX/96. 
at $54 \%$. Additionally, of the 74 viruses that were identified as $\mathrm{H} 3,63(85 \%)$ also contained the TX/96 PB2 and PB1 gene segments. Only $9.5 \%$ of the $74 \mathrm{H} 3$ viruses had the MN/99 PB2 gene and only 5.5\% had the MN/99 PB1 gene segment.

Based on correlation analysis of the genotypes identified between MN/99 and TX/96, four gene segments were shown to share more than $15 \%$ of the variance in common (Table 3-6). The M and NP correlated in 19.3\% of the genotypes while $\mathrm{M}$ and PA shared $20 \%$ of the variance. The NS segment correlated with both the NP at $27.2 \%$ and the $\mathrm{M}$ segment at $40.9 \%$.

There was less viral diversity identified in the genotyped viruses collected from the NC/02 and TX/96 coinfections. (Table 3-7). There were only 21 different genotypes identified compared to the 36 genotypes between MN/99 and TX/96. The most dominant genotype identified was the human $\mathrm{H} 3$ with the remaining 7 gene segments from $\mathrm{NC} / 02$ (34.4\%). The second most prevalent genotype was very similar, with both the $\mathrm{H} 3$ and TX/96 PB2 gene segment and the other 6 segments were from NC/02 (15.6\%). Of the 96 samples genotyped, $88.5 \%$ of them were H3 positive. Only $27(31.8 \%)$ of the $85 \mathrm{H} 3$ viruses contained the human derived PB1 segment while $58(68.2 \%)$ contained the NC/02 PB1 segment. The most interesting aspect of these reassortants was that 81 of the 85 $(95.3 \%) \mathrm{H} 3$ viruses contain at least one polymerase segment from the $\mathrm{NC} / 02$ virus. Of the $85 \mathrm{H} 3$ viruses $44.7 \%$ had all polymerase segments from $\mathrm{NC} / 02$. While $21.1 \%$ had both PB1 and PA from NC/02, only 8.2\% had NC/02 PB2 and PA gene segments. Only 1 virus $(1.2 \%)$ had both $\mathrm{PB} 2$ and $\mathrm{PB} 1$ from $\mathrm{NC} / 02$. There are considerably more $\mathrm{NC} / 02$ polymerase gene segments reassorted with the human $\mathrm{H} 3$ than what was observed between MN/99 and TX/96 where only 34 of the $74(45.9 \%) \mathrm{H} 3$ viruses contain at least one MN/99 segment, most of which is the PA gene segment 23 of $34(67.6 \%)$.

Table 3-6: Correlation analysis of $\mathrm{MN}$ and $\mathrm{TX}$ reassortant genotypes

\begin{tabular}{ccccccccc}
\hline $\begin{array}{c}\text { Gene } \\
\text { segment }\end{array}$ & PB2 & PB1 & PA & HA & NP & NA & M & NS \\
\hline PB2 & & 0.098 & 0.239 & 0.257 & 0.167 & -0.110 & 0.374 & 0.306 \\
PB1 & 0.010 & & 0.247 & 0.225 & 0.181 & 0.053 & 0.208 & 0.233 \\
PA & 0.057 & 0.061 & & 0.268 & 0.214 & -0.002 & 0.447 & 0.317 \\
HA & 0.066 & 0.051 & 0.072 & & 0.177 & 0.243 & 0.149 & 0.274 \\
NP & 0.028 & 0.033 & 0.046 & 0.031 & & 0.025 & 0.439 & 0.522 \\
NA & 0.012 & 0.003 & 0.000 & 0.059 & 0.001 & & 0.104 & 0.128 \\
M & 0.140 & 0.043 & 0.200 & 0.022 & 0.193 & 0.011 & & 0.639 \\
NS & 0.094 & 0.054 & 0.100 & 0.075 & 0.272 & 0.016 & 0.409 & \\
\hline
\end{tabular}

The top half of the table shows the correlation $r$ values and the bottom half are the $r^{2}$ values which are the coefficient of determination values and represent the fraction of variance shared between the gene segments.

Highlighted values show $15 \%$ or more correlation between the gene segments. 
Table 3-7: Reassortment frequency between $\mathrm{NC} / 02$ and $\mathrm{TX} / 96$ when coinfected in pSRECs at an MOI of 0.01

\begin{tabular}{llllllllcc}
\hline PB2 & PB1 & PA & HA & NP & NA & M & NS & $\begin{array}{c}\text { Number } \\
\text { identified }\end{array}$ & $\begin{array}{c}\% \text { of } \\
\text { sample }\end{array}$ \\
\hline NC & NC & NC & TX & NC & NC & NC & NC & 33 & $34.4 \%$ \\
TX & NC & NC & TX & NC & NC & NC & NC & 15 & $15.6 \%$ \\
NC & NC & NC & NC & NC & NC & NC & NC & 9 & $9.4 \%$ \\
NC & TX & NC & TX & NC & NC & NC & NC & 7 & $7.3 \%$ \\
TX & TX & NC & TX & NC & NC & NC & NC & 5 & $5.2 \%$ \\
NC & NC & NC & TX & NC & TX & NC & NC & 4 & $4.2 \%$ \\
TX & TX & TX & TX & TX & TX & TX & TX & 4 & $4.2 \%$ \\
TX & TX & NC & TX & NC & TX & NC & NC & 3 & $3.1 \%$ \\
TX & NC & NC & TX & NC & TX & NC & NC & 2 & $2.1 \%$ \\
TX & TX & TX & TX & NC & NC & NC & NC & 2 & $2.1 \%$ \\
TX & TX & TX & TX & NC & NC & TX & NC & 2 & $2.1 \%$ \\
NC & NC & NC & TX & NC & NC & NC & TX & 1 & $1.0 \%$ \\
NC & NC & TX & TX & NC & NC & NC & NC & 1 & $1.0 \%$ \\
NC & TX & NC & NC & NC & NC & NC & NC & 1 & $1.0 \%$ \\
NC & TX & NC & TX & NC & TX & NC & NC & 1 & $1.0 \%$ \\
NC & TX & TX & TX & NC & TX & TX & NC & 1 & $1.0 \%$ \\
NC & TX & NC & TX & NC & TX & NC & NC & 1 & $1.0 \%$ \\
TX & NC & NC & TX & NC & TX & NC & TX & 1 & $1.0 \%$ \\
TX & NC & TX & TX & TX & TX & TX & NC & 1 & $1.0 \%$ \\
TX & TX & NC & NC & NC & NC & NC & NC & 1 & $1.0 \%$ \\
TX & TX & NC & TX & NC & NC & NC & TX & 1 & $1.0 \%$ \\
\hline
\end{tabular}

The orange boxes indicate gene segments of the TRIG swine lineage and the green boxes are genes derived from the human H3N2 virus, TX/96. 
The genotypes identified between NC/02 and TX/96 showed an increased number of correlated gene segments when compared to MN/99 and TX/96. The PA segment correlated with numerous segments including PB1 (16.3\%), NP (42.5\%), M (70.2\%), and NS (16.2\%) (Table 3-8). The NP segment also showed significant correlation with the NA (23.8\%), M (60.4\%), and NS (43.0\%) segments. The NA and M segments also shared $18.9 \%$ of the variation while M and NS were correlated in $24.5 \%$ of the viruses.

\section{MDCK Cell Growth Differences}

Growth kinetics of particular viral reassortants were tested to identify if they have sufficient growth fitness to compete with the parental strains. As seen in Figure 3-1, the parental viral strains show very similar growth kinetics to the $6+2$ viruses where the human $\mathrm{H} 3$ and $\mathrm{N} 2$ are added on either the classical swine or the triple reassortant backbones. The different viral surface glycoproteins showed no effect on the viral growth kinetics. Compared to MN/99, NC/02 grew to higher titers at 10 and $12 \mathrm{hpi}(p<0.001)$ and 20 and 24 hpi $(p<0.01)$, while NC/TX grew to higher titers than MN/TX at 10 and 20 hpi $(p<0.001)$. Similarly, TX/96 grew to significantly higher titers than MN/TX at 10 and 12 hpi $(p<0.001)$ and 20 hpi $(p<0.01)$.

When the gene segments of the polymerase complex in both the classical swine virus and TRIG virus are reassorted in the context of the human $\mathrm{H} 3$ and N2, there are some identifiable growth differences observed (Figures 3-2 and 3-3). The reverse genetics MN/TX virus grew at significantly lower titers compared to TX/96 at 10, 12, and $20 \mathrm{hpi}(\mathrm{P}<0.001)$. Additionally, none of the reverse genetics viruses containing any of the $\mathrm{NC} / 02$ polymerase segments showed increased growth kinetics compared to MN/TX.

Table 3-8: Correlation analysis of $\mathrm{NC}$ and $\mathrm{TX}$ reassortant genotypes

\begin{tabular}{ccccccccc}
\hline $\begin{array}{c}\text { Gene } \\
\text { segment }\end{array}$ & PB2 & PB1 & PA & HA & NP & NA & M & NS \\
\hline PB2 & & 0.318 & 0.320 & 0.218 & 0.296 & 0.223 & 0.303 & 0.272 \\
PB1 & 0.101 & & 0.404 & 0.094 & 0.254 & 0.265 & 0.376 & 0.252 \\
PA & 0.102 & 0.163 & & 0.129 & 0.652 & 0.330 & 0.838 & 0.402 \\
HA & 0.047 & 0.009 & 0.017 & & 0.084 & 0.173 & 0.108 & 0.101 \\
NP & 0.088 & 0.065 & 0.425 & 0.007 & & 0.488 & 0.777 & 0.656 \\
NA & 0.050 & 0.070 & 0.109 & 0.030 & 0.238 & & 0.435 & 0.379 \\
M & 0.092 & 0.142 & 0.702 & 0.012 & 0.604 & 0.189 & & 0.495 \\
NS & 0.074 & 0.063 & 0.162 & 0.010 & 0.430 & 0.143 & 0.245 & \\
\hline
\end{tabular}

The top half of the table shows the correlation $r$ values and the bottom half are the $r^{2}$ values which are the coefficient of determination values and represent the fraction of variance shared between the gene segments.

Highlighted values show $15 \%$ or more correlation between the gene segments. 


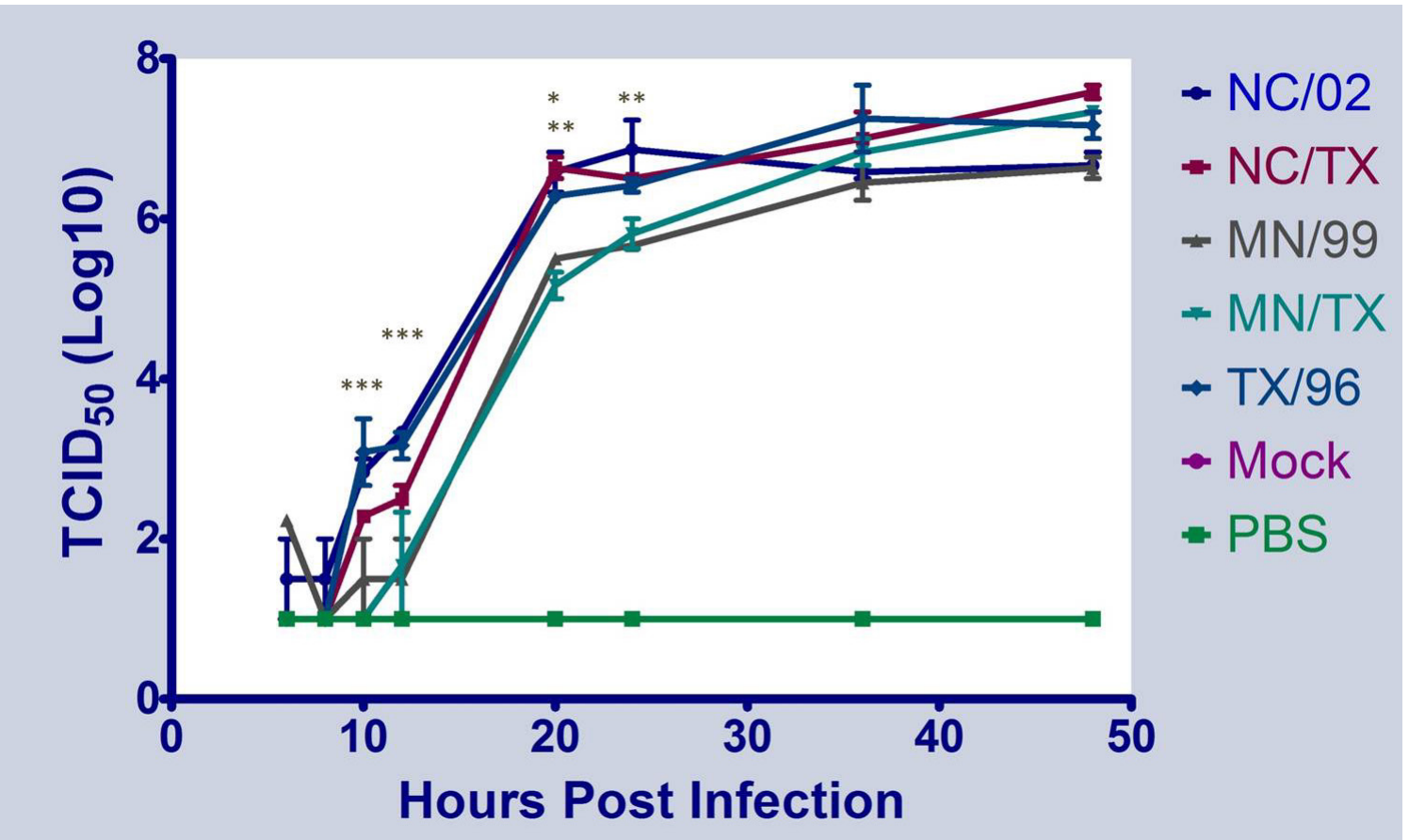

Figure 3-1: MDCK growth kinetics of parental and 6+2 viruses at an $\mathrm{MOI}=0.01$ There were no significant differences observed between MN/99 and MN/TX or between $\mathrm{NC} / 02$ and NC/TX. MN/99 does show significantly lower titers than both NC/02 and TX/96 at 10 and 12 hpi $(\mathrm{P}<0.001)$ and just $\mathrm{NC} / 02$ at 20 and 24 hpi $(\mathrm{P}<0.01) . \mathrm{MN} / 99$ also has significantly lower viral titers at 12 and 20 hpi when compared to NC/TX $(\mathrm{P}<0.05$ and $\mathrm{P}<0.01$ respectively). The asterisks denote time points with significant differences observed with the color matching the parental strain of the comparison.

$\begin{array}{ll}* * * & \mathrm{P}<0.001 \\ * * & \mathrm{P}<0.01 \\ * & \mathrm{P}<0.05\end{array}$




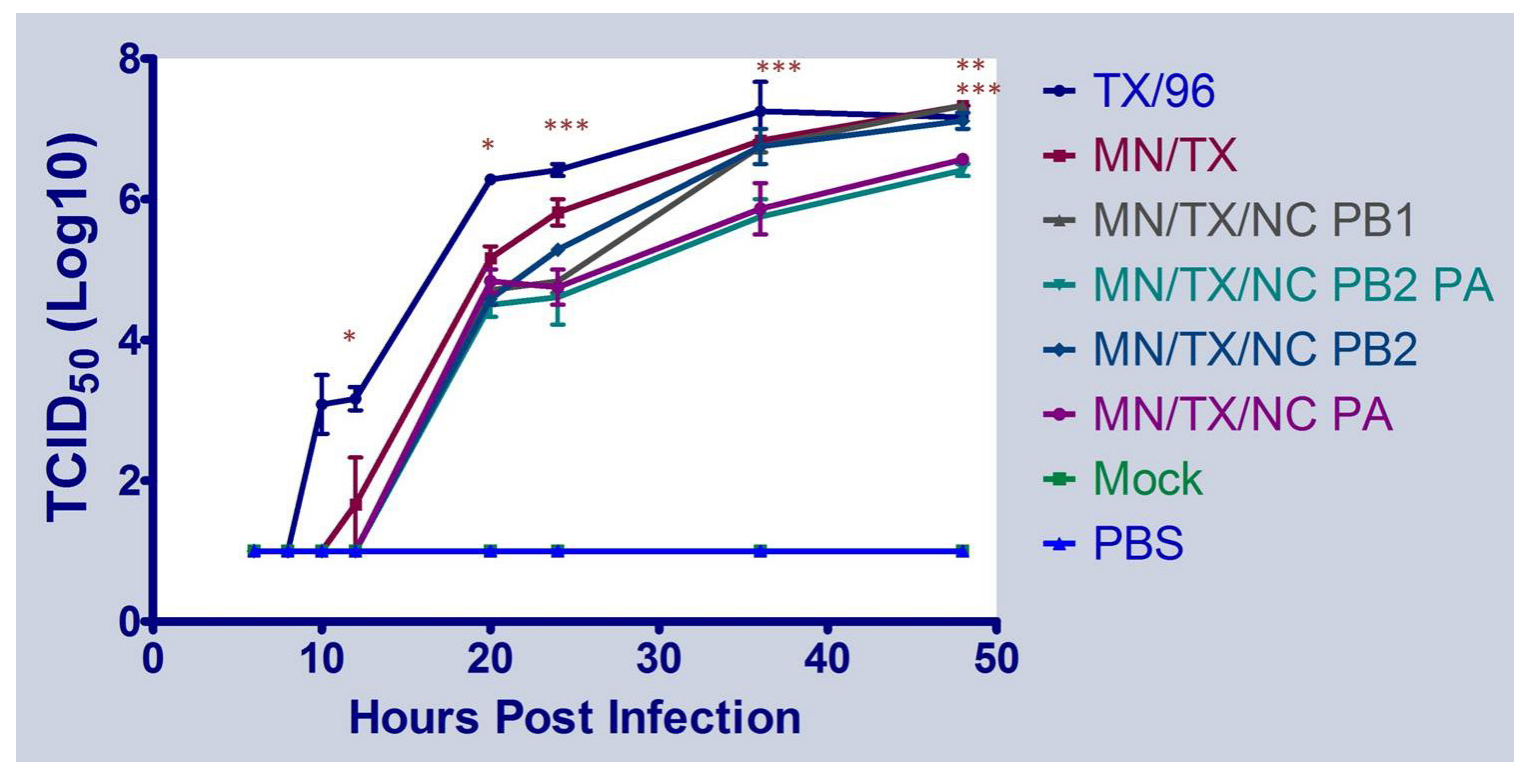

Figure 3-2: Growth kinetics of RG viruses in MDCK cells where the polymerase gene segments have been swapped on the MN/TX viral backbone

$\mathrm{MN} / \mathrm{TX}$ grows at a significantly slower rate compared to TX/96 at 10, 12, and $20 \mathrm{hpi}$ $(\mathrm{P}<0.001)$. When comparing all of the polymerase reassortants to MN/TX, none show increased growth kinetics in MDCK cells. Addition of the NC-PB1 resulted in significantly lower titers at $12 \mathrm{hpi}(\mathrm{P}<0.05)$ and $24 \mathrm{hpi}(\mathrm{P}<0.001)$. The NC-PB2 causes a slight growth reduction at 12 phi $(\mathrm{P}<0.05)$ while NC-PA causes reduced viral titers at 12 $(\mathrm{P}<0.05), 24,36(\mathrm{P}<0.001)$, and $48(\mathrm{P}<0.01)$ hpi. When both NC-PB2 and PA are included they have a cumulative effect and significantly inhibit attenuate viral growth compared to MN/TX at 12 and 20 hpi $(\mathrm{P}<0.05)$ and 24-48 $(\mathrm{P}<0.001)$ hpi. The asterisks denote time points with significant differences observed with the color matching the parental strain of the comparison.

$\begin{array}{ll}* * * & \mathrm{P}<0.001 \\ * * & \mathrm{P}<0.01 \\ * & \mathrm{P}<0.05\end{array}$




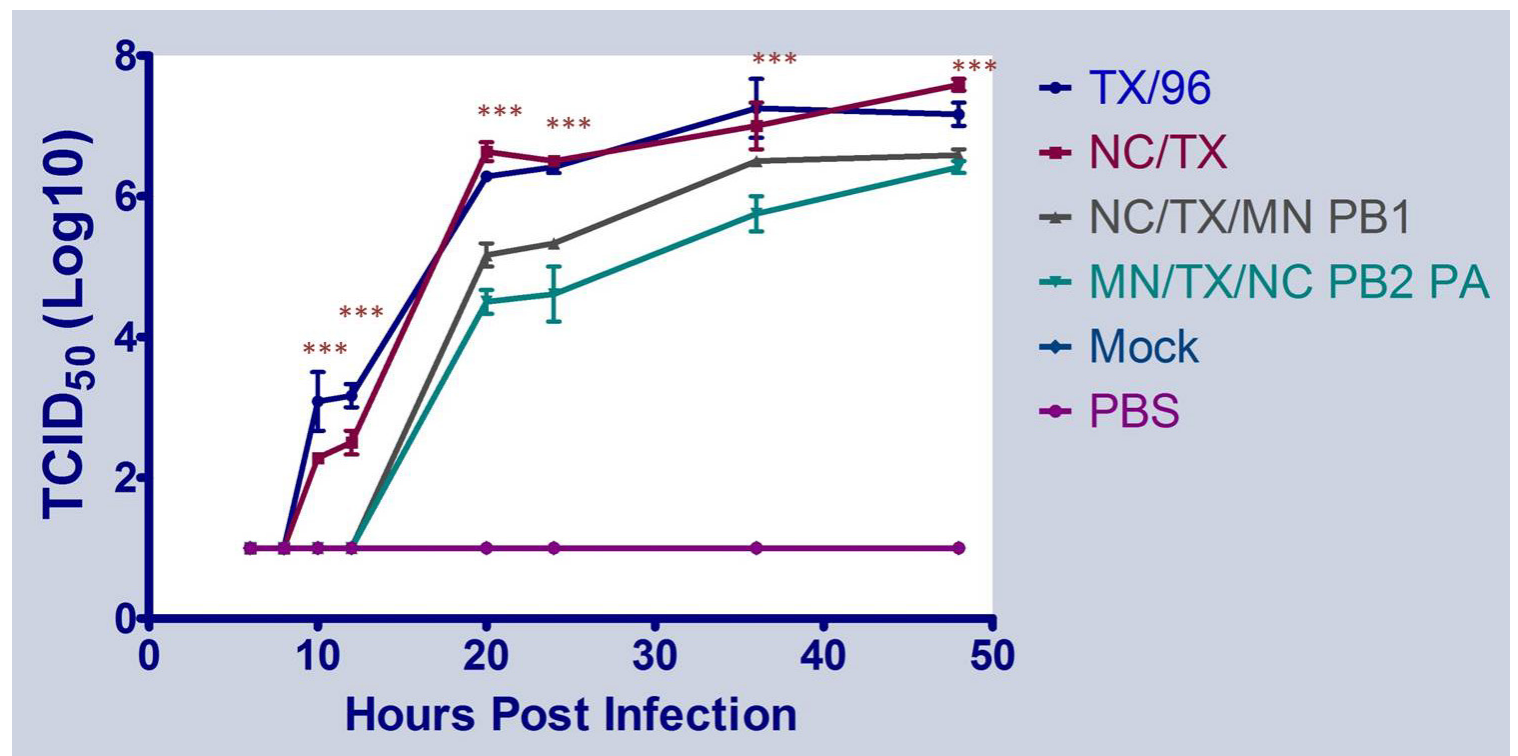

Figure 3-3: Growth kinetics of RG viruses in MDCK cells where MN-PB1 was swapped on the NC/TX viral backbone

NC/TX showed no significant growth difference compared to TX/96. Addition of the MN-PB1 did attenuate the virus compared to NC/TX at 10, 12, 20, 24, and $48(\mathrm{P}<0.001)$ hpi. Inclusion of the NC PB2 and PA in the MN/TX/NC-PB2 PA virus did not rescue the higher growth kinetics seen in the $\mathrm{NC} / \mathrm{TX}$ virus and was attenuated in all time points tested $(10-48$ hpi $\mathrm{P}<0.001)$. The asterisks denote time points with significant differences observed with the color matching the parental strain of the comparison.

$* * * \quad \mathrm{P}<0.001$ 
MN/TX/NC-PB1 grew to significantly lower titers at $12(\mathrm{P}<0.05)$ and 24 hpi $(\mathrm{P}<0.001)$. The NC-PB2 rescued in the MN/TX virus, causes a slight growth attenuation at $12 \mathrm{hpi}$ $(\mathrm{P}<0.05)$ while the NC-PA causes reduced viral titers at $12(\mathrm{P}<0.05), 24,36(\mathrm{P}<0.001)$, and $48(\mathrm{P}<0.01)$ hpi. When both the PB2 and PA are included in MN/TX/NC-PB2 PA, they have a cumulative effect and significantly inhibit attenuate viral growth compared to $\mathrm{MN} / \mathrm{TX}$ at 12 and 20 hpi $(\mathrm{P}<0.05)$ and 24-48 $(\mathrm{P}<0.001)$ hpi (Figure 3-2).

NC/TX showed no significant growth difference compared to TX/96. Addition of the MN-PB1 did attenuate the virus compared to NC/TX at 10,12, 20, 24, and 48 $(\mathrm{P}<0.001)$ hpi. Inclusion of the NC PB2 and PA in the MN/TX/NC-PB2 PA virus was unable to rescue the higher growth kinetics seen in the $\mathrm{NC} / \mathrm{TX}$ virus and the virus was significantly attenuated in all time points tested, 10-48 hpi ( $\mathrm{P}<0.001)$ (Figure 3-3).

Surprisingly, when the TRIG NS was reassorted with the MN/TX, growth was slowed at 12,20 , and 24 hpi at $\mathrm{P}<0.05, \mathrm{P}<0.01$, and $\mathrm{P}<0.001$ respectively. The MN/TX/NC NS virus had significantly lower titers than both NC/TX and TX/96 from 1024 hpi but then the titers recovered by about 36 hpi (Figure 3-4).

\section{pSREC Growth Kinetics}

Preliminary growth kinetic experiments in primary swine trachea cells showed kinetics similar to what has previously been reported for in vivo experiments (Figure 3-5). The human H3N2 virus (TX/96) grew to lower titers when compared to the swine viruses and the swine $6+2$ viruses, as expected. This followed the pattern of lower titers and poor transmission when swine have been experimentally infected as has been previously reported and based on what has been seen epidemiologically. ${ }^{66}$

More extensive evaluation of the swine, human, and $6+2$ viruses in the pSRECs revealed that there is little difference in growth abilities (Figure 3-6). The only significant difference observed was that TX/96 had a higher titer than MN/99 at $20 \mathrm{hpi}$ $(\mathrm{P}<0.05)$. This was opposite of what was expected due to the preliminary kinetic results.

Additionally, the pSRECs were infected with the reassorted viruses to determine the effects that the different polymerase gene segments played on the distinct swine backbones. The NC-PB1 in MN/TX/NC-PB1 results in significantly lower viral titers at 18 and 20 hpi $(\mathrm{P}<0.05)$ compared to MN/TX (Figure 3-7). During the early time points, $\mathrm{MN} / \mathrm{TX} / \mathrm{NC}-\mathrm{PB} 2$ grows at lower titers $14(\mathrm{P}<0.001)$ and $20 \mathrm{hpi}(\mathrm{P}<0.05)$, while the $\mathrm{NC} / 02-\mathrm{PA}$ in the MN/TX/NC-PA virus causes viral growth deficiencies later at $36 \mathrm{hpi}$ $(\mathrm{P}<0.05)$. Addition of both the $\mathrm{PB} 2$ and $\mathrm{PA}$ have cumulative effects in $\mathrm{MN} / \mathrm{TX} / \mathrm{NC}-\mathrm{PB} 2$ $\mathrm{PA}$ and attenuate the virus at $12 \mathrm{hpi}(\mathrm{P}<0.05), 12,16 \mathrm{hpi}(\mathrm{P}<0.001), 18 \mathrm{hpi}(\mathrm{P}<0.05)$, and 20 hpi $(\mathrm{P}<0.001)$. However, no growth defect is observed when the whole $\mathrm{NC}$ polymerase complex is exchanged for the $\mathrm{MN}$ polymerase trimer comparing MN/TX/NC-Pol to MN/TX. 


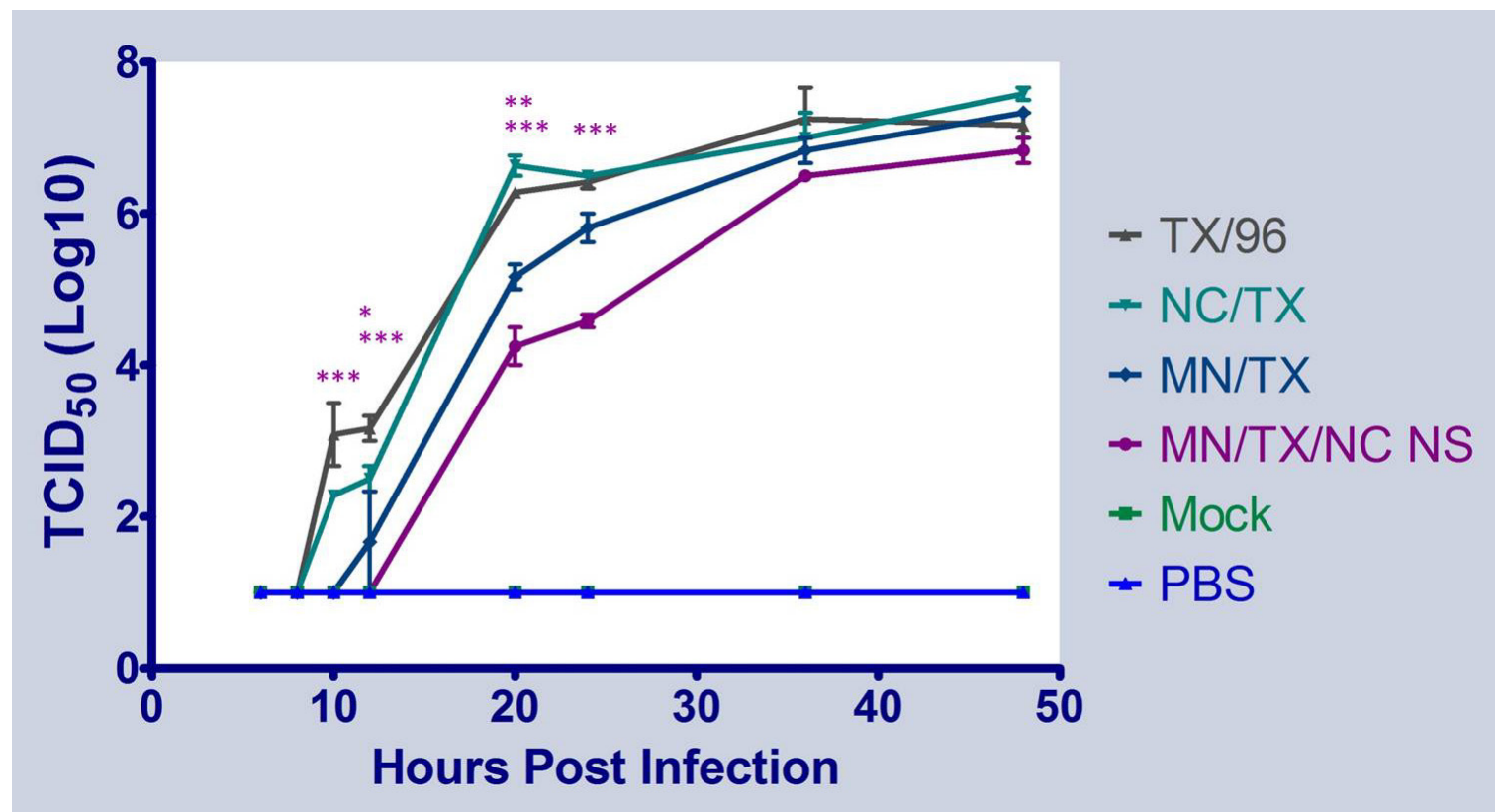

Figure 3-4: MDCK growth of RG viruses with TRIG NS

$\mathrm{MN} / \mathrm{TX} / \mathrm{NC}$ NS grows at a significantly slower rate compared to wt TX/96 and NC/TX at 10-24 hpi $(\mathrm{P}<0.001)$. At $12 \mathrm{hpi} \mathrm{MN/TX/NC} \mathrm{NS} \mathrm{grows} \mathrm{at} \mathrm{lower} \mathrm{titers} \mathrm{than} \mathrm{MN/TX} \mathrm{up}$ through 24 hpi $(p<0.05, p<0.01$, and $p<0.001$, respectively). The asterisks denote time points with significant differences observed with the color matching the strain being compared.
$* * * \quad \mathrm{P}<0.001$
** $\quad \mathrm{P}<0.01$
* $\quad \mathrm{P}<0.05$ 


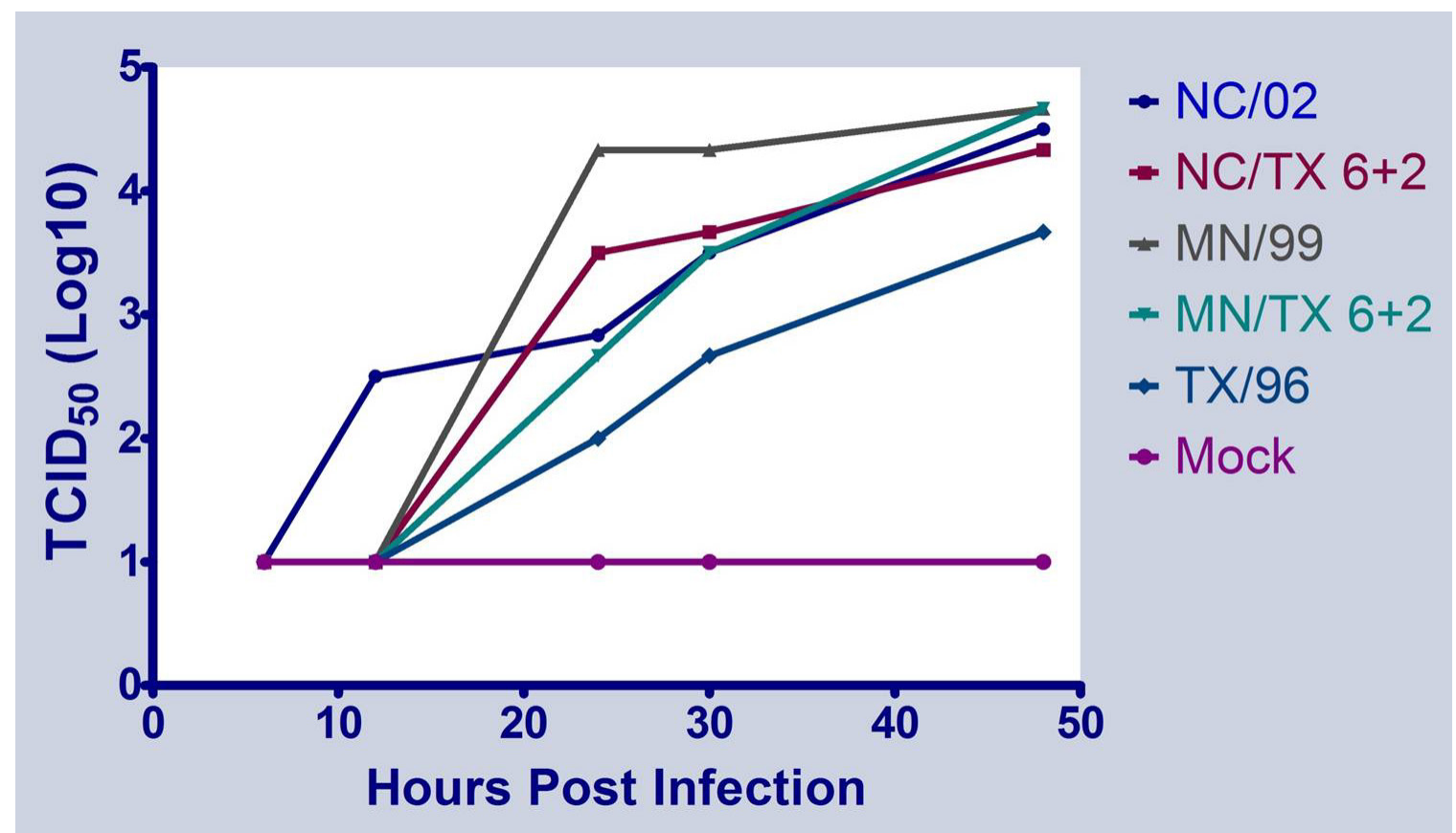

Figure 3-5: Preliminary pSREC growth kinetics at an MOI of 0.01

Preliminary kinetic experiments in pSRECs mirrored other experiments where the swine viruses grow rapidly and to higher titers compared to the human virus, TX/96. These kinetic experiments were completed with only 1 replicate, so significance could not be calculated. 


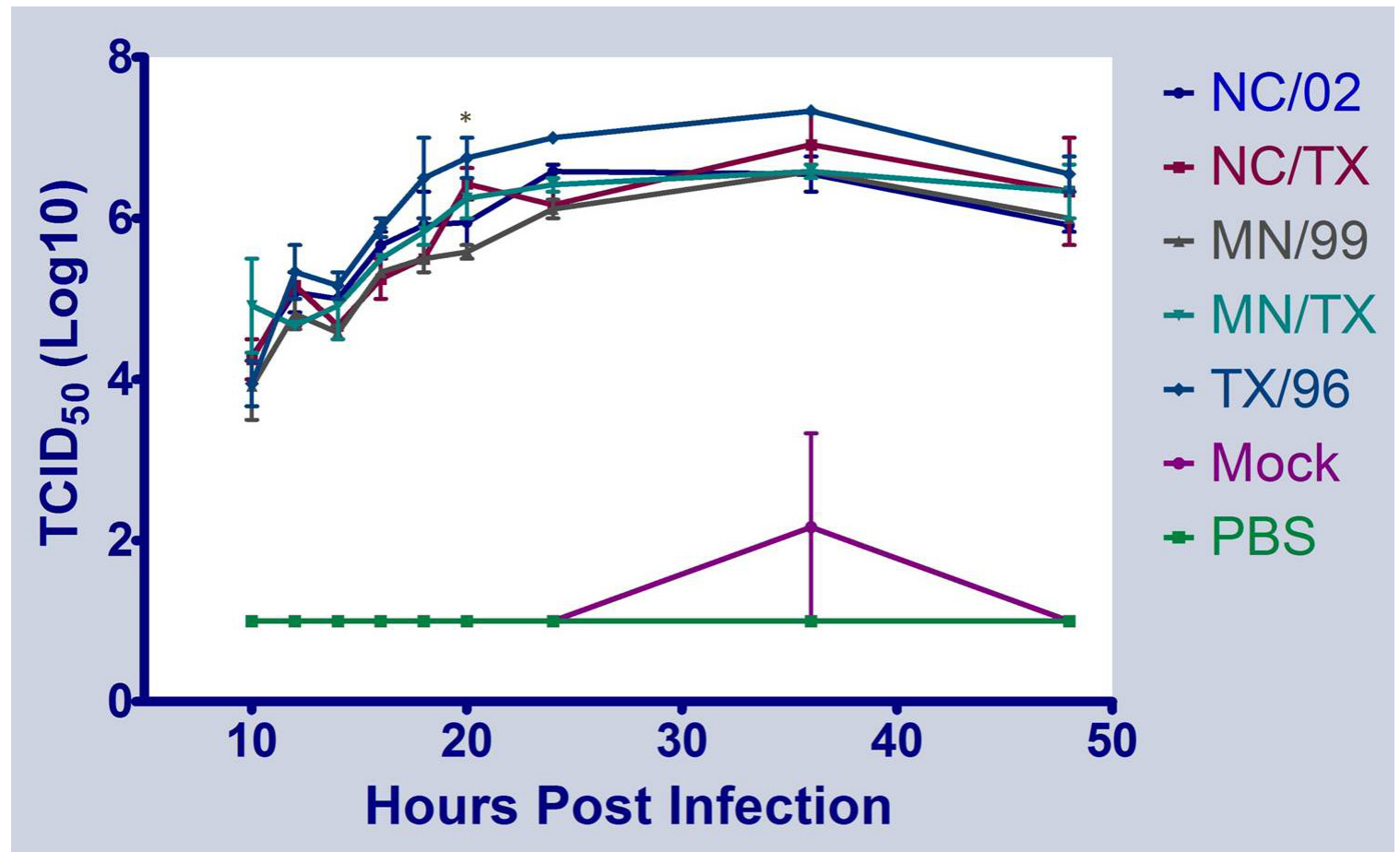

Figure 3-6: pSREC growth kinetics at an MOI of 0.01

There were no significant differences between any of the viruses when compared to TX/96 except MN/99 at 20 hpi $(\mathrm{P}<0.05)$. The asterisks denote time points with significant differences observed with the color matching the strain being compared. $* * * \quad \mathrm{P}<0.001$

** $\quad \mathrm{P}<0.01$

* $\quad \mathrm{P}<0.05$ 


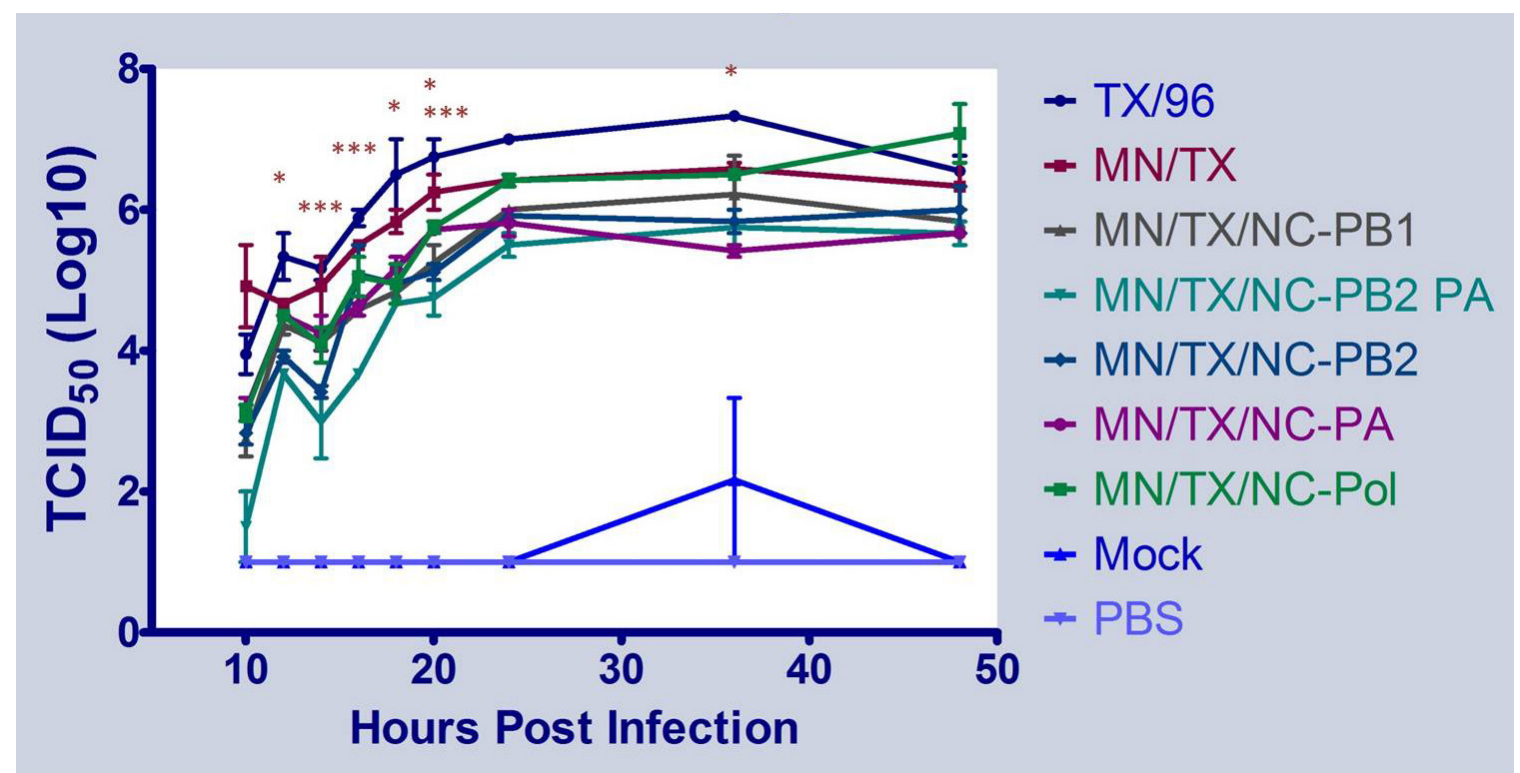

Figure 3-7: Growth kinetics of RG viruses in pSRECs where the polymerase gene segments have been swapped on the MN/TX viral backbone

The MN/TX/NC-PB1 virus grew to lower titers than MN/TX at 18 and 20 hpi $(\mathrm{P}<0.05)$. Compared to MN/TX, the NC/02-PB2 in MN/TX/NC-PB2 virus grows at lower titers during the early time points of 14 hpi $(\mathrm{P}<0.001)$ and 20 hpi $(\mathrm{P}<0.05)$, while the $\mathrm{NC} / 02-$ $\mathrm{PA}$ in the MN/TX/NC-PA virus causes viral growth deficiencies later at 36 hpi $(\mathrm{P}<0.05)$. Both the PB2 and PA have cumulative effects and attenuated the MN/TX/NC-PB2 PA virus at $12(\mathrm{P}<0.05), 14,16(\mathrm{P}<0.001), 18(\mathrm{P}<0.05)$, and 20 hpi $(\mathrm{P}<0.001)$. When the complete NC polymerase is included in MN/TX/NC-Pol, the growth is no different than MN/TX. The asterisks denote time points with significant differences observed with the color matching the parental strain of the comparison.

$\begin{array}{ll}* * * & \mathrm{P}<0.001 \\ * * & \mathrm{P}<0.01 \\ * & \mathrm{P}<0.05\end{array}$


When the classical swine PB1 was put into the TRIG polymerase complex with human $\mathrm{H} 3 \mathrm{~N} 2$ surface proteins, the $\mathrm{PB} 1$ attenuated growth of the virus at $14(\mathrm{P}<0.05), 20$, and 36 hpi $(\mathrm{P}<0.01)$ compared to NC/TX as seen in Figure 3-8. There are no growth differences observed when the 3 TRIG polymerase segments from NC/02 are rescued with MN/TX in MN/TX/NC-Pol compared to the NC/TX virus.

Finally, the TRIG NS had no significant effect of MN/TX/NC-NS growth in pSRECs when compared to MN/TX (Figure 3-9). Although it had no significant difference, the addition of the TRIG NS does seem to cause a slight reduction in its growth especially 10-20 hpi, but the virus is able to recover around $24 \mathrm{hpi}$ with an end point titer similar to TX/96, MN/TX, and NC/TX.

\section{Reassortant Swine Virus Infectivity and Transmissibility in Pigs}

To confirm in vitro results, pigs were used to monitor infectivity and transmissibility of a selection of reassortant swine viruses with the human viral glycoproteins and one virus with the TRIG PB1 in the classical swine backbone. As expected, the pigs inoculated with wt TX/96 became infected but no virus could be detected in any of the contact animals (Figure 3-10). The viral titers peaked 1 to $3 \mathrm{dpi}$ at $10^{3.667}$ and $10^{4.5} \mathrm{TCID}_{50}$ per ml, respectively. There was also no virus detected in the inoculated animals on day 7 , so the virus had been cleared between 5 and 7 dpi.

Pigs inoculated with the TRIG PB1 reassorted with the classical swine polymerase in the RG virus MN/TX/NC-PB1 shed detectable virus up to $7 \mathrm{dpi}$. Like the TX/96 virus, none of the contact animals shed any virus (Figure 3-11). The virus was slightly attenuated when compared to the other tested viruses because it was only detected in one inoculated pig from 3-7 dpi and from 1-7 dpi in the other inoculated animal. This virus also only reached an average peak titer of about $10^{3.987} \mathrm{TCID}_{50}$ per $\mathrm{ml}$ 5 dpi.

Interestingly, when the human HA and NA were rescued on the classical swine virus backbone (MN/TX), the virus established a robust infection, reaching an average peak titer of $10^{5.282} \mathrm{TCID}_{50}$ per $\mathrm{ml} 3 \mathrm{dpi}$ (Figure 3-12). Beyond the relatively high titer and despite the presence of the HA and NA from a human virus, MN/TX was able to transmit to all three contact animals. Virus was first detected in the contact animals starting $3 \mathrm{dpi}$ and the highest titers were detected 5 dpi in one of the animals and $7 \mathrm{dpi}$ in the other two contact animals. However, the average peak titer was slightly lower in the contact animals at $10^{5} \mathrm{TCID}_{50}$ per $\mathrm{ml}$.

Similar to MN/TX, when the human HA and NA were present on the TRIG cassette backbone (NC/TX), the virus reached relatively high titers in the inoculated animals as well as all three of the contact animals (Figure 3-13). However, the inoculated animals had peak titers 1 dpi with an average titer of $10^{4.909} \mathrm{TCID}_{50}$ per $\mathrm{ml}$ and the contacts had an average peak titer of $10^{4.41}$ TCID $_{50}$ per ml ranging from 3-7 dpi. Although 


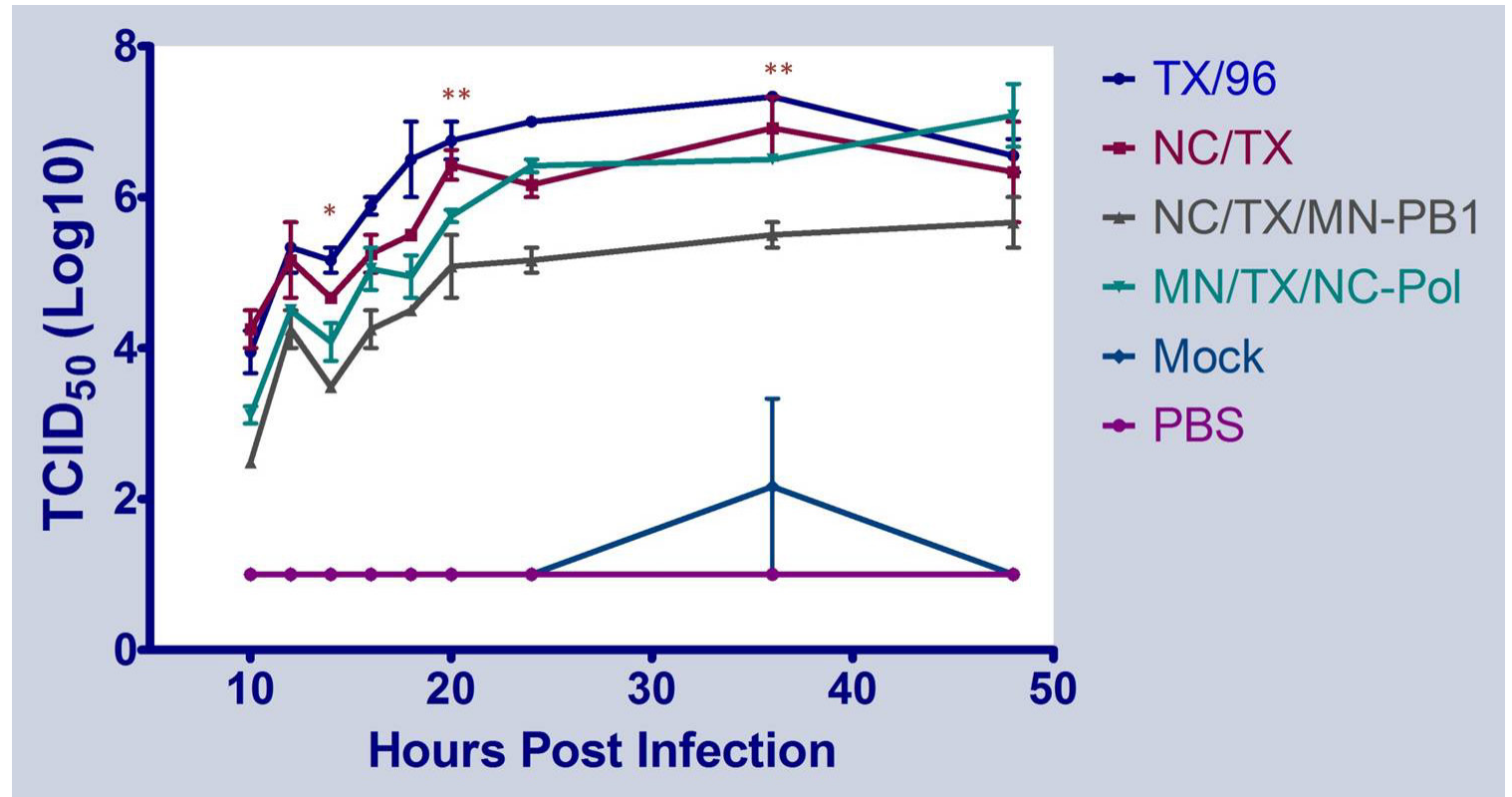

Figure 3-8: Growth kinetics of RG viruses in MDCK cells where MN-PB1 was swapped on the NC/TX viral backbone

The NC/TX/MN-PB1 virus grew to significantly lower titers at $14(\mathrm{P}<0.05), 20$, and 36 hpi $(\mathrm{P}<0.01)$ compared to NC/TX. MN/TX/NC-Pol with the 3 polymerase segments from $\mathrm{NC} / 02$ does not show any significant growth defects when compared to NC/TX. The asterisks denote time points with significant differences observed with the color matching the parental strain of the comparison.

$\begin{array}{ll}* * * & \mathrm{P}<0.001 \\ * * & \mathrm{P}<0.01 \\ * & \mathrm{P}<0.05\end{array}$




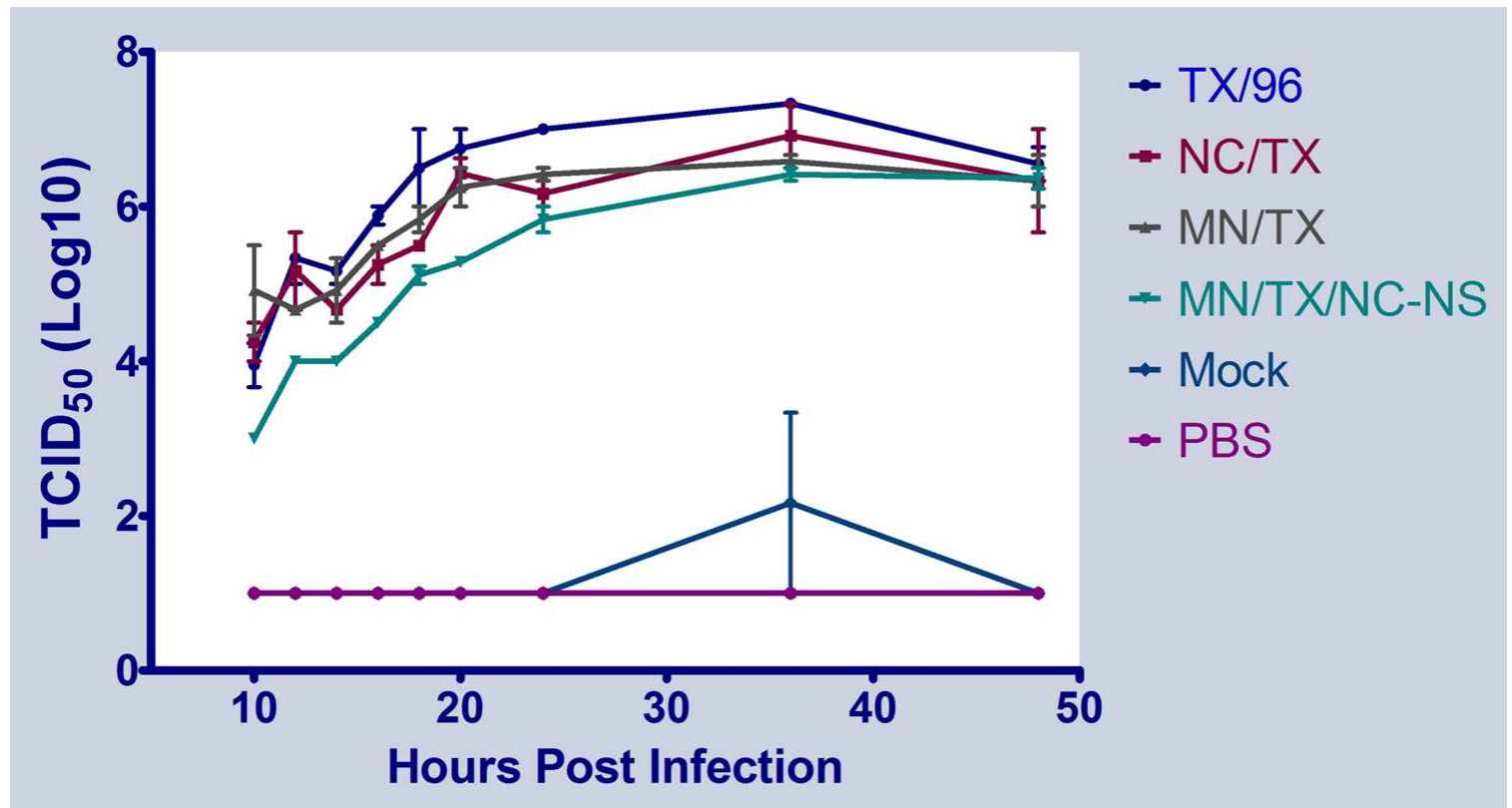

Figure 3-9: Reassortant viruses with TRIG NS in pSRECs

There were no significant growth differences between any of the viruses when compared to $\mathrm{MN} / \mathrm{TX}$. 


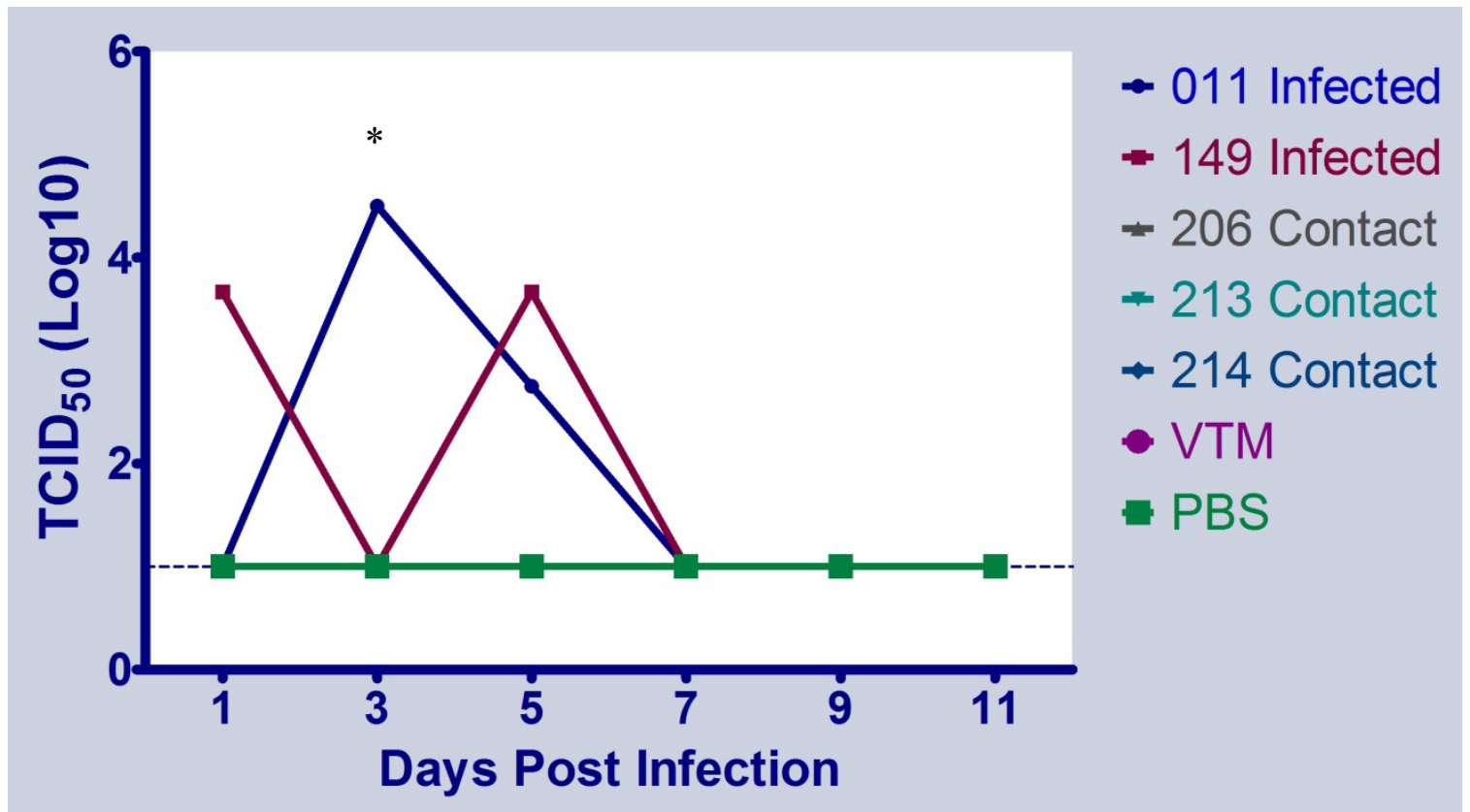

Figure 3-10: Growth and transmission of human TX/96 in pigs

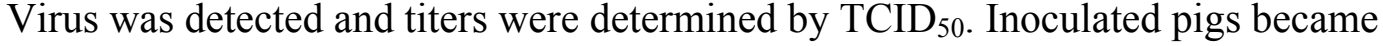
infected but the virus did not transmit to direct contact animals. The average peak titers reached $10^{4.08} \mathrm{TCID}_{50}$ per $\mathrm{ml}$.

* No virus detected from pig 149 likely the result of inadequate swab insertion. 


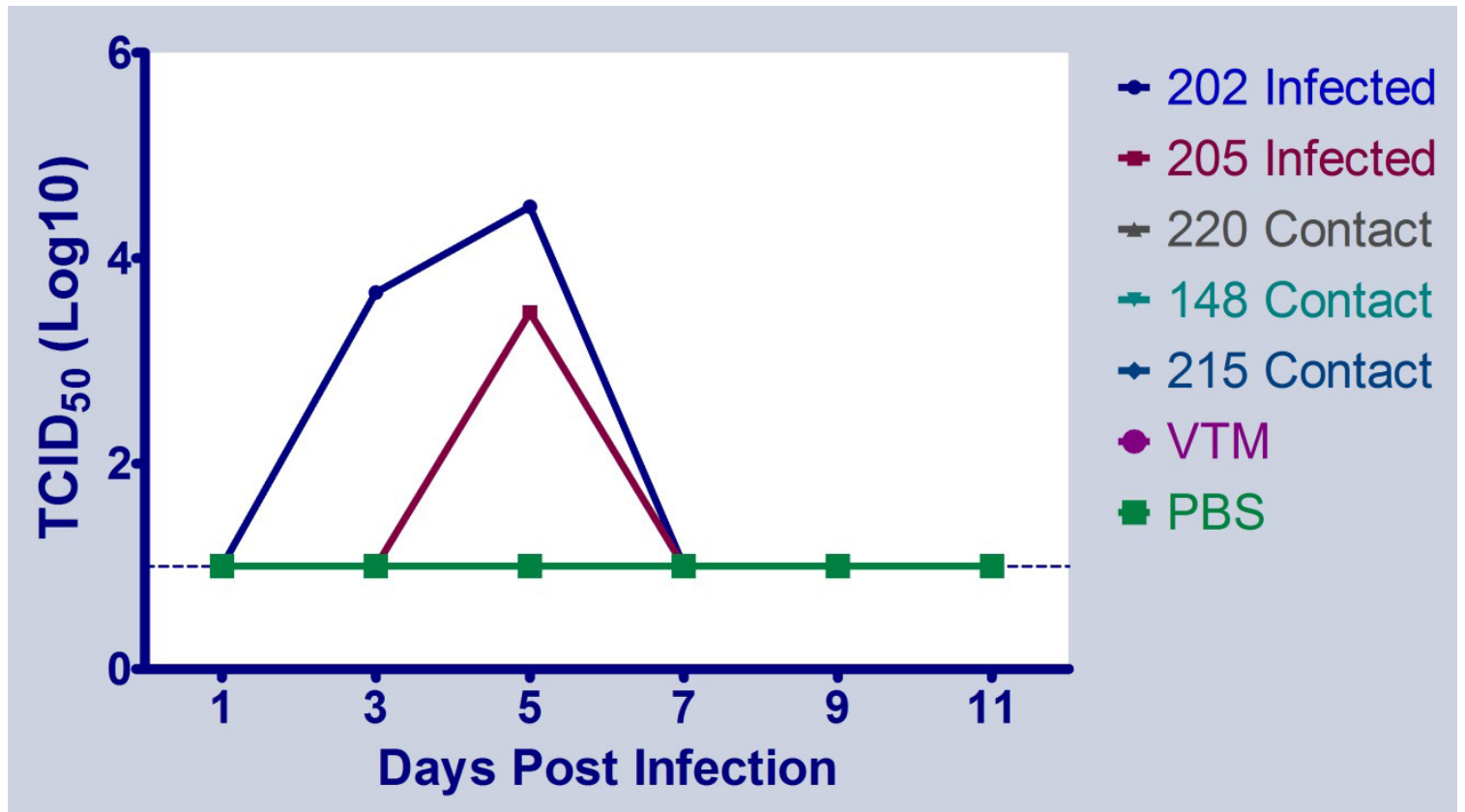

Figure 3-11: Growth and transmission of MN/TX/NC-PB1 in pigs

Virus was detected and titers were determined by TCID $_{50}$. Inoculated pigs became infected but the virus did not transmit to direct contact animals. The average peak titers reached $10^{3.99}$ TCID $_{50}$ per $\mathrm{ml} 5$ dpi. 


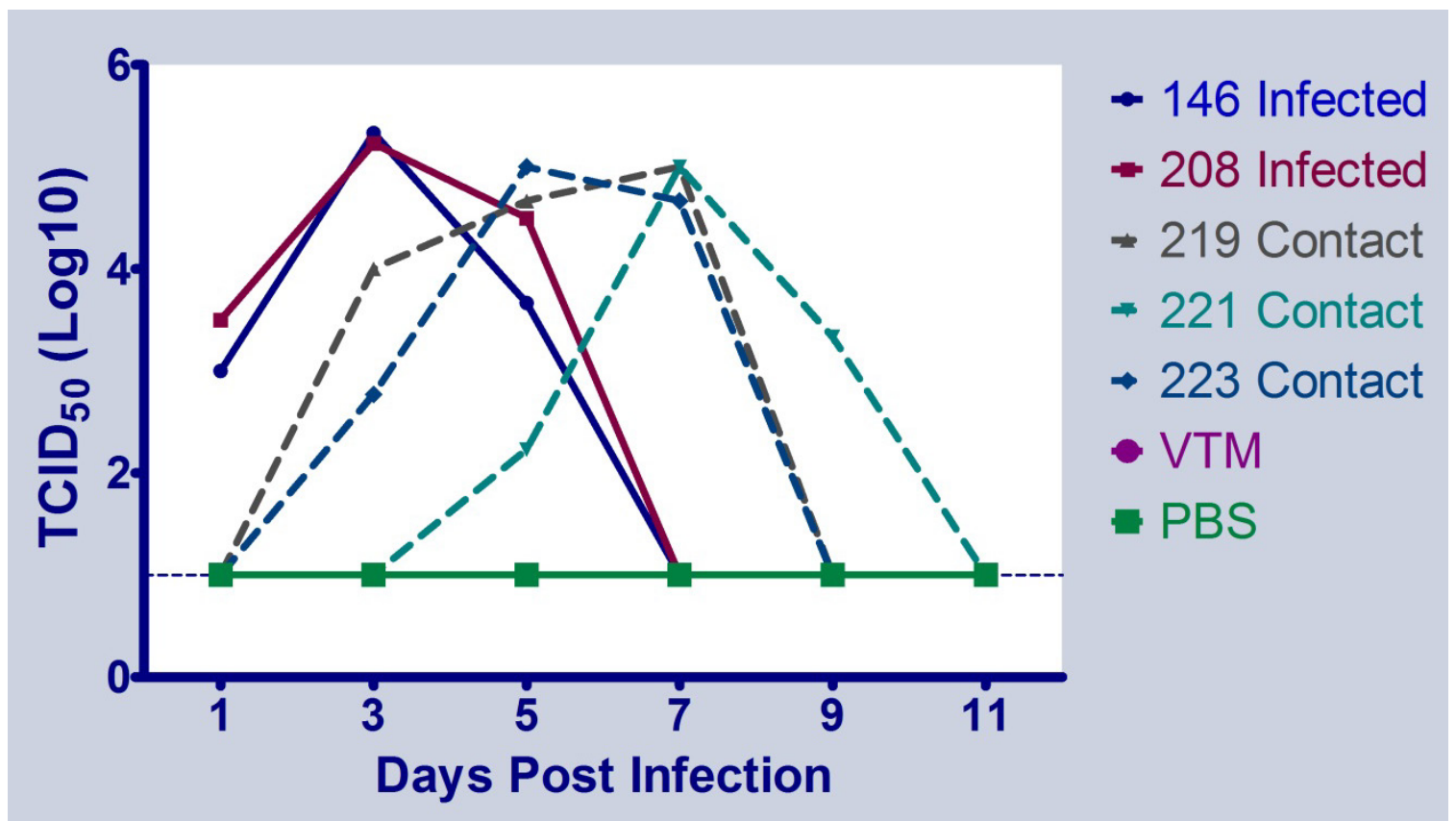

Figure 3-12: Growth and transmission of MN/TX in pigs

Virus was detected and titers were determined by TCID $_{50}$. Inoculated pigs became infected and the virus was capable of transmitting to all of the direct contact animals. The average peak titers in the inoculated animals reached $10^{5.28}$ TCID $_{50}$ per $\mathrm{ml} 3 \mathrm{dpi}$, while the contact animals reached an average peak titer of $10^{5}$ TCID $_{50}$ per $\mathrm{ml}$ 5-7 dpi. 


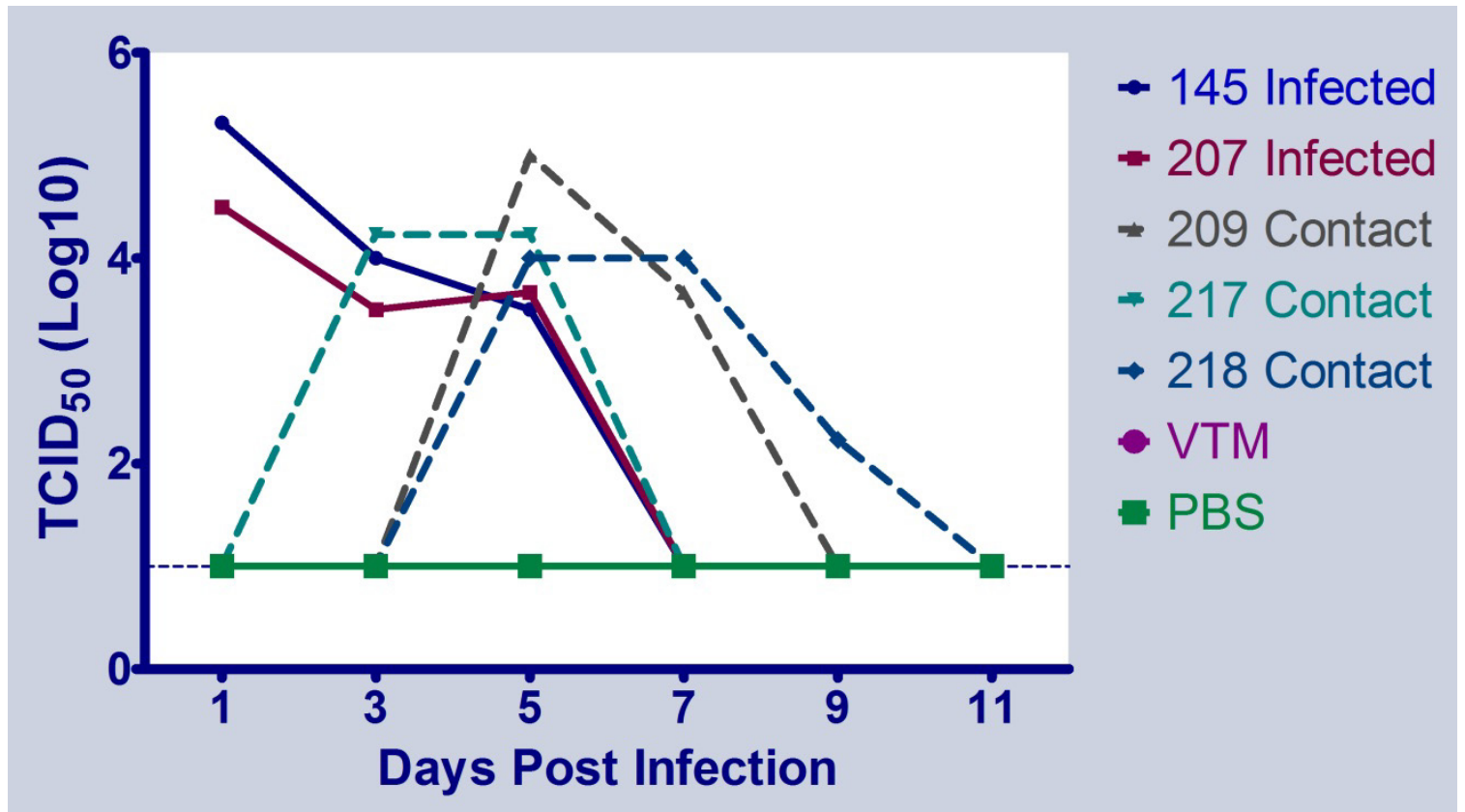

Figure 3-13: Growth and transmission of NC/TX in pigs

Virus was detected and titers were determined by TCID $_{50}$. Inoculated pigs became infected and the virus was capable of transmitting to all of the direct contact animals. The average peak titers in the inoculated animals reached $10^{4.91}$ TCID $_{50}$ per $\mathrm{ml} 1 \mathrm{dpi}$, while the contact animals reached an average peak titer of $10^{4.41}$ TCID $_{50}$ per $\mathrm{ml} 5 \mathrm{dpi}$. 
these titers are lower than MN/TX, the NC/TX virus was capable of reaching its peak titer several days earlier than MN/TX.

\section{Discussion}

\section{In Vitro Reassortment}

With the high throughput sequencing capabilities of the MiSeq platform, we were able to genotype a large number of viruses for both in vitro coinfection conditions. In previous coinfection experiments with the classical swine virus, no reassortants were detected. ${ }^{66}$ However, we see that MN/99 is capable of reassorting with TX/96 and produces a greater variety of viral genotypes than $\mathrm{NC} / 02$ and TX/96. When genotyping 96 potential reassortant viruses, we identified 34 different reassortant viruses between MN/99 and TX/96 compared to only 19 reassortant genotypes between NC/02 and TX/96. However, $21 \%$ of the reassortants between MN/99 and TX/96 were only detected once, while only $10 \%$ of the reassortants between NC/02 and TX/96 were detected once. This suggests that although $\mathrm{MN} / 99$ reassorts more frequently than $\mathrm{NC} / 02$, many of the reassortants have relatively slower growth characteristics compared to the parental strains or other more prevalent reassortant genotypes. The different reassortant genotypes with the TX/96 HA and NA suggest there may be some gene incompatibility when comparing $\mathrm{MN} / 99$ and NC/02. On the classical swine backbone, both the TX/96 HA and NA occur together in $68.8 \%$ of the reassortants compared to only $18.8 \%$ of the reassortants on the TRIG backbone. Additionally, the TX/96 HA and NA occur alone only $10.8 \%$ and $12.9 \%$, respectively, on the classical swine backbone. Conversely, the TX/96 HA alone occurs $69.8 \%$ of the time on the TRIG backbone with the NA from NC/02 producing an H3N1 genotype. This particular genotype has been identified in swine but at very low frequencies suggesting this is a favorable genetic composition but it may be limited in its ability to infect in vivo or to transmit. These statistics are not conclusive for gene compatibility, but they suggest that the classical HA or NA is incompatible with the TX HA or NA, while the TX/96 HA appears frequently with the NC/02 NA suggesting they are highly compatible. There may also be some restrictions based on the different polymerase segments. In reassortant viruses with the $\mathrm{H} 3$ between $\mathrm{MN} / 99$ and TX/96, $44.3 \%$ of the viruses contained all three polymerase segments from the human lineage virus while $55.7 \%$ contained at least one segment from $\mathrm{MN} / 99$ and one segment from TX/96. Similarly, 53.1\% of the reassortant $\mathrm{H} 3$ viruses between NC/02 and TX/96 contained at least one polymerase gene segment from $\mathrm{NC} / 02$ and at least one segment from $\mathrm{TX} / 96$. However, only $4.5 \%$ of the $\mathrm{H} 3$ viruses had all three gene segments from $\mathrm{TX} / 96$ and $46.9 \%$ had all three gene segments from $\mathrm{NC} / 02$. These percentages clearly demonstrate that the wholly $\mathrm{NC} / 02$ polymerase complex is more promiscuous in its ability to form viable viral genotypes with human $\mathrm{H} 3$ gene segments compared to the $\mathrm{MN} / 99$ polymerase gene segments.

There are very few gene segments that very strongly correlate as would have been expected if there were major gene incompatibilities. The strongest gene segment 
correlation between MN/99 and TX/96 was between the M and NS segments. This is likely because the matrix protein interacts with the NEP protein as the RNPs are exported out of the nucleus for virion formation. This interaction is crucial for new budding virions to completely form as well as for efficient replication.

There are several strongly correlated gene segments between NC/02 and TX/96 including, M and PA and M and NP. The correlation between M and NP likely plays a role in RNP export from the nucleus as well as viral packaging. The M and NP need to be able to efficiently interact because it has been suggested that this is a mechanism of "sensing" when all 8 gene segments have been incorporated into a new virion prior to budding. This correlation between M and PA is not well understood because there is no known interaction between the $\mathrm{M}$ and PA proteins. This may suggest that there is a protein interaction that has yet to be identified between the matrix and PA proteins.

\section{Early Kinetic Differences in MDCK Cells}

To determine if gene incompatibility was the driving factor for lack of observed reassortment between classical swine viruses with human HA and NA versus TRIG viruses, the growth kinetics were completed to compare the parental strains with the $6+2$ reassortant viruses. There were no differences observed between the MN/99 parental strain when compared to the MN/TX virus. Similarly, there was no observable difference between NC/02 and NC/TX. This demonstrates that addition of the human HA and NA on the different swine backbones does not attenuate either virus and therefore was not the limiting factor for the epidemiologic observations in which the classical swine viruses did not reassort.

The primary differences observed were between 10 to 24 hpi when comparing TX/96, NC/02, and NC/TX to the kinetics of MN/99 and MN/TX. MN/99 and MN/TX showed significantly lower titers at 10,12, 20, and 24 hpi when compared to the $\mathrm{NC} / 02$ virus. This indicates that $\mathrm{NC} / 02$ and $\mathrm{NC} / \mathrm{TX}$ have distinct growth advantages in the ability to initiate an infection and spread within the host when compared to MN/99 and MN/TX. This further suggests why the TRIG viruses have displaced the classical swine viruses, but does not provide evidence for the lack of classical swine virus reassortment.

To further explore if the polymerase gene segments affect genetic compatibility, multiple polymerase reassortants were rescued and growth kinetics were completed. Again, TX/96 and NC/TX proved to be the most fit kinetically out of the viruses tested. The other significant differences occurred when the TRIG PB2 and/or PA gene segments were rescued in the MN/TX virus. Unexpectedly, the polymerase reassortants with the TRIG PB2 and PA show reduced fitness suggesting that they may not be fully compatible with the cs PB1. Despite the observed differences, they only occur at the later time points of 24 through 48 hpi and do not occur during the full time course. Within this model, the addition of the TRIG PB2 and/or PA does not confer any growth advantage to MN/TX. 
Not only do the polymerase gene segments need to be well matched for efficient replication, even the NS1 and/or NEP proteins need to be matched with the other gene segments. The inclusion of TRIG NS in the MN/TX virus also disrupts viral growth efficiency. However, the effects are only noticeable between 12 and $24 \mathrm{hpi}$, as the end point viral titers are not different from the other tested viruses. This demonstrates a clear polygenic cooperation in these viruses when tested in MDCK cells.

\section{RG Virus Growth Kinetics in pSRECs}

The growth kinetics in MDCK cells indicate that TX/96 grows more rapidly than either MN/99 or NC/02. However, other studies have shown that TX/96 does not efficiently replicate in swine, ${ }^{66}$ suggesting that the MDCK model is not adequate for swine virus studies. Preliminary growth kinetics in pSRECs from laboratory pigs mirrored previous studies in which the TX/96 virus grew at lower titers than either of the swine viruses. Additionally, the reassortant MN/TX and NC/TX viruses grew to similar titers as $\mathrm{MN} / 99$ and $\mathrm{NC} / 02$.

Despite the promising results of the initial studies, when the growth kinetics were repeated in pSRECs derived from naturally farmed swine, there were no kinetic differences between any of the viruses except TX/96 and MN/99 at 20 hpi. These differing results can be explained by several factors. The use of primary cells from varying sources can lead to inconsistent results as seen here. Additionally, the pSRECs used for the initial studies included epithelial cells from beyond the bronchi bifurcation and included some bronchioles. The later experiments only used cells harvested from the trachea. It is possible that these factors could have contributed to a differing receptor expression patterns on the cells used, although, the upper and lower respiratory tracts of swine predominantly express $\alpha 2,6$ linked sialic acids. ${ }^{82}$ It is also possible that the pigs used for the latter experiments had previous exposure to influenza viruses and may have had some preexisting immunity that was present during the experiment.

Further growth kinetics were completed to determine if the reassorted polymerase complex had any effects on viral growth in the pSRECs. Similar to growth kinetic results in MDCK cells, there are identified time points where the viral kinetics were significantly different, but no viruses showed consistent attenuation when compared to the other tested viruses. One genotype that matched the results seen in MDCK cells was MN/TX/NCPB2 PA. This virus grew at significantly lower titers at 12-20 hpi compared to MN/TX. Furthermore, when the whole TRIG polymerase complex is rescued in the MN/TX virus, the virus is no longer attenuated. This strongly suggests that the polymerase complex must be well matched for efficient replication and that the TRIG PB2 and PA do not efficiently interact with the classical swine PB1.

When the TRIG NS is rescued in the MN/TX virus, there is no significant difference observed in the growth kinetics using pSRECs, however, the MN/TX/NC-NS virus does show some slight attenuation 10-20 hpi. This is different than what was seen in MDCK cells in which the MN/TX/NC-NS virus was significantly attenuated. This 
suggests that introduction of the TRIG NS causes some incompatibility but this incompatibility can be overcome in the swine cells. One possible explanation for overcoming the incompatibility in the pSRECs is that the TRIG NEP more specifically interacts with swine CRM1 than canine CRM1 thereby reducing the effect of a new gene segment. CRM1 has been shown to mediate protein export from the nucleus and is conserved among species.

\section{Swine Backbones Restore Transmission in Vivo}

Pigs were infected with the wt TX/96 and the reverse genetic NC/TX, MN/TX, and MN/TX/NC-PB1 viruses to test the ability of swine viruses with human $\mathrm{H} 3$ and $\mathrm{N} 2$ surface glycoprotein to infect and transmit. As expected, TX/96 did not transmit to any of the contact animals despite establishing an infection in the directly inoculated animals. One of the inoculated animals did not have a titer on day 3 but had titers on 1 and 5 dpi. This was likely the result of poor swabbing. The virus was cleared by both infected animals by day 7 post infection.

Similarly, when MN/TX/NC-PB1 was used for inoculation, the two inoculated animals became infected and all three contact animals remained negative throughout the experiment. However, both MN/TX and NC/TX were able to transmit to $100 \%$ of the contact animals. This indicates that disruption of the MN polymerase complex with the TRIG PB1 causes a decrease in viral growth as well as diminishes its ability to transmit.

Most surprising is the ability of the MN/TX and NC/TX viruses to transmit to all contact animals. The MN/TX virus appeared in contact animals starting 3-5 dpi and was detected for about 6 days prior to clearance. The duration of viral shedding and peak titers were similar between inoculated and contact animals. This provides compelling evidence that HA and NA are not the primary host determinant factors, but rather the interaction of the internal gene products with each other and with host proteins. However, this experiment cannot rule out a virus' inability to infect a host due to poor receptor recognition.

Additionally, NC/TX $6+2$ showed similar growth characteristics to MN/TX. $\mathrm{NC} / \mathrm{TX}$ transmitted to all three contact animals starting 3-5 dpi and could be detected for 4-6 days prior to clearance. Inoculated animals had similar peak titers to contact animals and these peak titers were also comparable to those seen with MN/TX. However, NC/TX appears to reach peak titers 1 to 2 days before MN/TX. The pigs inoculated with NC/TX peaked $1 \mathrm{dpi}$ and the contact animals reached peak titers 3-5 days post inoculation. The peak titers of MN/TX were delayed 1-2 days when compared to NC/TX in that the inoculated animals reached peak titers $3 \mathrm{dpi}$ and the contact animals reached peak titers 5-7 dpi. This indicates that the TRIG backbone provides an inherent growth advantage because the TRIG viruses can reach peak titers more rapidly and therefore establish a productive infection prior to the viruses with the classical swine backbone. 


\section{Conclusions}

The success of influenza viruses with the TRIG cassette is difficult to dispute due to the high epidemiologic prevalence in U.S. swine herds. This success can be attributed to the virus' ability to rapidly establish an infection when compared to the classical swine viruses. However, incorporating the TRIG polymerase heterotrimer into the classical swine virus does not confer this rapid viral replication phenotype suggesting that the growth advantage seen in the TRIG viruses is a trait inferred by the other segments or optimized gene and protein interactions. It does lend evidence for why the TRIG viruses displaced the classical swine viruses, but cannot provide an answer for how reassortment was restricted in classical swine viruses. The data suggests that there is no virologic reason for why the classical swine viruses did not reassort because they are capable in in vitro experiments. In vivo experiments also demonstrated that the human $\mathrm{H} 3$ and $\mathrm{N} 2$ segments were capable of infecting and transmitting. This indicates that there are other factors, including host and environmental, that caused the epidemiologically observed differences in reassortment between the TRIG viruses and classical swine viruses.

The HA and NA are regarded as the main contributors of host restriction. However, when rescued on different backbones, the same viral glycoproteins can show transmissible phenotypes and restricted phenotypes. This suggests that host restriction can also be attributed to some aspects of the internal genes. This data only confounds the questions further as to why no reassortants were seen with the classical swine virus backbone. 


\section{CHAPTER 4. EVOLUTIONARY BURST OF REVERSE GENETIC VIRUSES PASSAGED IN SWINE EPITHELIAL CELLS}

\section{Introduction}

The classical swine HAs underwent minimal antigenic drift during roughly 80 years of circulation in U.S. swine herds. This is largely the result of minimal immune pressure due to the limited life span of farmed swine as well as the continual introduction of young naïve piglets for growing and finishing. ${ }^{62}$ However, once the TRIG cassette formed within the swine viruses, there was a considerable increase in genetic reassortment as well as increased genetic drift. ${ }^{63}$ The increased genetic variation has yet to be fully explained.

Several hypotheses have been proposed for why the TRIG provides this evolutionary burst, but they have not been extensively examined experimentally as of yet. The increased growth kinetics resulting from the optimized polymerase complex could afford greater statistical probability that a virus with beneficial mutations would arise and be capable of becoming the dominant viral species within the population, thus transmitting to new hosts. The RNA dependent RNA polymerase complex is inherently inaccurate during replication, so more virus progeny are produced increasing the probability of successful variants. Another possibility is that the TRIG NS provides an initial growth advantage for the virus by greater suppression of the host interferon response (P. Thomas, personal communication, October 13, 2010). This early burst of replication may provide an opportunity for increased viral variants, some of which may have advantageous mutations. Where more research is needed, recent computational modeling reveals that viruses containing the TRIG cassette as well as the TRIG NS appear to undergo accelerated nucleotide substitution when compared to viruses that lack

these internal genes. ${ }^{83}$ The epidemiologic data and phylogenetic analysis suggests there is a strong relationship between the TRIG cassette and NS leading to increased evolution of the HA and the virus as a whole. The increased propensity for reassortment and the evolutionary burst could have significant implications for influenza evolution, host adaption, and human health.

The increased promiscuity of the TRIG polymerase complex increases the possibility of incorporation of novel HAs on the TRIG backbone as well as the ability to more readily adapt to a new host. This has important implications for agricultural health especially if more virulent viruses are able to reassort with the TRIG and transmit among the pig population. This scenario also poses serious implications for public health. With the emergence of the TRIG in the human population during the $2009 \mathrm{H} 1 \mathrm{~N} 1$ pandemic, the opportunities of reassortment with novel avian and highly pathogenic avian HAs has increased. Along with the risk that these novel HAs can more readily adapt to the human host receptors raising the likelihood for sustained transmission. Additionally recent studies have indicated that as few as five mutations are required for highly pathogenic H5N1 viruses to transmit via aerosol contact between ferrets. ${ }^{84,85}$ The evolutionary characteristics of the TRIG cassette and TRIG NS need to be further investigated in order 
to better understand how influenza viruses will continue to evolve and the risks posed to swine and human health.

\section{Material and Methods}

\section{Viruses}

Multiple reverse genetics viruses were rescued based around the RG-MN/99 classical swine $\mathrm{H} 1 \mathrm{~N} 1$ virus, the RG-NC/02 triple reassortant $\mathrm{H} 1 \mathrm{~N} 1$ virus, and TX/96 human $\mathrm{H} 3 \mathrm{~N} 2$ virus. The RG viruses were generated using the dual promoter eight plasmid system as outlined in Figure 2-1. ${ }^{70}$ The rescued virus supernatants were then injected into 10 day old embryonated chicken eggs and incubated at $35^{\circ} \mathrm{C}$ for 48 hours. The allantoic fluid is harvested and re-injected into embryonated chicken eggs for a second passage. The virus was harvested, aliquoted, and stored at $-80^{\circ} \mathrm{C}$. Each vial was only thawed once before use in each experiment. All of the genotypes used for the viral passage experiments are identified in Table 3-1.

\section{Viral Passaging in pSRECs}

The pSRECs were grown on collagen coated tissue culture plates to about $80-90 \%$ confluence and the cells were washed with 1X PBS. The HA titer was determined for each virus using $0.5 \%(\mathrm{v} / \mathrm{v})$ turkey red blood cells. Prior to infecting the cells, each virus was diluted to an HA unit of 1 (the minimal amount of virus required to prevent agglutination of red blood cells), in a total of $3 \mathrm{ml}$ of infection media. The pSRECs were then infected with $1 \mathrm{ml}$ of the virus dilution and incubated at $37^{\circ} \mathrm{C}$ with $5 \% \mathrm{CO}_{2}$ for 1 hour. The viral dilutions were then washed from the cells using $1 \mathrm{X}$ PBS and infection media with $0.5 \mu \mathrm{g} / \mathrm{ml}$ TPCK-Trypsin.

The cells were monitored daily for cytopathic effect (CPE). CPE is change in observable cellular morphology resulting from infection or natural cell death. When the cells reached a CPE score of 2-3, the viral supernatant was collected and a $1 \mathrm{ml}$ aliquot was stored at $-80^{\circ} \mathrm{C}$ and the $\mathrm{HA}$ titer was determined using a portion of the remaining volume. The viruses were again diluted to an HA titer of 1 and used to infect a new 80$90 \%$ confluent well of pSRECs. If there was no detectable HA titer, the virus was diluted at 1:8 and this dilution was used for pSREC infection. This process was repeated for a total of 6 viral passages.

\section{Viral Sequencing}

To determine a relative nucleotide substitution rate, the HAs of the cell-1 (C1) passage, egg-1 (E1) passage, and egg-2 (E2) passage of each rescued virus were all sequenced using the MiSeq Illumina platform as described in chapter 3 using the Bioo 
Scientific NEXTflex sequencing kits (catalog number 5140-02). Nucleotide variations were determined using the CLC Genomics Workbench 6.0.1 quality-based variant detection algorithm.

\section{Results}

\section{Viral Passaging in pSRECs}

We observed a decline of HA titers for several viruses over the course of the initial viral passaging experiment. The classical swine virus with the TRIG PB2 and PA showed a gradual decrease from an HA titer of 64 at viral passage (vPx) 2 to a titer of 16 at $\mathrm{vPx} 4$ (Figure 4-1A). This was similar to NC/TX/MN-PB1 which the HA titer had decreased from 64 to 32 in vPx 2 to a titer of 0 by vPx 4 . Numerous viruses resulted in an HA titer of 0 by the fourth passage, including MN/TX, TX/96, MN/TX/NC-NS, and $\mathrm{MN} / \mathrm{TX} / \mathrm{NC}-\mathrm{PB} 1$. The only virus that maintained a relatively stable HA titer was NC/TX with a titer of 64 for all 4 passages. All of the viruses that maintained an HA titer through four passages, had an avian PB2 and/or PA gene segment constellation in the polymerase complex, except for NC/TX/MN-PB1 (Table 4-1).

To confirm that the reduction in HA titer was not a random occurrence, the passaging experiment was repeated and all viruses were passaged 6 times in the pSRECs even if the HA titers dropped below detectable levels. Like the previous experiments, $\mathrm{NC} / \mathrm{TX}$ maintained an HA titer for all 6 passages, although the titers did decrease at vPx 2 and increased to a titer of 128 by vPx 5 (Figure 4-1B). As with the first trial, many of the viruses showed decreasing titers around $\mathrm{vPx} 4$, however, after continuing passaging within the pSRECs, viruses recovered titers including MN/99, MN/TX/NC-NS, MN/TX/NC-PB1, and MN/TX/NC-PA. Despite a similar pattern of HA titer decrease and recovery, only 2 viruses showed this commonality between the $1^{\text {st }}$ and $2^{\text {nd }}$ experiments (Table 4-2). Unexpectedly, $\mathrm{NC} / 02$ showed a decreasing titer through $\mathrm{vPx} 3$ and did not recover.

Surprisingly, when $\mathrm{TCID}_{50}$ titers were determined for all of the viruses from the first experiment, all of the viruses maintained $\mathrm{TCID}_{50}$ titers for all passages except MN/TX/NC-PB1 which had no detectable titer after the $4^{\text {th }}$ passage (Figure 4-2). Even more interesting is that as the HA titers were decreasing up to passage 4 , the infectivity titers were all increasing from passage 3 to 4 .

\section{TRIG NS Evolutionary Burst}

Deep sequencing data of the human $\mathrm{H} 3$ on the classical swine backbone, TRIG backbone, and classical swine with TRIG NS revealed very few nucleotide substitutions. There was one nucleotide substitution identified in the $\mathrm{H} 3$ on the classical swine backbone at position 1179 from the $\mathrm{C} 1$ to the $\mathrm{E} 1$ passage (Figure 4-3A and Table 4-3). 


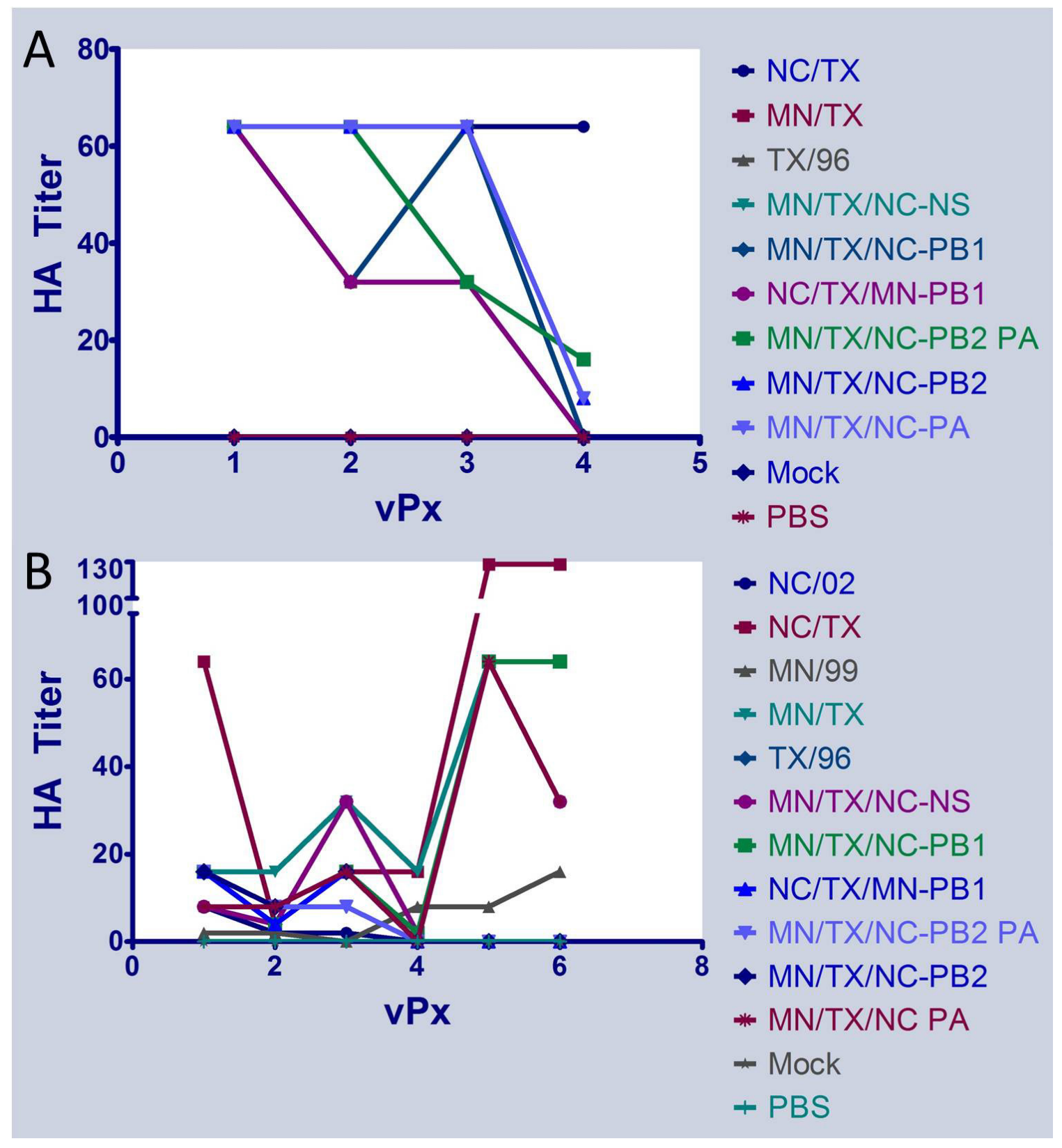

Figure 4-1: HA titers of viruses during passaging within pSRECs

A) Shows HA titer over the course of viral passages in the pSRECs up the passage 4. B) Shows HA titers for a $2^{\text {nd }}$ experiment over the course of 6 viral passages in the pSRECs. 
Table 4-1: Viral genotypes and gene constellations for pSREC passage

\begin{tabular}{|c|c|c|c|c|c|c|c|c|}
\hline Virus & PB2 & PB1 & PA & HA & NP & NA & $\mathbf{M}$ & NS \\
\hline NC/TX & $\mathrm{NC}$ & $\mathrm{NC}$ & $\mathrm{NC}$ & $\mathrm{TX}$ & $\mathrm{NC}$ & $\mathrm{TX}$ & $\mathrm{NC}$ & $\mathrm{NC}$ \\
\hline MN/TX & $\mathrm{MN}$ & $\mathrm{MN}$ & $\mathrm{MN}$ & $\mathrm{TX}$ & $\mathrm{MN}$ & $\mathrm{TX}$ & $\mathrm{MN}$ & $\mathrm{MN}$ \\
\hline TX/96 & $\mathrm{TX}$ & $\mathrm{TX}$ & TX & $\mathrm{TX}$ & TX & $\mathrm{TX}$ & $\mathrm{TX}$ & TX \\
\hline $\begin{array}{c}\mathrm{MN} / \mathrm{TX} / \mathrm{NC}- \\
\mathrm{NS}\end{array}$ & $\mathrm{MN}$ & $\mathrm{MN}$ & $\mathrm{MN}$ & TX & $\mathrm{MN}$ & $\mathrm{TX}$ & $\mathrm{MN}$ & $\mathrm{NC}$ \\
\hline $\begin{array}{c}\mathrm{MN} / \mathrm{TX} / \mathrm{NC}- \\
\mathrm{PB} 1\end{array}$ & $\mathrm{MN}$ & $\mathrm{NC}$ & $\mathrm{MN}$ & TX & $\mathrm{MN}$ & $\mathrm{TX}$ & $\mathrm{MN}$ & $\mathrm{MN}$ \\
\hline $\begin{array}{c}\text { NC/TX/MN- } \\
\text { PB1 }\end{array}$ & $\mathrm{NC}$ & $\mathrm{MN}$ & $\mathrm{NC}$ & $\mathrm{TX}$ & $\mathrm{NC}$ & $\mathrm{TX}$ & $\mathrm{NC}$ & $\mathrm{NC}$ \\
\hline $\begin{array}{c}\mathrm{MN} / \mathrm{TX} / \mathrm{NC}- \\
\text { PB2 PA }\end{array}$ & $\mathrm{NC}$ & $\mathrm{MN}$ & $\mathrm{NC}$ & $\mathrm{TX}$ & $\mathrm{MN}$ & $\mathrm{TX}$ & $\mathrm{MN}$ & $\mathrm{MN}$ \\
\hline $\begin{array}{c}\mathrm{MN} / \mathrm{TX} / \mathrm{NC}- \\
\text { PB2 }\end{array}$ & $\mathrm{NC}$ & $\mathrm{MN}$ & $\mathrm{MN}$ & $\mathrm{TX}$ & $\mathrm{MN}$ & $\mathrm{TX}$ & $\mathrm{MN}$ & $\mathrm{MN}$ \\
\hline $\begin{array}{c}\mathrm{MN} / \mathrm{TX} / \mathrm{NC}- \\
\mathrm{PA}\end{array}$ & $\mathrm{MN}$ & $\mathrm{MN}$ & $\mathrm{NC}$ & $\mathrm{TX}$ & $\mathrm{MN}$ & $\mathrm{TX}$ & $\mathrm{MN}$ & $\mathrm{MN}$ \\
\hline
\end{tabular}

The orange boxes symbolize gene segments sourced from the TRIG virus NC/02, Blue boxes indicate gene segments of classical swine lineage and the green boxes are genes from the human H3N2 virus, TX/96. The yellow highlighted RG viruses maintained HA titers through the 4 pSREC passages. The viruses with no color had an HA titer crash with no recovery. 
Table 4-2: Viral genotypes and gene constellations for pSREC passaging after 6 viral passages

\begin{tabular}{|c|c|c|c|c|c|c|c|c|}
\hline Virus & PB2 & PB1 & PA & HA & NP & NA & $\mathbf{M}$ & NS \\
\hline $\mathrm{NC} / 02$ & $\mathrm{NC}$ & $\mathrm{NC}$ & $\mathrm{NC}$ & $\mathrm{NC}$ & $\mathrm{NC}$ & $\mathrm{NC}$ & $\mathrm{NC}$ & $\mathrm{NC}$ \\
\hline NC/TX & $\mathrm{NC}$ & $\mathrm{NC}$ & $\mathrm{NC}$ & TX & $\mathrm{NC}$ & $\mathrm{TX}$ & $\mathrm{NC}$ & $\mathrm{NC}$ \\
\hline MN/99 & $\mathrm{MN}$ & $\mathrm{MN}$ & $\mathrm{MN}$ & $\mathrm{MN}$ & $\mathrm{MN}$ & $\mathrm{MN}$ & $\mathrm{MN}$ & $\mathrm{MN}$ \\
\hline MN/TX & $\mathrm{MN}$ & MN & $\mathrm{MN}$ & TX & $\mathrm{MN}$ & TX & $\mathrm{MN}$ & MN \\
\hline TX/96 & TX & TX & TX & TX & TX & TX & TX & TX \\
\hline $\begin{array}{c}\mathrm{MN} / \mathrm{TX} / \mathrm{NC}- \\
\mathrm{NS}\end{array}$ & $\mathrm{MN}$ & $\mathrm{MN}$ & $\mathrm{MN}$ & $\mathrm{TX}$ & $\mathrm{MN}$ & $\mathrm{TX}$ & $\mathrm{MN}$ & $\mathrm{NC}$ \\
\hline $\begin{array}{c}\text { MN/TX/NC- } \\
\text { PB1 }\end{array}$ & $\mathrm{MN}$ & $\mathrm{NC}$ & $\mathrm{MN}$ & TX & $\mathrm{MN}$ & $\mathrm{TX}$ & $\mathrm{MN}$ & MN \\
\hline $\begin{array}{c}\text { NC/TX/MN- } \\
\text { PB1 }\end{array}$ & $\mathrm{NC}$ & $\mathrm{MN}$ & $\mathrm{NC}$ & TX & $\mathrm{NC}$ & $\mathrm{TX}$ & $\mathrm{NC}$ & $\mathrm{NC}$ \\
\hline $\begin{array}{c}\text { MN/TX/NC- } \\
\text { PB2 PA }\end{array}$ & $\mathrm{NC}$ & $\mathrm{MN}$ & $\mathrm{NC}$ & TX & $\mathrm{MN}$ & TX & $\mathrm{MN}$ & $\mathrm{MN}$ \\
\hline $\begin{array}{c}\text { MN/TX/NC- } \\
\text { PB2 }\end{array}$ & $\mathrm{NC}$ & $\mathrm{MN}$ & $\mathrm{MN}$ & $\mathrm{TX}$ & $\mathrm{MN}$ & $\mathrm{TX}$ & $\mathrm{MN}$ & $\mathrm{MN}$ \\
\hline $\begin{array}{c}\text { MN/TX/NC- } \\
\text { PA }\end{array}$ & $\mathrm{MN}$ & $\mathrm{MN}$ & $\mathrm{NC}$ & TX & $\mathrm{MN}$ & $\mathrm{TX}$ & $\mathrm{MN}$ & $\mathrm{MN}$ \\
\hline
\end{tabular}

The orange boxes symbolize gene segments sourced from the TRIG virus NC/02, Blue boxes indicate gene segments of classical swine lineage and the green boxes are genes from the human $\mathrm{H} 3 \mathrm{~N} 2$ virus, TX/96. The yellow highlighted RG viruses maintained HA titers through the $6 \mathrm{pSREC}$ passages. The viruses with no color had an HA titer crash with no recovery. 


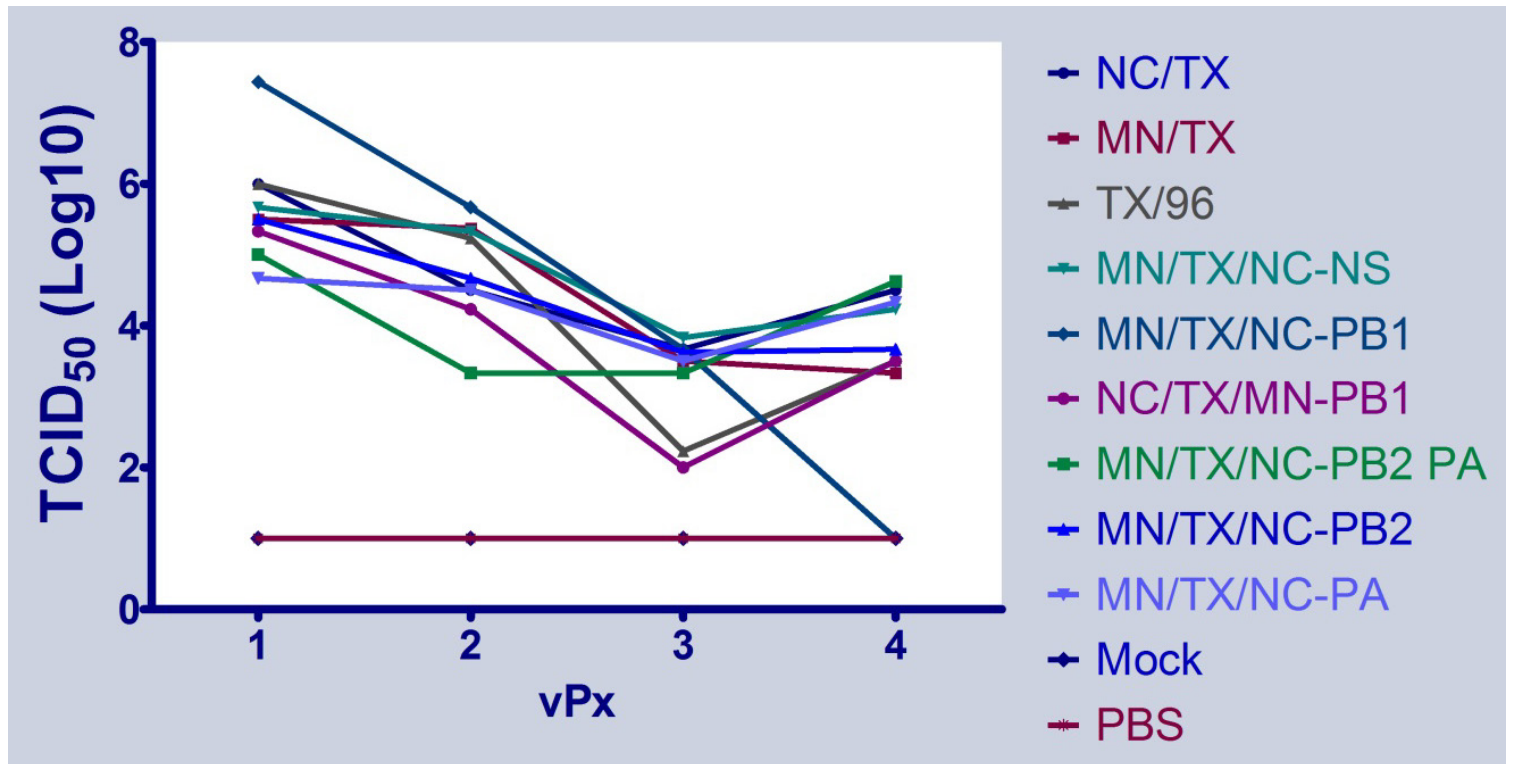

Figure 4-2: Infectivity titers of the RG viruses after serial passaging in pSRECs $\mathrm{TCID}_{50}$ titers determined for RG viruses over the course of 4 passages in pSRECS. 
Figure 4-3: Comparison of quality-based variant detection results between MN/TX, NC/TX, and MN/TX/NC-NS

A) Nucleotide variant detection for HA of MN/TX passage $\mathrm{C} 1$ through E2. The blue graph indicates HA segment read coverage and the orange bar graph identifies location and prevalence of variants. B) Nucleotide variant detection for HA of NC/TX passage $\mathrm{C} 1$ through E2. The blue graph indicates HA segment read coverage and the orange bar graph identifies location and prevalence of variants. C) Nucleotide variant detection for $\mathrm{HA}$ of MN/TX/NC-NS passage $\mathrm{C} 1$ through E2. The blue graph indicates HA segment read coverage and the orange bar graph identifies location and prevalence of variants. The 2 common variants identified on the 5' and 3' ends of all data sets include mutations derived from the universal primers. 


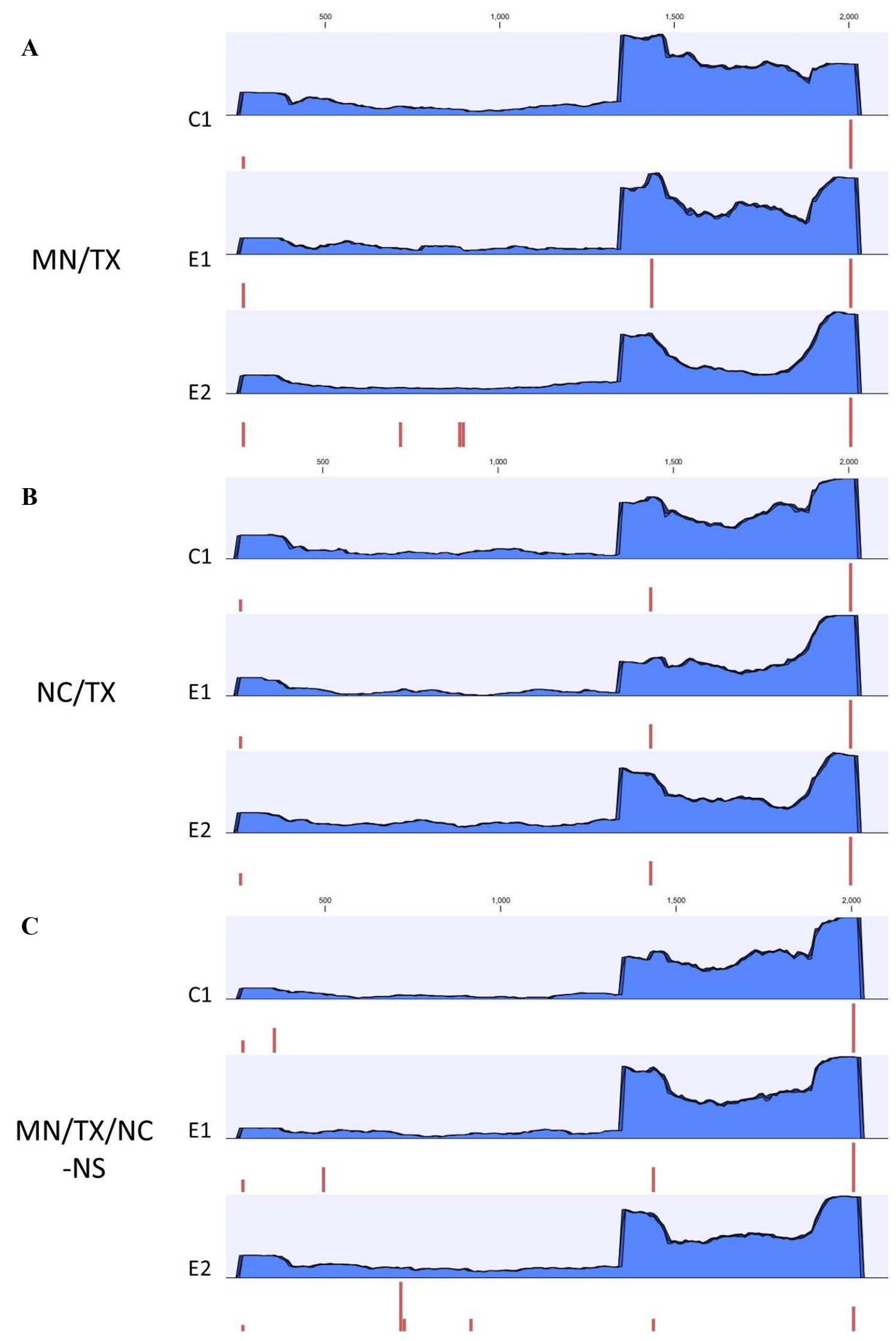


Table 4-3: Nucleotide position and frequency of detected variants

\begin{tabular}{|c|c|c|c|c|c|c|}
\hline \multirow[b]{2}{*}{$\begin{array}{c}\text { Virus } \\
\text { passage }\end{array}$} & \multicolumn{2}{|c|}{ MN/TX } & \multicolumn{2}{|c|}{$\mathrm{NC} / \mathrm{TX}$} & \multicolumn{2}{|c|}{ MN/TX/NC-NS } \\
\hline & $\begin{array}{c}\text { Nucleotide } \\
\text { position }\end{array}$ & $\begin{array}{l}\text { Percent of } \\
\text { population }\end{array}$ & $\begin{array}{c}\text { Nucleotide } \\
\text { position }\end{array}$ & $\begin{array}{l}\text { Percent of } \\
\text { population }\end{array}$ & $\begin{array}{c}\text { Nucleotide } \\
\text { position }\end{array}$ & $\begin{array}{l}\text { Percent of } \\
\text { population }\end{array}$ \\
\hline $\mathrm{C} 1$ & & & 1177 & $6.33 \%$ & 98 & $13.33 \%$ \\
\hline E1 & 1179 & $12.66 \%$ & 1177 & $7.55 \%$ & $\begin{array}{c}233 \\
1177\end{array}$ & $\begin{array}{l}9.09 \% \\
6.19 \%\end{array}$ \\
\hline E2 & $\begin{array}{l}462 \\
624 \\
637\end{array}$ & $\begin{array}{c}16.67 \% \\
8 \% \\
21.74 \%\end{array}$ & 1177 & $6.06 \%$ & $\begin{array}{c}457 \\
458 \\
462 \\
463 \\
660 \\
1177\end{array}$ & $\begin{array}{c}29.03 \% \\
38.71 \% \\
8 \% \\
8.33 \% \\
9.52 \% \\
5.85 \%\end{array}$ \\
\hline
\end{tabular}


This mutant made up $12.66 \%$ of the population but was undetectable from the viral population in the E2 passage. However, the E2 passage resulted in 3 new nucleotide mutations compared to the $\mathrm{C} 1$ passage at positions $462(16.67 \%), 624(8 \%)$, and 637 $(21.74 \%)$.

Despite the presence of the TRIG NS in the NC/TX virus, through all three virus passages, only 1 variant was detected (Figure 4-3B). This variant was detected at nucleotide position 1177. This variant is identified in all 3 passages; however it only occurs at relatively low frequency, ranging $7.55 \%$ at passage E1 to $6.06 \%$ at passage E2 (Table 4-3).

Interestingly, when the TRIG NS is rescued on the classical swine backbone and human $\mathrm{H} 3 \mathrm{~N} 2$ surface proteins, there seem to be an increased number of nucleotide mutations. In the $\mathrm{C} 1$ passage, 1 variant was detected at position $98(13.33 \%)$ as seen in

Figure 4-3C. By passage E1 the nucleotide variant at position 98 was no longer detected in the population and was replaced by 2 other variants at positions $233(9.09 \%)$ and 1177 $(6.19 \%)$. In the E2 passage, the variant at 1177 was maintained in the population at $5.85 \%$ and 5 additional variants were detected. The first 4 variants were detected close together at positions $457(29.03 \%), 458$ (38.71\%), $462(8 \%)$, and $463(8.33 \%)$. The final variant identified made up $9.52 \%$ of the population at position 660 (Table 4-3).

\section{Discussion}

\section{Viral Passages in pSRECs Do Not Mirror Nature}

The passaging experiments in pSRECs were conducted to determine evolutionary rates, but some viruses did not have the ability to maintain productive infections through multiple passages. However, further investigation revealed that although the HA titers had become undetectable, most of the TCID $_{50}$ titers were maintained albeit they were decreasing through passage 3 . All of the viruses except MN/TX/NC-PB1 showed increasing titers from passage 3 to 4 . Coincidentally, MN/TX/NC-PB1 also failed to transmit in the pig experiments. However, when the passaging experiment was repeated, several viruses showed unexpected HA titer crashes including NC/02, MN/TX/NC-PB2 $\mathrm{PA}$, and MN/TX/NC-PB2. These were unexpected because $\mathrm{NC} / 02$ has proven to be successful in swine and MN/TX/NC-PB2 PA and MN/TX/NC-PB2 were able to maintain HA titers in the initial experiment. Despite these inconsistencies, the overall HA titer patterns are similar between both experiments. The titers in general seem to continue to decrease up to vPx 4 and then in the second experiment many HA titers recover. This could be an indication of the viruses switching receptor specificities. All of the viruses used were previously passaged twice in eggs to obtain sufficient viral titers and volumes for experiments. When used in the pSRECs, the viruses may need to adapt back to the swine receptors. 


\section{The TRIG NS Does Cause an Evolutionary Burst on the Classical Swine Backbone}

Deep sequencing of the TX/96 HA on several different backbones revealed different nucleotide substitutions. The NC/TX appeared the most stable with a single nucleotide substitution, at nucleotide position 1177 that appeared in all 3 passages but remained a relatively small proportion of the population despite being maintained. This could likely be a complimentary mutation which is matched with one or more mutations in another segment(s). Interestingly, the nonsynonymous substitution at 1177 or nearby at 1179 appeared in the other viruses as well. The MN/TX virus had 4 nucleotide variants over the course of the 3 passages suggesting that the virus is more prone to mutation than $\mathrm{NC} / \mathrm{TX}$. This is further supported in that the nucleotide substitution in the E1 passage becomes undetectable following the E2 passage. These multiple changes indicate a higher nucleotide substitution rate, but a larger sample size with more passages would be required to confirm. Finally, MN/TX/NC-NS showed the most nucleotide substitutions in the TX HA. Through the course of the 3 passages there were 6 total nucleotide variants in the HA segment. Most of these cause amino acid substitutions in the globular head around the receptor binding site. This indicates that there is greater instability in the $\mathrm{MN} / \mathrm{TX} / \mathrm{NC}-\mathrm{NS}$ virus compared to the other 2 viruses. But, if it was solely attributed to the TRIG NS, then an increased number of substitutions should have been detected in the HA of NC/TX. So, the greater instability in the HA of MN/TX/NC-NS could be the result of an additional foreign segment. This experiment is largely limited to the number of passages as well as sequencing limitations. In order to reduce sequencing inaccuracies, the threshold for variant detection needs to be set high enough to eliminate background substitutions. This could potentially mask the detection of many other minor variants. The study also needs an increased number of segments to be sequenced to determine if the genetic instability is observed in all of the gene segments and try to identify complimentary mutations.

\section{Conclusions}

Initial data suggested that the classical swine virus may not have reassorted in nature because transmission could not be sustained in swine. However, this trend was not observed in the later experiments described in this chapter. It is possible that the experimental passages were not continued long enough for all viruses to reach sufficient concentration to be detected by the HA assay. The variability of the primary cell model may also lead to the viral titer crashes observed.

Preliminary studies also support the role of the TRIG NS in viral evolution. However, it cannot be excluded that the additional reassorted gene segment is responsible for the increased nucleotide substitutions rather than the TRIG NS itself. Many factors could be responsible for the increased nucleotide substitution frequencies; however, this study provides a new technique that can be used to study viral evolution through the detection of minor variants. 


\section{CHAPTER 5. GENERAL DISCUSSION, CONCLUSIONS, AND FUTURE DIRECTIONS}

Swine have often been postulated as the primary mixing vessel for the generation of pandemic viruses because they are a susceptible host for both avian and mammalian influenza viruses. However, there is no direct link between pigs and the pandemic viruses from 1918, 1957, and 1968. Prior to the $2009 \mathrm{H} 1 \mathrm{~N} 1$ pandemic, the specific pandemic genotype had not been detected or isolated from swine but following the pandemic, there have been numerous viruses isolated from swine with the pandemic genotype. There have also been numerous reassortant viruses isolated from swine with the TRIG cassette. Swine viruses containing the TRIG cassette have shown increased viral diversity since the TRIG introduction around 1998. This is in stark contrast to the swine virus stability observed for the roughly 80 years prior to the TRIG formation. This study set out to determine what virologic mechanisms are responsible for the promiscuity of the TRIG or what restrictions are present in the classical swine viruses that prevented reassortment.

The data presented in this dissertation suggests that there is no distinct virologic factor that prevented the classical swine viruses from reassorting compared to the TRIG viruses. As found in many of the experiments, there were trends to suggest that MN/99 was slightly less adept at reassorting when compared to the $\mathrm{NC} / 02$. The numerous small differences observed do suggest that MN/99 cannot reassort as readily as NC/02. This phenomenon can also be explained by the transition from traditional pig farming to intensive farming that occurred starting in the late 1980s to the late 1990s. Traditional pig farming entailed relatively small farms which raised pigs from birth to market with limited movement between different herds. Intensive farming consists of very large farms with specialized functions. The pigs are farrowed and weaned at one farm and then transferred to another farm for growing and in some instances transferred again for finishing prior to being sent to market. Intensive farming leads to significantly more opportunities for pigs from different farms to interact at the different stages of growth, and these interactions increase the possibility for different influenza viruses to transmit among the herds and reassort.

The data shows that the classical swine virus and TRIG virus are able to superinfect cells with the human $\mathrm{H} 3 \mathrm{~N} 2$ virus, albeit, the classical swine virus does show a reduced number of superinfected cells. The results also indicate that the classical swine viruses are capable of reassortment similarly to the TRIG virus however, when the classical virus was grown with gene segments from the TRIG, it is slightly attenuated. This could be explained by the previous 80 years of evolution. These classical swine viruses were stable for so long because they had optimized their genetic composition. Ultimately, the generation of the TRIG resulted in viruses with a significant growth advantage over the classical swine viruses resulting in its ability to supplant the classical viruses as the dominant viruses in U.S. swine herds.

Unexpectedly, not all of the cells were infected during the flow cytometry

superinfection experiment. This indicates that there are additional mechanisms preventing 
cellular infection that could also be preventing superinfection other than NA expression. It is possible that the uninfected cells are in an IFN induced antiviral state; however, MDCK cells do not produce a very robust IFN response. It is also possible that DI particles are being produced by these viruses and these interfering particles are reducing the viral efficiency to infect all of the cells. To test these scenarios, the experiment should be repeated with IFN incompetent cells to prevent naïve cells from entering an antiviral state. Additionally, a fluorescent in situ hybridization assay can be performed to identify if the uninfected cells contain any viral segments. This would provide evidence of DI particle interference by entering the cell but not establishing a productive infection. The viral supernatant could also be used for next generation sequencing to identify if any viral populations contain deletions leading to DI particle formation.

None of the data suggested that the TRIG was more capable of reassorting than the classical swine virus, however, the in vitro reassortment data shows that the reassortants generated with the TRIG virus tend to be more fit than those generated with the classical swine virus. Despite this, there were unexpected results. The most prevalent viral genotype detected (34.4\%) between the TRIG and $\mathrm{H} 3 \mathrm{~N} 2$ virus was an $\mathrm{H} 3 \mathrm{~N} 1$ virus on the TRIG backbone. The first H3N1 viruses were isolated from swine around 2004 and the prevalence has been very low. This is contradictory to what is seen in vitro. This suggests that the H3N1 genotype is a favorable gene composition; however, the virus may have difficulty transmitting. To determine the optimal genotypes for infectivity and transmission, the in vitro reassortment viral supernatant should be used to inoculate naïve pigs with contacts. The results would suggest what viral genotypes are optimal for infection and transmission. Additionally, it will indicate if the H3N1 viral genotype is hindered in its ability to transmit because a large percentage of the inoculating virus will consist of this $\mathrm{H} 3 \mathrm{~N} 1$ virus.

Another major finding of this project is the role that the internal gene segments play in viral transmission. The in vivo transmission experiment clearly demonstrates that the TX/96 virus is not capable of transmitting in pigs, but when the HA and NA from the $\mathrm{TX} / 96$ virus are rescued on the swine virus backbones, these reverse genetics $6+2$ viruses are capable of transmitting among pigs. This could have significant consequences if the viral backbone can also allow avian HA and NA combinations to infect and transmit in mammalian hosts, especially because pigs and humans are immunologically naïve to many subtypes of influenza viruses. The increased transmissibility of different HA and NA gene segments needs to be further explored, especially by rescuing avian viral surface glycoproteins on the different swine virus backbones. Additionally, the viruses that are capable of transmission can be sequenced to compare whether the avian HAs mutate to preferentially bind to mammalian receptors, or if the internal gene segments can overcome this barrier.

Although this study shows the increased fitness of viruses with the TRIG cassette compared to viruses based on the classical swine backbone, it is narrowed by the use of mammalian adapted viral surface glycoproteins. It will be important to further study the ability of the TRIG to reassort with avian lineage HA and NA gene segments. Additionally, it will be important to look at the ability of these viruses to adapt to 
mammalian type receptors. Some preliminary data suggests that the TRIG virus with novel glycoproteins is relatively stable, but this needs to be further analyzed due to the very limited number of viruses sampled. This would also benefit from analyzing the number of changes that occur in avian origin HA and NA gene segments on the different backbone in a mammalian model. This data will help to better model the adaptation rate if the avian HA and NA glycoproteins were to cross the species boundary on the TRIG backbone. These experiments also demonstrate that the incorporation of the TRIG NS does increase the number of nucleotide changes in the HA gene segment around the receptor binding domain compared to not having a new gene segment. The initial hypothesis was that the TRIG NS was more efficient at inhibiting the IFN response leading to increased viral replication and diversity. This has since been shown to not be correct and that the TRIG virus evades the innate response by some other mechanism. Due to this information and the observed results, I believe that the increased nucleotide substitution rate is the result of a foreign gene segment rather than specifically the TRIG NS. The phylogenetic data shows an evolutionary burst, but all of the viruses undergoing the burst are identified with at least one gene segment from a different virus. If a different gene segment other than the TRIG NS was rescued in the MN/TX virus, it would also likely cause increased nucleotide substitutions as well. The introduction of these genetically different gene segments likely causes a disruption of certain protein-protein interactions leading to destabilization of the genome. It remains unclear as to whether this destabilization is spread throughout the genome equally or if there are particular proteins that undergo increased nucleotide substitution rates. Further experiments should look at substitutions throughout the genome when different gene segments are introduced to pinpoint if any of the 8 segments plays more of a role in the observed evolutionary burst as well as to determine if the whole influenza virus genome undergoes the evolutionary burst.

Viruses with the TRIG cassette not only have become the predominant viral genotypes in swine, but with the 2009 pandemic, the TRIG backbone has become one of the predominant viral genotypes in humans as well. This is of particular concern, because the TRIG has shown that it is capable of reassorting frequently and it has acquired novel HA and NA gene segments in its relatively short evolutionary history. Additionally, data presented here suggests that host restriction can be overcome by the internal gene cassette, whether it is based on the classical swine backbone or the TRIG cassette. With the current dominance of the TRIG in viruses isolated from both swine and humans, the possibility of reassorting with novel surface glycoproteins is greatly enhanced.

Not only does the TRIG show a promiscuous history, but data in this study show that it has the ability to rapidly establish an infection and transmit rapidly. This could easily explain why the 2009 pandemic virus was able to circulate globally in such a short period of time. This characteristic poses a serious problem for agricultural health and public health. If it does acquire novel viral glycoproteins of increased pathogenicity, it will be able to infect a larger proportion of the population prior to its detection and control which could result in significantly more morbidity and mortality than slower growing viruses. 
Finally, this study demonstrates that host restriction is clearly a polygenic characteristic that needs to be further explored. The TRIG provides a backbone that has the proven ability to reassort and grow with HA and NA surface proteins from different lineage viruses. It has also proven that it can infect and rapidly transmit in the human and swine populations. This provides an ideal combination for further generation of novel genotypes that can enter the human population, quickly adapt, and rapidly circulate. This study provides the foundation of how the TRIG backbone has become so dominant in influenza viruses today, but suggests that much more work needs to be conducted to identify what unique traits give it its evolutionary advantage. This study also demonstrates that although the viruses have some differences in their abilities to reassort, the ecology of the hosts also plays a significant role in viral reassortment and evolution. These traits will help drive increased influenza evolution in humans and swine throughout the U.S. and the world. Therefore, influenza A surveillance in both swine and humans needs to be continued to identify the emergence of novel viruses before they become a public health and agricultural problem. 


\section{LIST OF REFERENCES}

1 A revision of the system of nomenclature for influenza viruses: a WHO memorandum. Bull World Health Organ 58, 585-591 (1980).

2 Fouchier, R. A. et al. Characterization of a novel influenza A virus hemagglutinin subtype (H16) obtained from black-headed gulls. J Virol 79, 2814-2822, doi:10.1128/JVI.79.5.2814-2822.2005 (2005).

3 Rohm, C., Zhou, N., Suss, J., Mackenzie, J. \& Webster, R. G. Characterization of a novel influenza hemagglutinin, H15: criteria for determination of influenza A subtypes. Virology 217, 508-516, doi:10.1006/viro.1996.0145 (1996).

4 Kawaoka, Y., Yamnikova, S., Chambers, T. M., Lvov, D. K. \& Webster, R. G. Molecular characterization of a new hemagglutinin, subtype H14, of influenza A virus. Virology 179, 759-767 (1990).

5 Hinshaw, V. S. et al. Antigenic and genetic characterization of a novel hemagglutinin subtype of influenza A viruses from gulls. $J$ Virol 42, 865-872 (1982).

6 Webster, R. G., Bean, W. J., Gorman, O. T., Chambers, T. M. \& Kawaoka, Y. Evolution and ecology of influenza A viruses. Microbiol Rev 56, 152-179 (1992).

7 Palese, P., Shaw, M.L. in Fields Virology Vol. 2 (ed D.M. Knipe, Howley, P.M.) Ch. 47, 1645 - 1689 (Lippincott Williams \& Wilkins, a Wolters Kluwer business, 2007).

8 Compans, R. W., Meier-Ewert, H. \& Palese, P. Assembly of lipid-containing viruses. J Supramol Struct 2, 496-511, doi:10.1002/jss.400020234 (1974).

9 Gibbs, J. S., Malide, D., Hornung, F., Bennink, J. R. \& Yewdell, J. W. The influenza A virus PB1-F2 protein targets the inner mitochondrial membrane via a predicted basic amphipathic helix that disrupts mitochondrial function. J Virol 77, 7214-7224 (2003).

10 Connor, R. J., Kawaoka, Y., Webster, R. G. \& Paulson, J. C. Receptor specificity in human, avian, and equine $\mathrm{H} 2$ and $\mathrm{H} 3$ influenza virus isolates. Virology 205, 1723, doi:10.1006/viro.1994.1615 (1994).

11 Rogers, G. N. \& Paulson, J. C. Receptor determinants of human and animal influenza virus isolates: differences in receptor specificity of the $\mathrm{H} 3$ hemagglutinin based on species of origin. Virology 127, 361-373 (1983).

12 Gong, J., Xu, W. \& Zhang, J. Structure and functions of influenza virus neuraminidase. Current medicinal chemistry 14, 113-122 (2007). 
13 Gonzalez, S., Zurcher, T. \& Ortin, J. Identification of two separate domains in the influenza virus PB1 protein involved in the interaction with the PB2 and PA subunits: a model for the viral RNA polymerase structure. Nucleic Acids Res 24, 4456-4463 (1996).

14 Cianci, C., Tiley, L. \& Krystal, M. Differential activation of the influenza virus polymerase via template RNA binding. J Virol 69, 3995-3999 (1995).

15 Li, M. L., Ramirez, B. C. \& Krug, R. M. RNA-dependent activation of primer RNA production by influenza virus polymerase: different regions of the same protein subunit constitute the two required RNA-binding sites. The EMBO journal 17, 5844-5852, doi:10.1093/emboj/17.19.5844 (1998).

16 Jagger, B. W. et al. An overlapping protein-coding region in influenza A virus segment 3 modulates the host response. Science 337, 199-204, doi:10.1126/science.1222213 (2012).

17 Perales, B. et al. The replication activity of influenza virus polymerase is linked to the capacity of the PA subunit to induce proteolysis. J Virol 74, 1307-1312 (2000).

18 Huarte, M., Sanz-Ezquerro, J. J., Roncal, F., Ortin, J. \& Nieto, A. PA subunit from influenza virus polymerase complex interacts with a cellular protein with homology to a family of transcriptional activators. J Virol 75, 8597-8604 (2001).

19 Elton, D., Medcalf, L., Bishop, K., Harrison, D. \& Digard, P. Identification of amino acid residues of influenza virus nucleoprotein essential for RNA binding. $J$ Virol 73, 7357-7367 (1999).

20 Biswas, S. K., Boutz, P. L. \& Nayak, D. P. Influenza virus nucleoprotein interacts with influenza virus polymerase proteins. J Virol 72, 5493-5501 (1998).

21 Area, E. et al. 3D structure of the influenza virus polymerase complex: localization of subunit domains. Proc Natl Acad Sci U S A 101, 308-313, doi:10.1073/pnas.0307127101 (2004).

22 Ruigrok, R. W. et al. Membrane interaction of influenza virus M1 protein. Virology 267, 289-298, doi:10.1006/viro.1999.0134 (2000).

23 Yasuda, J., Nakada, S., Kato, A., Toyoda, T. \& Ishihama, A. Molecular assembly of influenza virus: association of the NS2 protein with virion matrix. Virology 196, 249-255, doi:10.1006/viro.1993.1473 (1993).

24 Gomez-Puertas, P., Albo, C., Perez-Pastrana, E., Vivo, A. \& Portela, A. Influenza virus matrix protein is the major driving force in virus budding. $J$ Virol 74, 11538 11547 (2000). 
25 Pinto, L. H., Holsinger, L. J. \& Lamb, R. A. Influenza virus M2 protein has ion channel activity. Cell 69, 517-528 (1992).

26 Fontana, J., Cardone, G., Heymann, J. B., Winkler, D. C. \& Steven, A. C. Structural changes in Influenza virus at low $\mathrm{pH}$ characterized by cryo-electron tomography. J Virol 86, 2919-2929, doi:10.1128/JVI.06698-11 (2012).

27 Sakaguchi, T., Leser, G. P. \& Lamb, R. A. The ion channel activity of the influenza virus M2 protein affects transport through the Golgi apparatus. J Cell Biol 133, 733-747 (1996).

28 Chien, C. Y. et al. Biophysical characterization of the complex between doublestranded RNA and the N-terminal domain of the NS1 protein from influenza A virus: evidence for a novel RNA-binding mode. Biochemistry 43, 1950-1962, doi:10.1021/bi030176o (2004).

29 Talon, J. et al. Activation of interferon regulatory factor 3 is inhibited by the influenza A virus NS1 protein. J Virol 74, 7989-7996 (2000).

30 Wang, X. et al. Influenza A virus NS1 protein prevents activation of NF-kappaB and induction of alpha/beta interferon. $J$ Virol 74, 11566-11573 (2000).

31 Hale, B. G., Randall, R. E., Ortin, J. \& Jackson, D. The multifunctional NS1 protein of influenza A viruses. J Gen Virol 89, 2359-2376, doi:10.1099/vir.0.2008/004606-0 (2008).

32 Akarsu, H. et al. Crystal structure of the M1 protein-binding domain of the influenza A virus nuclear export protein (NEP/NS2). The EMBO journal 22, 4646-4655, doi:10.1093/emboj/cdg449 (2003).

33 Neumann, G., Hughes, M. T. \& Kawaoka, Y. Influenza A virus NS2 protein mediates vRNP nuclear export through NES-independent interaction with hCRM1. The EMBO journal 19, 6751-6758, doi:10.1093/emboj/19.24.6751 (2000).

34 Fornerod, M., Ohno, M., Yoshida, M. \& Mattaj, I. W. CRM1 is an export receptor for leucine-rich nuclear export signals. Cell 90, 1051-1060 (1997).

35 Squires, B. et al. BioHealthBase: informatics support in the elucidation of influenza virus host pathogen interactions and virulence. Nucleic Acids Res 36, D497-503, doi:10.1093/nar/gkm905 (2008).

36 Ludwig, S. et al. European swine virus as a possible source for the next influenza pandemic? Virology 212, 555-561, doi:10.1006/viro.1995.1513 (1995).

37 Kilbourne, E. D. Influenza pandemics of the 20th century. Emerg Infect Dis 12, 914, doi:10.3201/eid1201.051254 (2006). 
38 Fanning, T. G. et al. 1917 avian influenza virus sequences suggest that the 1918 pandemic virus did not acquire its hemagglutinin directly from birds. $J$ Virol 76, 7860-7862 (2002).

39 Smith, G. J. et al. Dating the emergence of pandemic influenza viruses. Proc Natl Acad Sci U S A 106, 11709-11712, doi:10.1073/pnas.0904991106 (2009).

40 Reid, A. H., Fanning, T. G., Hultin, J. V. \& Taubenberger, J. K. Origin and evolution of the 1918 "Spanish" influenza virus hemagglutinin gene. Proc Natl Acad Sci U S A 96, 1651-1656 (1999).

41 Koen, J. A practical method for field diagnosis of swine diseases. American Journal of Veterinary medicine, 468-470 (1919).

42 Taubenberger, J. K. \& Morens, D. M. 1918 Influenza: the mother of all pandemics. Emerg Infect Dis 12, 15-22 (2006).

43 Kawaoka, Y., Krauss, S. \& Webster, R. G. Avian-to-human transmission of the PB1 gene of influenza A viruses in the 1957 and 1968 pandemics. J Virol 63, 4603-4608 (1989).

44 Webster, R. G. The importance of animal influenza for human disease. Vaccine 20 Suppl 2, S16-20 (2002).

45 Scholtissek, C., Rohde, W., Von Hoyningen, V. \& Rott, R. On the origin of the human influenza virus subtypes H2N2 and H3N2. Virology 87, 13-20 (1978).

46 Hinshaw, V. S., Bean, W. J., Jr., Webster, R. G. \& Easterday, B. C. The prevalence of influenza viruses in swine and the antigenic and genetic relatedness of influenza viruses from man and swine. Virology 84, 51-62 (1978).

47 Nakajima, K., Desselberger, U. \& Palese, P. Recent human influenza A (H1N1) viruses are closely related genetically to strains isolated in 1950 . Nature $\mathbf{2 7 4}, 334-$ 339 (1978).

48 Zhou, N. N. et al. Genetic reassortment of avian, swine, and human influenza A viruses in American pigs. J Virol 73, 8851-8856 (1999).

49 Webby, R. J. et al. Evolution of swine H3N2 influenza viruses in the United States. J Virol 74, 8243-8251 (2000).

50 Vincent, A. L. et al. Evaluation of hemagglutinin subtype 1 swine influenza viruses from the United States. Vet Microbiol 118, 212-222, doi:10.1016/j.vetmic.2006.07.017 (2006).

51 Garten, R. J. et al. Antigenic and genetic characteristics of swine-origin 2009 A(H1N1) influenza viruses circulating in humans. Science 325, 197-201, doi:10.1126/science.1176225 (2009). 
52 Kida, H. et al. Potential for transmission of avian influenza viruses to pigs. $J$ Gen Virol 75 ( Pt 9), 2183-2188 (1994).

53 Ito, T. et al. Molecular basis for the generation in pigs of influenza A viruses with pandemic potential. J Virol 72, 7367-7373 (1998).

54 Noble, S., McGregor, M. S., Wentworth, D. E. \& Hinshaw, V. S. Antigenic and genetic conservation of the haemagglutinin in H1N1 swine influenza viruses. $J$ Gen Virol 74 ( Pt 6), 1197-1200 (1993).

55 Castrucci, M. R. et al. Genetic reassortment between avian and human influenza A viruses in Italian pigs. Virology 193, 503-506, doi:10.1006/viro.1993.1155 (1993).

56 Chambers, T. M., Hinshaw, V. S., Kawaoka, Y., Easterday, B. C. \& Webster, R. G. Influenza viral infection of swine in the United States 1988-1989. Arch Virol 116, 261-265 (1991).

57 Karasin, A. I. et al. Genetic characterization of H3N2 influenza viruses isolated from pigs in North America, 1977-1999: evidence for wholly human and reassortant virus genotypes. Virus Res 68, 71-85 (2000).

58 Olsen, C. W., Carey, S., Hinshaw, L. \& Karasin, A. I. Virologic and serologic surveillance for human, swine and avian influenza virus infections among pigs in the north-central United States. Arch Virol 145, 1399-1419 (2000).

59 Choi, Y. K., Goyal, S. M. \& Joo, H. S. Prevalence of swine influenza virus subtypes on swine farms in the United States. Arch Virol 147, 1209-1220, doi:10.1007/s00705-002-0788-4 (2002).

60 Karasin, A. I., Olsen, C. W. \& Anderson, G. A. Genetic characterization of an H1N2 influenza virus isolated from a pig in Indiana. J Clin Microbiol 38, 2453$2456(2000)$.

61 Ma, W., Gramer, M., Rossow, K. \& Yoon, K. J. Isolation and genetic characterization of new reassortant $\mathrm{H} 3 \mathrm{~N} 1$ swine influenza virus from pigs in the midwestern United States. J Virol 80, 5092-5096, doi:10.1128/JVI.80.10.50925096.2006 (2006).

62 Environmental Protection Agency. Pork Production, $<$ http://www.epa.gov/agriculture/ag101/printpork.html\#pophase $>$ (2009).

63 Vincent, A. L., Ma, W., Lager, K. M., Janke, B. H. \& Richt, J. A. Swine influenza viruses a North American perspective. Adv Virus Res 72, 127-154, doi:10.1016/S0065-3527(08)00403-X (2008). 
64 Webby, R. J., Rossow, K., Erickson, G., Sims, Y. \& Webster, R. Multiple lineages of antigenically and genetically diverse influenza A virus co-circulate in the United States swine population. Virus Res 103, 67-73, doi:10.1016/j.virusres.2004.02.015 (2004).

65 Ma, W. et al. Viral reassortment and transmission after co-infection of pigs with classical $\mathrm{H} 1 \mathrm{~N} 1$ and triple-reassortant $\mathrm{H} 3 \mathrm{~N} 2$ swine influenza viruses. J Gen Virol 91, 2314-2321, doi:10.1099/vir.0.021402-0 (2010).

66 Staats, C. B. Pandemic potential of reassortant swine influenza A viruses Doctor of Philosopy thesis, The University of Tennessee Health Science Center, (2009).

67 Huang, I. C. et al. Influenza A virus neuraminidase limits viral superinfection. $J$ Virol 82, 4834-4843, doi:10.1128/JVI.00079-08 (2008).

68 Barnard, R. J., Elleder, D. \& Young, J. A. Avian sarcoma and leukosis virusreceptor interactions: from classical genetics to novel insights into virus-cell membrane fusion. Virology 344, 25-29, doi:10.1016/j.virol.2005.09.021 (2006).

69 Geleziunas, R., Bour, S. \& Wainberg, M. A. Cell surface down-modulation of CD4 after infection by HIV-1. The FASEB journal : official publication of the Federation of American Societies for Experimental Biology 8, 593-600 (1994).

70 Hoffmann, E., Neumann, G., Kawaoka, Y., Hobom, G. \& Webster, R. G. A DNA transfection system for generation of influenza A virus from eight plasmids. Proc Natl Acad Sci U S A 97, 6108-6113, doi:10.1073/pnas.100133697 (2000).

71 Bateman, A. C., Busch, M. G., Karasin, A. I., Bovin, N. \& Olsen, C. W. Amino acid 226 in the hemagglutinin of H4N6 influenza virus determines binding affinity for alpha2,6-linked sialic acid and infectivity levels in primary swine and human respiratory epithelial cells. J Virol 82, 8204-8209, doi:10.1128/JVI.0071808 (2008).

72 Chen, L. M., Davis, C. T., Zhou, H., Cox, N. J. \& Donis, R. O. Genetic compatibility and virulence of reassortants derived from contemporary avian H5N1 and human H3N2 influenza A viruses. PLoS Pathog 4, e1000072, doi:10.1371/journal.ppat.1000072 (2008).

73 Sun, Y. et al. High genetic compatibility and increased pathogenicity of reassortants derived from avian H9N2 and pandemic H1N1/2009 influenza viruses. Proc Natl Acad Sci U S A 108, 4164-4169, doi:10.1073/pnas.1019109108 (2011).

74 Octaviani, C. P., Ozawa, M., Yamada, S., Goto, H. \& Kawaoka, Y. High level of genetic compatibility between swine-origin $\mathrm{H} 1 \mathrm{~N} 1$ and highly pathogenic avian H5N1 influenza viruses. J Virol 84, 10918-10922, doi:10.1128/JVI.01140-10 (2010). 
75 Wagner, R., Matrosovich, M. \& Klenk, H. D. Functional balance between haemagglutinin and neuraminidase in influenza virus infections. Reviews in medical virology 12, 159-166, doi:10.1002/rmv.352 (2002).

76 Mitnaul, L. J. et al. Balanced hemagglutinin and neuraminidase activities are critical for efficient replication of influenza A virus. J Virol 74, 6015-6020 (2000).

77 Doms, R. W., Helenius, A. \& White, J. Membrane fusion activity of the influenza virus hemagglutinin. The low $\mathrm{pH}$-induced conformational change. J Biol Chem 260, 2973-2981 (1985).

78 Zhang, K. et al. Dissection of influenza A virus M1 protein: $\mathrm{pH}-\mathrm{dependent}$ oligomerization of N-terminal domain and dimerization of C-terminal domain. PLoS One 7, e37786, doi:10.1371/journal.pone.0037786 (2012).

79 Naffakh, N., Massin, P., Escriou, N., Crescenzo-Chaigne, B. \& van der Werf, S. Genetic analysis of the compatibility between polymerase proteins from human and avian strains of influenza A viruses. J Gen Virol 81, 1283-1291 (2000).

80 Mehle, A. \& Doudna, J. A. Adaptive strategies of the influenza virus polymerase for replication in humans. Proc Natl Acad Sci U S A 106, 21312-21316, doi:10.1073/pnas.0911915106 (2009).

81 Busch, M. G. et al. Identification of amino acids in the HA of H3 influenza viruses that determine infectivity levels in primary swine respiratory epithelial cells. Virus Res 133, 269-279, doi:10.1016/j.virusres.2008.01.014 (2008).

82 Nelli, R. K. et al. Comparative distribution of human and avian type sialic acid influenza receptors in the pig. BMC Vet Res 6, 4, doi:10.1186/1746-6148-6-4 (2010).

83 Vijaykrishna, D. et al. Long-term evolution and transmission dynamics of swine influenza A virus. Nature 473, 519-522, doi:10.1038/nature10004 (2011).

84 Herfst, S. et al. Airborne transmission of influenza A/H5N1 virus between ferrets. Science 336, 1534-1541, doi:10.1126/science.1213362 (2012).

85 Imai, M. et al. Experimental adaptation of an influenza H5 HA confers respiratory droplet transmission to a reassortant $\mathrm{H} 5 \mathrm{HA} / \mathrm{H} 1 \mathrm{~N} 1$ virus in ferrets. Nature 486, 420-428, doi:10.1038/nature10831 (2012). 


\section{APPENDIX A. ANTIBODY PURIFICATION FROM ASCITES FLUID}

1) Delipify the ascites fluid

a. Use $1 \mathrm{~g}$ Liposorb per $25 \mathrm{ml}$ ascites at $1-5 \mathrm{mg} / \mathrm{ml}$ (Calbiochem $\# 524371$ PHM-L Liposorb Absorbent) to bind lipoproteins in the sample (1g will bind $>50 \mathrm{mg}$ lipoprotein)

b. Incubate at $4^{\circ} \mathrm{C} 1$ hour to overnight

c. Centrifuge at $1000 \mathrm{x}$ g for $5 \mathrm{~min}$

d. Pipet ascites into new tube

2) Dilute ascites

a. Dilute delipified ascites fluid to 1:50 (add 49ml 1XPBS to $1 \mathrm{ml}$ ascites)

b. Filter diluted ascites through a $0.2 \mu \mathrm{m}$ filter to remove any remaining liposorb

3) Bind antibody to Protein G column

a. Use a 1ml HiTrap Protein G column (GE Healthcare \#17-0404-01 1ml HiTrap Protein G HP column) Avoid air bubbles in column by filling top nozzle with liquid and then secure syringe connector

b. Wash column with 5 column volumes of ddH2O $(5 \mathrm{ml})$

c. Wash column with 5 column volumes 1 XPBS $(5 \mathrm{ml})$

d. Add $50 \mathrm{ml}$ diluted ascites fluid and pass through filter with $60 \mathrm{ml}$ syringe (keep all flow through)

e. Wash column with 20 column volumes of 1 XPBS (20ml) (Save flow through)

f. Check optical density (O.D.) absorbance at $280 \mathrm{~nm}$ (A280) of the flow through

g. If $>0.002$ then continue washing with $1 \mathrm{XPBS}$. If $<0.002$ then elute antibody. (A280 should be close to 0 )

4) Elute antibody

a. In five $1 \mathrm{ml}$ tubes add $100 \mu \mathrm{l}$ of $1 \mathrm{M}$ Tris- $\mathrm{HCl} \mathrm{pH} 8.0$

b. Elute antibody with 5 column volumes $(5 \mathrm{ml})$ of $0.1 \mathrm{M}$ Glycine- $\mathrm{HCl} \mathrm{pH} 2.7$

i. Collect in $1 \mathrm{ml}$ fractions in tubes with $100 \mu \mathrm{l}$ of $1 \mathrm{M}$ Tris- $\mathrm{HCl} \mathrm{pH}$ 8.0

c. Invert tubes to neutralize low $\mathrm{pH}$

5) Measure O.D. of fractions

a. Blank spectrophotometer with 1:10 dilution of $1 \mathrm{M}$ Tris- $\mathrm{HCl} \mathrm{pH} 8.0$ in $0.1 \mathrm{M}$ Glycine- $\mathrm{HCl} \mathrm{pH} 2.7(100 \mu \mathrm{l}$ of $1 \mathrm{M}$ Tris- $\mathrm{HCl} \mathrm{pH} 8.0 \mathrm{in} 1 \mathrm{ml}$ of $0.1 \mathrm{M}$ Glycine- $\mathrm{HCl} \mathrm{pH}$ 2.7)

b. Measure absorbance of each fraction at $280 \mathrm{~nm}$ to quantify and determine purity of purified antibodies

6) Column Storage 
a. Wash column with 10 column volumes $(10 \mathrm{ml})$ of 1 XPBS

b. Wash column with 10 column volumes $(10 \mathrm{ml})$ of ddH2O

c. Add 5 column volumes $(5 \mathrm{ml})$ of $20 \%$ Ethanol

d. Seal ends of column and store at $4{ }^{\circ} \mathrm{C}$

7) Antibody Desalting (Desalt for labeling)

a. Use Zeba desalting column and follow buffer exchange protocol.

\section{Antibody Isotyping (Mouse sourced antibody)}

1) Coat 6 wells per antibody of an ELISA plate with antibody target (HA or disrupted virus)

a. Add $50 \mu \mathrm{l} /$ well of HA or disrupted virus

b. Incubate at $4{ }^{\circ} \mathrm{C}$ overnight

c. Wash wells 3 times with 1 XPBS $+0.05 \%$ Tween 20

2) Block wells

a. Block wells with $300 \mu 1$ XPBS $+10 \%$ FCS (or BSA)

b. Incubate at room temp. for 1 hour

3) Antibody binding

a. Add purified antibody to each well - add $50 \mu \mathrm{l}$ of $1 \mu \mathrm{g} / \mathrm{ml}$

b. Incubate at room temp. for $30 \mathrm{~min}$

c. Wash wells 3 times with 1 XPBS $+0.05 \%$ Tween 20

4) Secondary Antibody

a. Add $50 \mu 1$ secondary anti-mouse $\operatorname{IgG}, \operatorname{IgG} 1, \operatorname{IgG} 2 \mathrm{~A}, \operatorname{IgG} 2 \mathrm{~B}, \operatorname{IgG} 3$, and $\mathrm{Neg}$ (can include IgM if expected other than IgG) conjugated antibodies (1:1000 Alkaline Phosphotase conjugated or 1:5000 HRP conjugated)

b. Incubate for $10 \mathrm{~min}$ at room temp.

c. Wash 6 times with 1 XPBS $+0.05 \%$ Tween 20

d. Add appropriate substrate

i. Expect two positive wells (IgG and Isotype)

\section{Buffers}

1) $0.1 \mathrm{M}$ Glycine-HCl, $\mathrm{pH} 2.7$

- $11.1 \mathrm{~g}$ Glycine-HCl

- $800 \mathrm{ml} \mathrm{dH2O}$

- Adjust pH to 2.7 with $\mathrm{HCl}$

- Add dH2O to $1 \mathrm{~L}$

$\bullet$

2) $1.0 \mathrm{M}$ Tris, $\mathrm{pH} 8.0$

- $\quad 121.1 \mathrm{~g}$ Tris

- $700 \mathrm{ml}$ of ddH2O

- Adjust $\mathrm{pH}$ to 8.0 with $\mathrm{HCl}$ 
- Add ddH2O to $1 \mathrm{~L}$

- Sterile Filter 


\section{APPENDIX B. ISOLATION AND GROWTH OF PRIMARY SWINE RESPIRATORY EPITHELIAL CELLS}

\section{Isolation of primary swine respiratory epithelial cells}

1) Place trachea on sterile $4 X 4$ gauze on Petri dish lid

2) Trim excess tissue from trachea and cut off ends

3) Wash 2-3X in cold PBS

4) Place tissue in $50 \mathrm{ml}$ conical with Pronase/DNAsolution

5) Incubate $48-72 \mathrm{hrs}$ at $4^{\mathrm{O}}$

\section{2-3 days later}

1) Add $4 \mathrm{ml}$ sterile filtered FCS (final concentration 10\%)

2) Invert tube several times

3) Remove cell suspension with a pipet and place into new $50 \mathrm{ml}$ conical

4) Rinse trachea and tube with $44 \mathrm{ml}$ DMEM/F12, place extra cells in new $50 \mathrm{ml}$ conical

5) Spin tubes for $10 \mathrm{~min}$ at $1200 \mathrm{RPM}$ at $4^{\mathrm{O}} \mathrm{C}$

6) Remove supernatant, resuspend and combine cells from both $50 \mathrm{ml}$ conicals in 10 $\mathrm{ml}$ of complete media (see complete RE media),

7) Place in a petri dish and incubate $2 \mathrm{hrs}$ in $37^{\circ}$ incubator (fibroblasts adhere, epithelial cells do not)

8) Transfer supernatant into a new petri dish and incubate $2 \mathrm{hrs}$ in $37^{\mathrm{O}}$ incubator

9) Transfer supernatant into a 50ml conical tube

10) Wash petri dish with DMEM/F12 and add to conical tube

11) Spin tube for $10 \mathrm{~min}$ at $1200 \mathrm{RPM}$ at $4^{\mathrm{O}}$

12) Resuspend cells in $10 \mathrm{ml}$ DMEM/F12

13) Count cells

14) Spin tube for $10 \mathrm{~min}$ at $1200 \mathrm{RPM}$ at $4^{\mathrm{O}}$

15) Resuspend cells in BEGM at a concentration of $1 \times 10^{6}$ cells $/ \mathrm{ml}$

16) Place $1 \mathrm{ml}$ in a collagen coated $\mathrm{T} 75$ and add $10 \mathrm{ml}$ BEGM

Freeze the remaining cells with $1 \mathrm{ml}\left(1 \times 10^{6}\right.$ cells $)$ per vial

\section{Buffers}

1) $\mathrm{Ca}^{+}$and $\mathrm{Mg}^{+}$free $\mathrm{MEM}$

(makes 1L)

$0.4 \mathrm{~g}[5.36 \mathrm{mM}] \mathrm{KCl}$

$6.4 \mathrm{~g}[0.1 \mathrm{M}] \mathrm{NaCl}$

$3.7 \mathrm{~g}[44 \mathrm{mM}] \mathrm{NaHCO}_{3}$

$0.125 \mathrm{~g}[0.9 \mathrm{mM}] \mathrm{NaH}_{2} \mathrm{PO}_{4} \cdot \mathrm{H}_{2} \mathrm{O}$

$0.1 \mathrm{mg}[0.25 \mu \mathrm{M}] \mathrm{Fe}\left(\mathrm{NO}_{3}\right)_{3} \cdot 9 \mathrm{H}_{2} \mathrm{O}$ (Dissolve $10 \mathrm{mg}$ in $10 \mathrm{ml} \mathrm{H} \mathrm{H}_{2} \mathrm{O}$ and use $100 \mu \mathrm{l}$ of this)

$4.5 \mathrm{~g}[25 \mathrm{mM}] \mathrm{D}$-glucose

$0.015 \mathrm{~g}[40 \mu \mathrm{M}]$ Phenol Red 
$0.110 \mathrm{~g}[1 \mathrm{mM}]$ Sodium pyruvate

Add $950 \mathrm{ml}$ Sterile $\mathrm{H}_{2} \mathrm{O}$

$\mathrm{pH}$ balance to 7.5

add $10 \mathrm{ml} \mathrm{pen/strep} \mathrm{and} \mathrm{fill} \mathrm{to} 1 \mathrm{~L}$

Filter using $0.2 \mu \mathrm{m}$ filter

Store at $4{ }^{\circ} \mathrm{C}$

\section{2) Pronase/DNAsolution}

$56 \mathrm{mg}$ Pronase (Roche \#165921)

$4 \mathrm{mg}$ DNase (sigma DN-25)

$40 \mathrm{ml} \mathrm{Ca}+$ and $\mathrm{Mg}+$ free MEM (see $\mathrm{Ca}$ and $\mathrm{Mg}$ free MEM)

$400 \mu \mathrm{l} \mathrm{pen/strep} \mathrm{(sigma} \mathrm{P-0781)}$

Mix with stir bar until powder is dissolved

Sterile filter with $0.2 \mu \mathrm{m}$ Filter

Keep on ice

Put 2-3 50ml conical tubes with $40 \mathrm{ml}$ of sterile PBS

3) Complete Respiratory Epithelial (RE) Media

$2.5 \mathrm{ml} \mathrm{FCS}$

$0.5 \mathrm{~mL}$ MEM non essential amino acids (sigma M-7145)

$60 \mu \mathrm{insulin}$ (UWHC 8917700)

$47 \mathrm{ml}$ DMEM/F12 with $\mathrm{p} / \mathrm{s}(5 \mathrm{ml} / 500 \mathrm{ml}$ bottle $)$

Store at $4^{\mathrm{O}} \mathrm{C}$

\section{Growth and propagation of pSRECs}

\section{Making collagen}

1. In a beaker, add 10mg human placental collagen (type VI, Sigma C7521) to $20 \mathrm{ml}$ sterile $\mathrm{H}_{2} \mathrm{O}$

2. Add 40ul glacial acetic acid to the beaker (this helps to dissolve the collagen)

3. Add a stirbar, stir at room temp until collagen is dissolved (30-60 min or so)

4. Dilute collagen 1:10 (ie, add the $20 \mathrm{ml}$ mixture to $180 \mathrm{ml}$ sterile $\mathrm{H}_{2} \mathrm{O}$ )

5. Sterile-filter through a $0.2 \mathrm{um}$ filter (may take $30-60 \mathrm{~min}$ or more)

6. Store at $4 \mathrm{C}$, use for collagen-coating plastic. Can be stored for up to 4 months at 4C.

\section{Coating plastic with collagen}

1. Add collagen to tissue culture flasks/plates, leave overnight at room temp to adhere (or leave for at least $6 \mathrm{hr}$ in $37 \mathrm{C}$ incubator, for collagen to adhere) Amount of collagen to add: $6 \mathrm{ml}$ per T75 flask 
$\sim 500 \mathrm{ul}$ per well of 12 -well plate

$\sim 330$ ul per well of 24-well plate

2. After collagen has adhered, prep collagen:

-aspirate off the water, leave flasks/plates uncovered in tissue culture hood until the plastic dries completely (ie, until no liquid is visible on the plastic; usually takes $\sim 30$ min for T75 flasks, $\sim 15$ min for plates) -wash plastic $2 \mathrm{X}$ w/ PBS (6ml per T75, 500ul per 12-well, 330ul per 24-well) -add media (Bronchial Epithelial Growth Medium [BEGM] from Lonza), put in incubator until use.

\section{Reviving SRECs from $\mathrm{LN}_{2}$}

1. Pre-warm 10ml DMEM/F12 (we use Invitrogen's) and 10ml BEGM

2. Quick-thaw cells in $37 \mathrm{C}$ water bath

3. Transfer cells to a $50 \mathrm{ml}$ conical tube, very slowly add pre-warmed DMEM/F12

4. Spin for $10 \mathrm{~min}$ at $1000 \mathrm{rpm}$

5. Resuspend cells in $10 \mathrm{ml} \mathrm{BEGM,} \mathrm{add} \mathrm{to} \mathrm{the} \mathrm{collagen-coated} \mathrm{flask}$

6. Change half of the media after a day or two; cells should be ready to split/plate in 2-3 days

\section{Splitting/plating SRECs}

Day 1: collagen coat T75 flasks/12-well plates

Day 2:

1. Take cells out of incubator, aspirate off BEGM

2. Add $4 \mathrm{ml}$ trypsin to each $\mathrm{T} 75$ flask, return to incubator for 5-6 min (during this time, make $6 \mathrm{ml}$ of DMEM/F-12+10\% FBS)

3. After trypsinization, stop with DMEM/F-12+10\% FBS, put cells into $50 \mathrm{~mL}$ conical tubes

4. Spin cells for $10 \mathrm{~min}$ at $1,000 \mathrm{rpm}$

5. Remove supernatant, resuspend cells in exactly $10 \mathrm{~mL}$ of plain DMEM/F-12

6. Take out 10ul of cells to count by hemocytometer

7. Spin cells for $10 \mathrm{~min}$ at $1,000 \mathrm{rpm}$ (while spinning, count cells)

8. Take off supernatant, resuspend in BEGM for $\sim 200,000 \mathrm{cell} / \mathrm{s} / \mathrm{ml}$

9. Add cells to flasks and plates

$1.5 \mathrm{ml}(\sim 300,000$ cells $)$ to each T75 flask

$0.5 \mathrm{ml}(\sim 100,000$ cells $)$ to each well of 12 -well plate

$0.25 \mathrm{ul}(\sim 50,000$ cells $)$ to each well of 24 -well plate

Day 3

6) Change media.

\section{Typical cycle for using SRECs}

Day 1: collagen-coat 1 T75 flask

Day 2: thaw one vial of passage $1(\mathrm{P} 1)$ cells, plate in one $\mathrm{T} 75$ 
Day 3: media change, collagen-coat $3 \mathrm{~T} 75$

Day 4: expand cells, from $1 \mathrm{~T} 75$ to $3 \mathrm{~T} 75$ (cells are now at passage 2)

Day 5: media change, collagen-coat 1 T75 and 4-6 12-well plates

Day 6: split/plate cells, into T75 (for continuing cell growth) and 12-well plates (for experiments (cells now at passage 3 )

Day 7: media change, collagen-coat $3 \mathrm{~T} 75$

Day 8: do the experiments on cells in 12-well plates, expand T75 cells from 1 into 3 T75 (these cells are now at passage 4)

Day 9: media change, collagen-coat 4-6 12-well plates

Day 10: plate cells in 12-well plates for experiments (cells now at passage 5)

Day 11: media change

Day 12: do experiments on passage 5 cells

\section{Notes}

-We have also used Lonza's Small Airway Epithelial Growth Medium (SAGM), but we use BEGM most of the time

-When drying collagen, ensure that all of the liquid is gone; the cells don't like residual acetic acid

-typical 37C, 5\% CO2 incubator throughout

-we have typically only used cells up to passage 5 for infectivity/replication experiments, because we do not want them to differentiate (and it has been shown by others that after passage 5 cells may differentiate), but cells remain viable past this point. 


\section{VITA}

Thomas P. Fabrizio II was born in 1985. He attended and graduated from Regis Jesuit High School in Aurora, Colorado in 2003. He then attended Gonzaga University where he began his scientific research career working in the lab of Dr. David Boose. He received his Bachelor of Science degree from Gonzaga University in 2007. Following his undergraduate studies he was awarded an Emerging Infectious Diseases Training Fellowship through the Association of Public Health Laboratories and the Centers for Disease Control and Prevention. This fellowship placed Tom in Arkansas public health laboratory from 2007 to 2008 where he worked to establish a real time PCR test for the identification of Noroviruses as well as rapid detection of respiratory pathogens. In 2008, Tom matriculated into the Integrated Program in Biomedical Sciences at the University of Tennessee Health Science Center to pursue his Ph.D. He entered the lab of Dr. Richard Webby at St. Jude Children's Research Hospital in 2009 to complete his dissertation research. Following completion of his defense in 2013, Tom received his Ph.D. with a concentration in microbial pathogenesis, immunology, and inflammation. 